\title{
Las industrias líticas y óseas de Praileaitz I (Deba, Gipuzkoa)
}

\author{
Praileaitz leko (Deba, Gipuzkoa) harri- eta hezur-industriak \\ Lithic and bone industries from Praileaitz I (Deba, Gipuzkoa)
}

PALABRAS CLAVE: Cueva, Industria ósea, Industria lítica, Colgantes de piedra, Bastones perforados, Arte mueble.

GAKO-HITZAK: Haitzulo, Hezurrezko industria, Harrizko industria, Harrizko zintzilikarioak, Makila zulatuak, Arte higigarria. KEYWORDS: Cave, Bone industry, Lithic industry, Stone pendants, Perforated batons, Movable Art.

Jose Antonio MUJIKA-ALUSTIZA ${ }^{(1)}$

\section{RESUMEN}

En la cueva de Praileaitz I se han recogido restos de industrias en seis áreas (exterior, vestíbulo, pasillo, galería noroeste, primera y segunda sala interiores), que muestran estratigrafías distintas como consecuencia de su emplazamiento. El número de objetos líticos recuperados en cada nivel es pequeño (en todos ellos menos de 100 ejemplares), pero algunos de ellos (por ejemplo puntas de retoques planos), muy significativos desde el punto de vista cronocultural. También es de gran interés el conjunto de restos recuperados en torno a un hogar del Magdaleniense Inferior. Destacamos un conjunto de colgantes en cantos rodados de siluetas singulares y decorados con incisiones, y algunos objetos adscribibles a la industria ósea (una azagaya de base hendida, tres dientes perforados etc.). Finalmente, se producen a lo largo del Magdaleniense Final y Aziliense breves ocupaciones con escasos restos, entre los que destacaríamos un bastón con doble perforación y un arpón. Los restos recuperados son el resultado de breves ocupaciones de carácter estacional de pequeños grupos humanos procedentes probablemente de otros asentamientos mayores del entorno, como podrían ser Urtiaga, Ermittia, Aizkoltxo, etc.

\section{LABURPENA}

Praileaitz I haitzuloan industria aztarnak jaso dira sei gunetan (kanpo aldea, ataria, igarobide, ipar-mendebaldeko larruspea, lehenengo eta bigarren barneko gelak), eta toki bakoitzeko estratigrafía ezberdina da kokapenaren ondorioz. Maila bakoitzean berreskuratutako objektu litiko kopurua txikia da (guztietan 100 ale baino gutxiago), baina hori bai, hauetako batzuk oso esanguratsuak dira ikuspegi kronokultural batetik (ukiera lauez landutako puntak adibidez). Gainera azpimarratzekoa da Behe Madelein aldiko sutegiaren inguruan berreskuratutako aztarna multzoa, bertan gailentzen direlarik uharrietan egindako zintzilikarioak, soslai bitxikoak eta ebaketaz apainduak batzuk, eta hezurrezko industrian sar daitezkeen batzuk (oin pitzatudun azagaia, hiru hortz zulatu, etab.). Azkenik, Azken Madelein aldian eta Azil aldian beste bizialdi oso laburren aztarna gutxi batzuk aurkitu dira, hauen artean bi zulo dituen makila bat et arrankazi bat gailentzen direlarik. Berreskuratutako aztarna hauek urtaroko okupazio labur batzuetan utzitako aztarnak izango lirateke, ziur aski inguruko beste aztarnategi nagusi batzuetan (adibidez, Urtiaga, Ermittia, Aizkoltxo, etab.) jatorria zuten giza-talde txiki batzuenak.

\section{ABSTRACT}

In the cave of Praileaitz I remains of industries, that show different stratigraphy due to their location, have been collected in six areas (outside, in the foyer, in the corridor, in the northwest gallery, and in the first and second interior rooms). The number of lithic objects recovered at each level is small (in all of them less than 100 copies), but some of them (for example tips of flat retouch) are very significant from a chronocultural point of view. It is also of great interest a set of remains recovered around a Lower Magdalenian fireplace. We highlight a set of pendants made with river stones of unique shapes and decorated with incisions, and some objects ascribable to the bone industry (a cloven base spear, three perforated teeth, etc.). Finally, along the Final Magdalenian and Azilian, occupations that leave scanty remains took place; among which we highlight doubly perforated baton and a harpoon. The recovered remains are the result of brief occupations of seasonal character of small human groups probably from other larger settlements on the surroundings, as Urtiaga, Ermittia, Aizkoltxo, etc.

\section{1.- INTRODUCCIÓN}

Las características físicas de la cueva de Praileaitz I condicionan el estudio de las industrias y evidencias de arte mobiliar procedentes del yacimiento. Atendiendo a su localización se han delimitado 6 áreas (exterior, vestíbulo, pasillo, galería noroeste, primera y segunda sala interiores) (Fig. 1), que muestran estratigrafías distintas o matizadas, derivadas de su emplazamiento y de la mayor o menor presencia humana.

El número de restos industriales recuperados durante la excavación de Praileaitz I, que ha afectado a 191 $\mathrm{m}^{2}$, es de en torno a 450 objetos de distinta naturaleza: 16 óseos, 400 de sílex (389 en el interior y 11 en el rellano exterior) y de otras rocas (7 de "vulcanita", uno de

\footnotetext{
(1) Facultad de Letras (UPV-EHU). Tomás y Valiente s/n. Vitoria-Gasteiz. joseantonio.mugica@ehu.es
} 


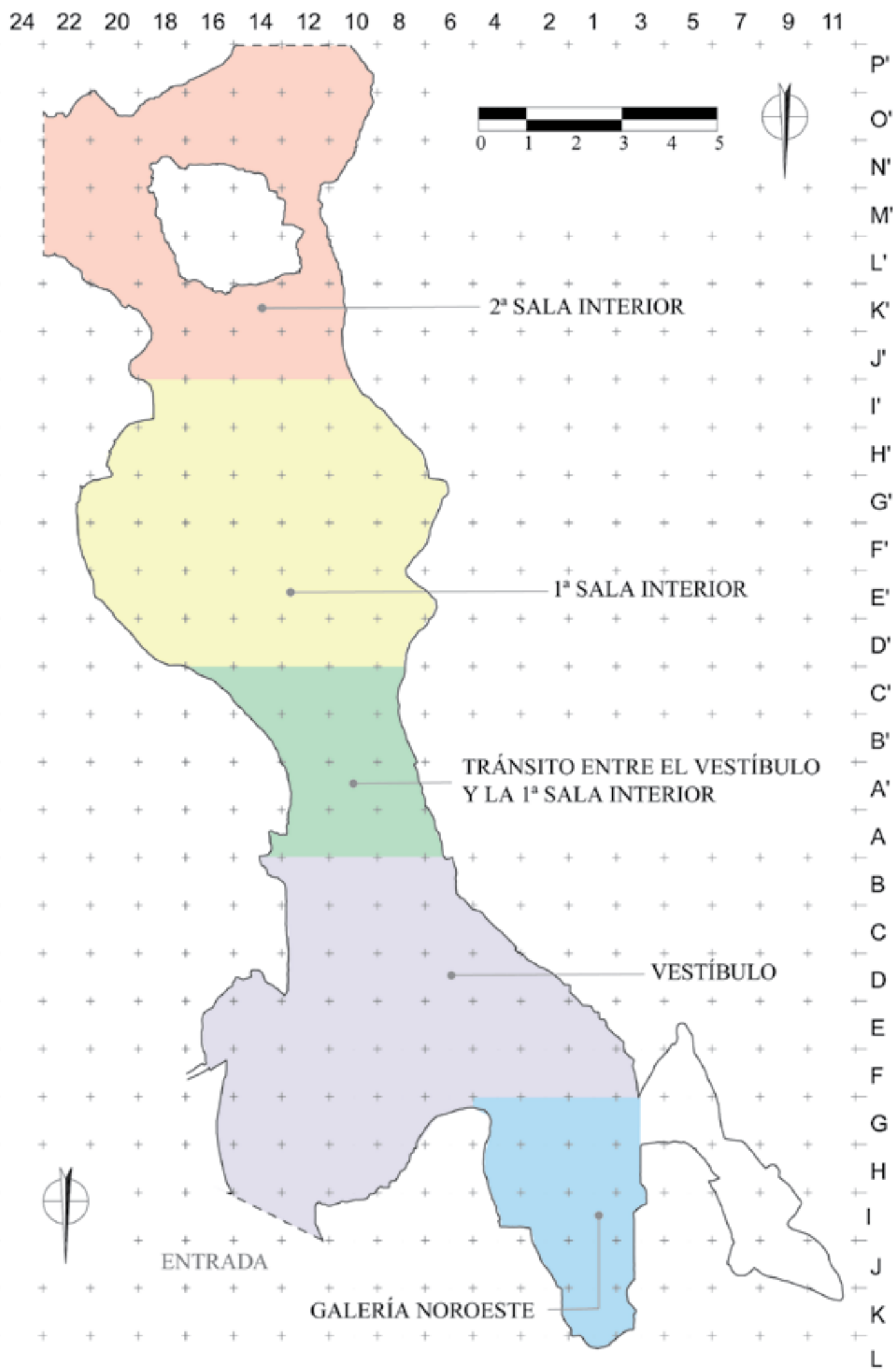

$\begin{array}{llllllllllllllllll}24 & 22 & 20 & 18 & 16 & 14 & 12 & 10 & 8 & 6 & 4 & 2 & 1 & 3 & 5 & 7 & 9 & 11\end{array}$

Fig. 1. Planta y cuadrícula de Praileaitz I. / Plan and grid of Praileaitz I. 
cuarzo, 7 de ocre, uno de arenisca calcárea), otro lote de cantos rodados, etc. La distribución de la industria de sílex es desigual en las diferentes zonas en las que se ha subdividido el yacimiento: 11 (2,75\%) en el exterior, 272 (68\%) en el vestíbulo, 28 (7\%) en el pasillo, 38 (9,5\%) en la galería noroeste, $42(10,5 \%)$ en la primera sala interior y $9(2,25 \%)$ en la segunda (Tabl. 1$)$.

\begin{tabular}{|c|c|c|c|}
\hline ZONA & NIVEL & TOTAL & RETOCADOS \\
\hline \multirow{4}{*}{ Vestíbulo } & \| & 94 & 23 \\
\hline & III & 96 & 14 \\
\hline & IV & 73 & 21 \\
\hline & V & 9 & 3 \\
\hline & & & \\
\hline \multirow{5}{*}{ Galería Noroeste } & $\|$ & 18 & 5 \\
\hline & IV & 6 & 0 \\
\hline & V & 7 & 2 \\
\hline & $\mathrm{Vl}$ & 5 & 2 \\
\hline & $\mathrm{VII}$ & 2 & 1 \\
\hline \multirow{4}{*}{ Pasillo } & I & 1 & 0 \\
\hline & $\|$ & 10 & 0 \\
\hline & IV & 15 & 6 \\
\hline & V & 2 & 1 \\
\hline \multirow{3}{*}{ Primera Sala Interior } & $\|$ & 21 & 5 \\
\hline & IV & 16 & 4 \\
\hline & V & 5 & 3 \\
\hline Segunda Sala Interior & IV & 9 & 1 \\
\hline
\end{tabular}

Tabl. 1. Distribución de la industria retocada por zonas y niveles. / Distribution of the retouched industry by zones and levels.

En el estudio de los restos retocados y de los restos se han seguido las propuestas y consideraciones que han realizado diferentes autores, como G. Laplace (1973; 1987), J. Fernández Eraso, (1985; 2006), M. García Rojas (2010), J. Fernández Eraso y García Rojas (2013), J. Ma Merino (1994), A. Sáenz de Buruaga (1991), etc.

\section{2.- EL VESTÍBULO}

Los primeros restos descubiertos en Praileaitz I proceden de las catas realizadas por miembros del grupo Munibe de Azkoitia en 1983, quienes recuperaron en superficie una escotadura, y en el lecho 11, entre otros restos, un fragmento proximal de lámina de decorticado de talón plano $(32 \times 17,1 \times 3,6 \mathrm{~mm})$ y una lasca reflejada de talón lineal (18,6 X $15 \times 3,4 \mathrm{~mm})$.

La excavación del yacimiento, inicialmente planteada como una intervención de urgencia, se centró al comienzo en el vestíbulo, donde las características del depósito estratigráfico variaban en función del proceso de sedimentación que se producía en cada sector del mismo. Aquí se pueden distinguir la propia entrada a la cueva, donde el depósito estratigráfico se asienta sobre otra galería de menores dimensiones que corre parcialmente paralela a una cota inferior, y que ha podido facilitar localmente pequeños hundimientos. También el hecho de que el dintel del vestíbulo se desplomara en un momento prácticamente contemporáneo a la ocupación correspondiente al Magdaleniense Inferior, o muy poco después, contribuyó a favorecer el aumento de la tasa de sedimentación hacia la entrada, al depositarse arcillas y otros restos que descendían de la parte superior de la ladera aportados por escorrentía o arroyada.

Por otra parte, en el lado derecho del vestíbulo hay una galería actualmente casi colmatada y recubierta por una capa estalagmítica a través de la cual llegaban sedimentos procedentes de otro posible acceso exterior existente en el otro extremo, pero cuya ubicación y desarrollo se desconocían hasta la campaña de 2014. Este proceso de removilización y transporte de sedimentos se incrementaría en períodos húmedos y entre ellos se incluirían también objetos antrópicos característicos del Paleolítico Medio, que desentonan en el contexto en el que se han recuperado.

Hay que señalar que en el exterior, en el lado izquierdo de la boca del vestíbulo, se abre un pequeño abrigo que fue ocupado recurrentemente de forma muy efímera por el ser humano.

El vestíbulo es la zona más espaciosa y luminosa, por lo que era la más adecuada para su ocupación. Estas han sido breves, y apenas han dejado restos estratificados de origen antrópico. En él se han distinguido cinco niveles, cuya cronología es la siguiente:

\begin{tabular}{|l|c|l|}
\hline \multicolumn{1}{|c|}{ Nivel } & Espesor & \multicolumn{1}{c|}{ Período cultural } \\
\hline Nivel I & $18-32 \mathrm{~cm}$ & Prácticamente estéril \\
\hline Nivel II & $65-80 \mathrm{~cm}$ & Epipaleolítico antiguo (Aziliense) \\
\hline Nivel III & $10-16 \mathrm{~cm}$ & Magdaleniense Superior-Final \\
\hline Nivel IV & $5-25 \mathrm{~cm}$ & Magdaleniense Inferior \\
\hline Nivel V & $2-4 \mathrm{~cm}$ & Solutrense Superior \\
\hline
\end{tabular}

Tabl. 2. Profundidades y espesores medios de los distintos niveles en el vestíbulo. / Average depths and thicknesses of the levels at the vestibule.

\subsection{Nivel I}

En este nivel se han recogido únicamente dos voluminosos cantos rodados regulares de arenisca, que no están asociados a otros vestigios industriales recuperados en este sector del yacimiento. Sus dimensiones son: $87,4 \times 64,5 \times 55,4 \mathrm{~mm}$ y $73,5 \times 52,5 \times 42 \mathrm{~mm}$.

\subsection{Nivel II}

El número de objetos de origen antrópico procedentes de este nivel ascienden a 111, pudiendo agruparse por su naturaleza en 2 óseos y 109 líticos. 


\subsubsection{Industria lítica}

Se han contabilizado 11 fragmentos de cantos rodados, la mayoría de arenisca (10) y uno de basalto u otro tipo de roca de similares características, que no muestran huellas netas de utilización, aunque las superficies de 3 de los cantos parecen alisadas. Sus dimensiones son: 67,8 X 37,1 X 22; 66,7 X 53 X 19 y 64,2 X 61 X $24,3 \mathrm{~mm}$. Entre los cantos rodados de arenisca sobresale uno de grano fino y de pequeño tamaño $(54,4 \times 46,2$ $X 20,1 \mathrm{~mm}$ ) que presenta dos planos oblicuos que convergen en el extremo distal -actualmente roto-, y donde se aprecia un levantamiento en una de sus caras que lo adelgaza (P.A.6A.243.105, Figs. 2.1a, 1b y 3.4). Además podemos señalar la presencia de 2 cristales de cuarzo y 2 fragmentos de ocre brutos.

En la industria de sílex se contabilizan 94 objetos, que se reparten en 71 (75,5\%) no retocados y $23(24,5 \%)$ retocados.
Los restos brutos ascienden a 71 objetos -5 de ellos con córtex-, de los cuales 27 (38,0\%) son lascas y 44 $(61,9 \%)$ soportes laminares. Entre las lascas 5 son enteras, 4 fragmentos proximales y 18 mediales, distales y fragmentos menores; y entre las láminas y laminillas, 3 son enteras, 18 corresponden a fragmentos proximales y 23 a mediales, distales o fragmentos menores. Entre los talones (30) dominan los planos con 25 ejemplares, 2 lineales y facetados, y un puntiforme.

Una decena de fragmentos de láminas (P.A.2D.209.3: Fig. 3.6), y de lascas presentan estigmas (desconchados, etc.) que pudieran interpretarse con reservas como huellas de uso, pero sería necesario su estudio más detallado (P.A.10D.219.3: Fig. 3.2; P.A.3F.197.29: Fig. 3.3; P.A.4l.211.45: Fig. 3.7; P.A.10D.216: Fig. 3.11).

En el nivel se han hallado vestigios que prueban que se efectuaron actividades orientadas a la obtención de so-

Fig. 2. Industria litica del nivel II del
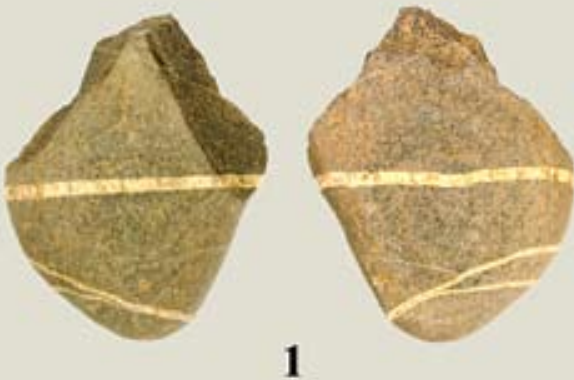

1

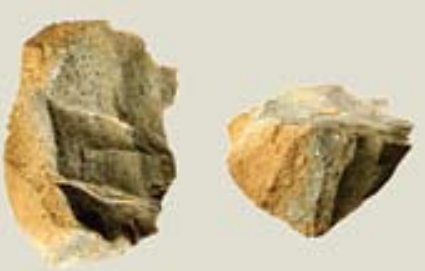

3

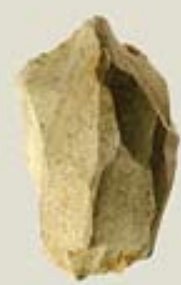

4

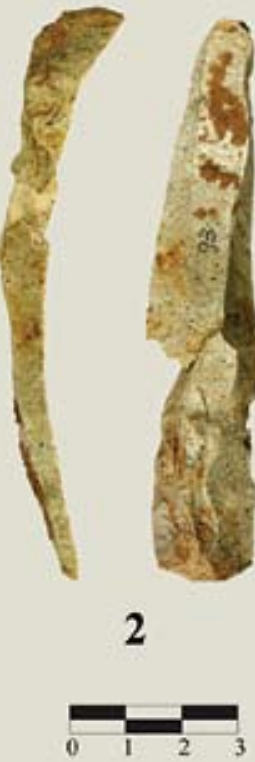

4
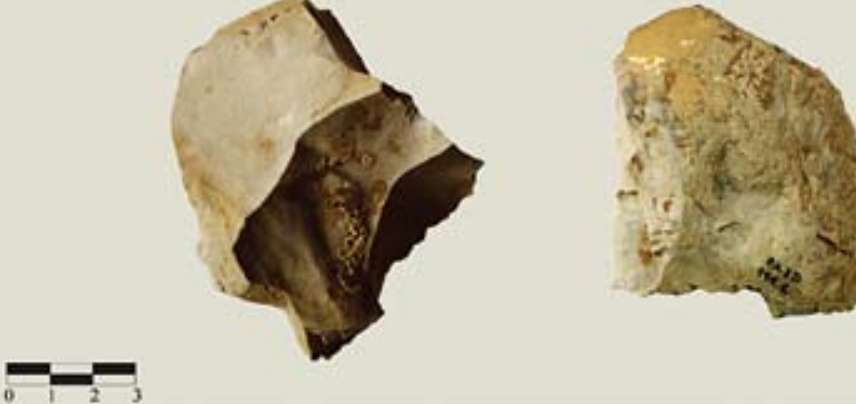

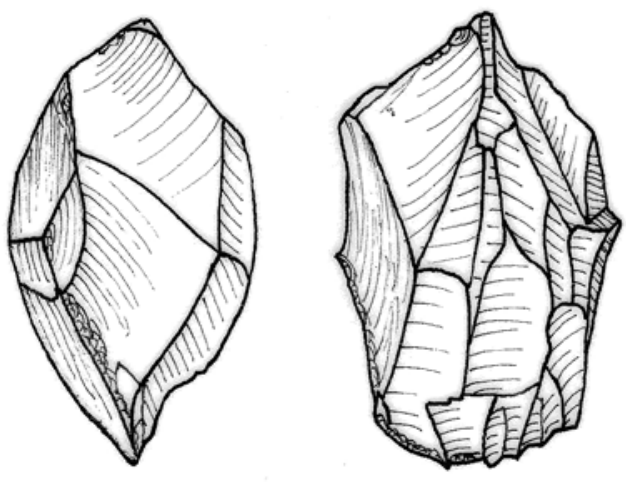

1
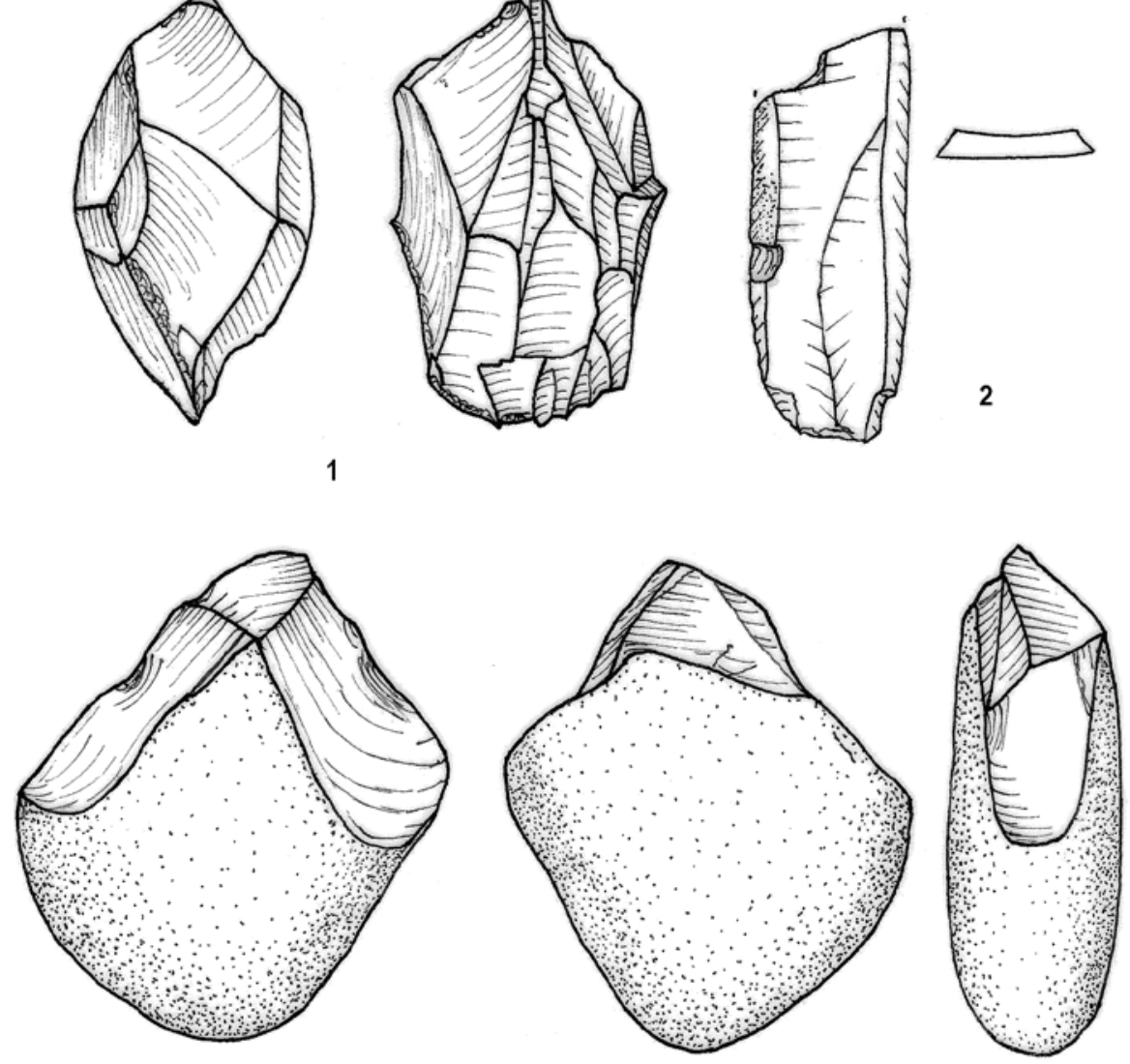
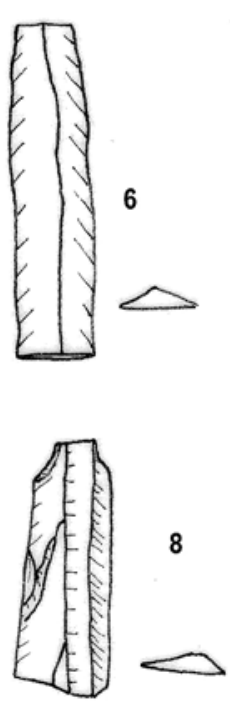
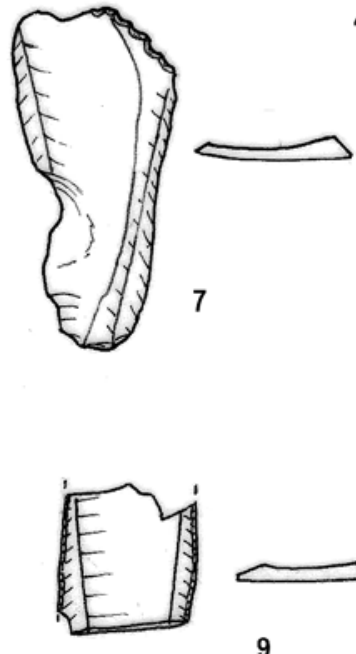
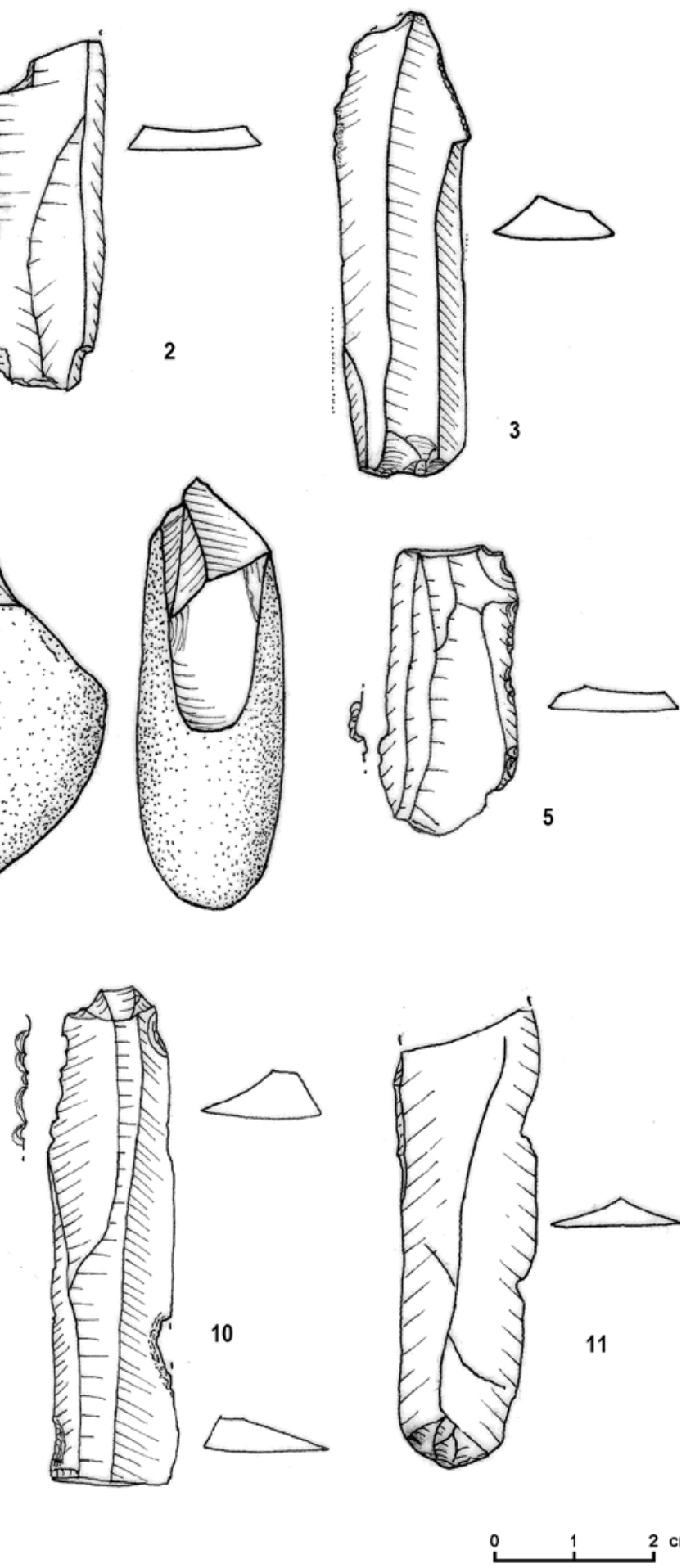

Fig. 3. Industria lítica del nivel II del vestíbulo. / Lithic industry from the level II of the vestibule.

portes y fabricación de instrumentos en la cavidad. Se han contabilizado 3 núcleos (P.A.4F.211.142: Figs. 2.4 y 3.1; P.A.2D.199.5: Fig. 2.5), 2 de ellos riñones de sílex que presentan córtex con indicios de abrasión marina. En uno de ellos, de $72 \times 55 \times 37$ mm, se observan extracciones de lascas laminares; otro, ortogonal agotado, de $37,4 \times 39 \times$ $27,2 \mathrm{~mm}$, y finalmente el tercero, de 45,7 X26 X 27,8 mm, es un núcleo bipolar con extracciones de lascas y láminas. 
Entre los restos que indican una actividad de preparación de núcleos para posteriores extracciones, o la fabricación de útiles, podemos citar una lámina cresta completa (P.A.4D.190.1 y 2: Fig. 2) y otros 2 fragmentos, un cuña o tableta de reavivado de núcleo (P.A.12A.277.5: Fig. 2.3a y 2.3b), 4 lascas de reavivado -en un caso quizás de una raedera-, un recorte de buril, etc.

Entre los útiles hemos clasificado 23 ejemplares líticos en los siguientes grupos tipológicos: 2 raederas, un raspador, 4 denticulados, 4 truncaduras, 5 láminillas de dorso, una laminilla de dorso y truncadura, 3 puntas de dorso, 2 buriles y un astillado.

En el grupo de las raederas hemos incluido 2 fragmentos de raedera (R1) (P.A.10G.209.1: Fig. 4.11), una de ellas parcial y de tendencia denticulada (P.A.10F.204.1: Figs. 3.5 y 5.4), y en el grupo tipológico de los raspadores uno frontal (G11) con retoque simple complementario en un lateral (Fig. 5.7). Esta pieza se ha hallado fracturada en 3 trozos (P.A.8G.218.4+P.A.8G.224.5+P.A.12H.20 $3.1)$, y sus emplazamientos indican un escaso buzamiento existente en esos momentos.

En el grupo de los denticulados se han clasificado 4 piezas: un raspador denticulado (D5) sobre un fragmento medial de lámina (P.A.4F.211.143: Figs. 3.10, 5.5), una escotadura sobre lámina (D1) con retoque simple inverso complementario en el borde opuesto (P.A.12G.254.2:
Figs. 4.2 y 5.3), una espina (D2) en extremo transversal distal (P.A.2D.20.4: Fig. 5.6) y una raedera denticulada parcial (D3) (P.A.4l.211.25: Figs. 3.7 y 5.10).

En el grupo de los buriles se han clasificado 2 ejemplares, concretamente un buril sobre plano (B11) fabricado sobre una lasca de decalotado (P.A.8D.200.1: Figs. 4.1 y 5.8) y un buril de paños laterales (B31), que además de una serie de retoques en el lateral izquierdo presenta la arista dorsal mellada o modificada por desconchados, quizás, por su uso como retocador (P.A.10E.203.11: Figs. 4.6 y 5.9).

En el grupo tipológico de los astillados se ha incluido un fragmento (E1) y en el de las truncaduras abruptas se han clasificado cuatro piezas, tres truncaduras normales (T1) (P.A.10G.209.2: Fig. 4.7, P.A.8G.216.3 -tendente a simple- y P.A.10E.203.11: Fig. 4.12 -marginal-), y una angulada (T3) (P.A.10H.235.2: Fig. 4.3).

En el grupo de las láminas de dorso se han estudiado 5 fragmentos mediales de LD21 (Fig. 4.10, 13, 14 y 15), una de ellas con un doble dorso marginal (LDD21) (Fig. 3.9), y en el de las láminas de dorso truncadas un fragmento proximal de LDT11 (Fig. 4.9).

En el grupo de las puntas de dorso se contabilizan 3 piezas (PD21), 2 de ellas completas (P.A.12C.221.2: Figs. 4.4 y 5.2; P.A.4B.188.1: Figs. 4.5 y 5.1) y un fragmento distal de pequeñas dimensiones.
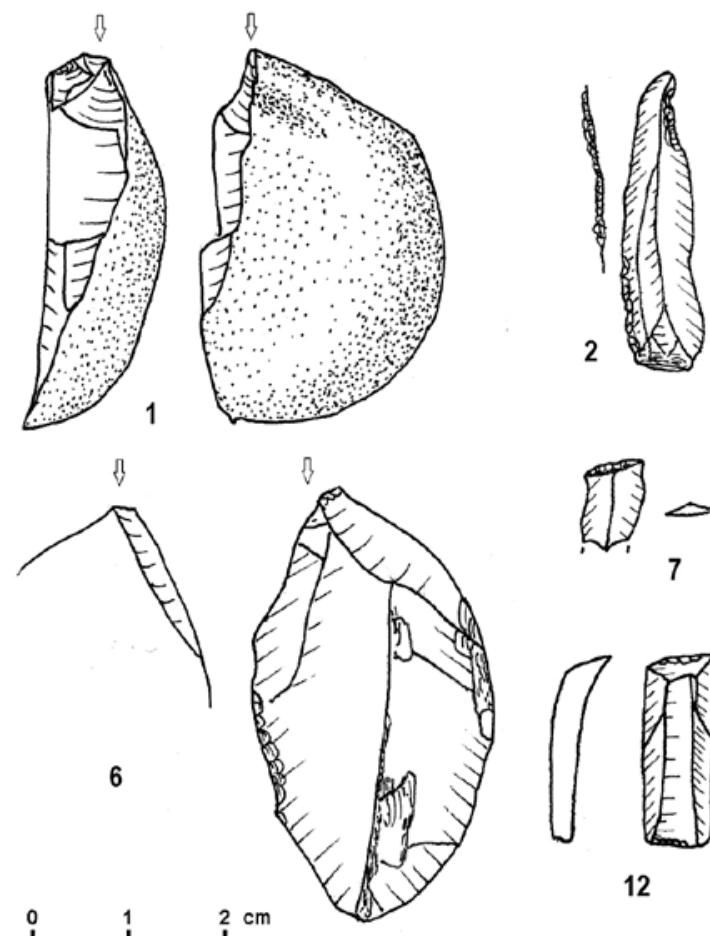

12
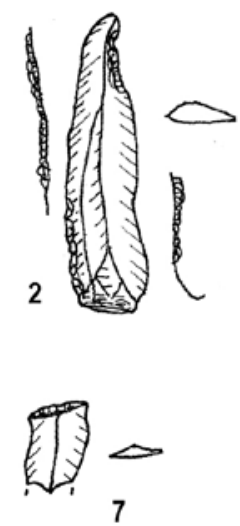

0

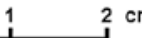

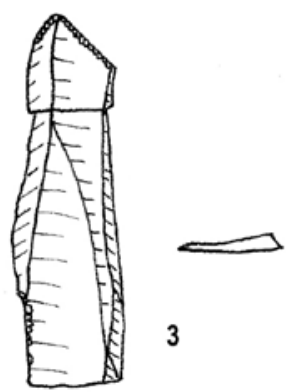
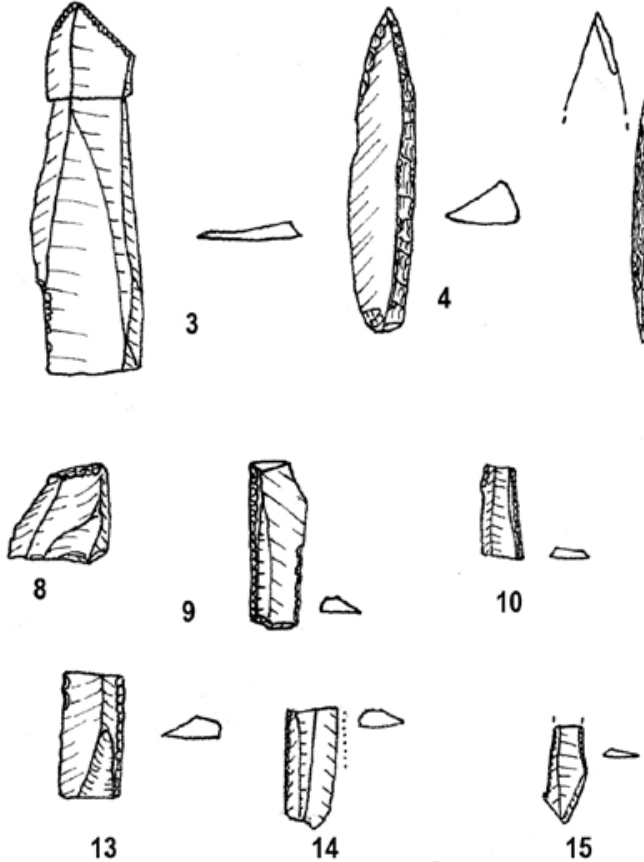
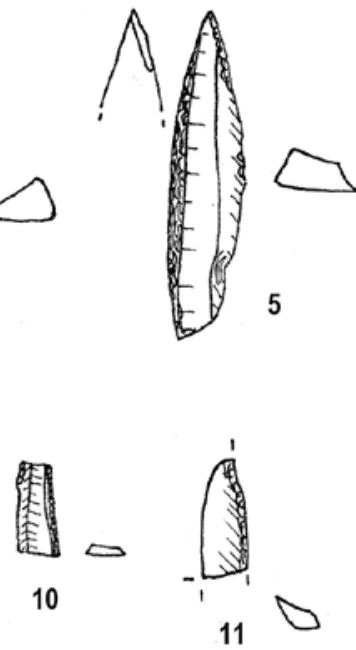

Fig. 4. Industria lítica del nivel II del vestíbulo. / Lithic industry from the level II of the vestibule. 


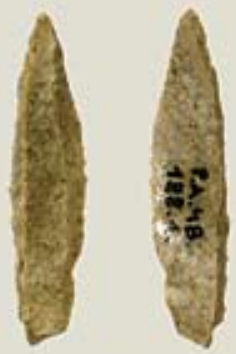

1

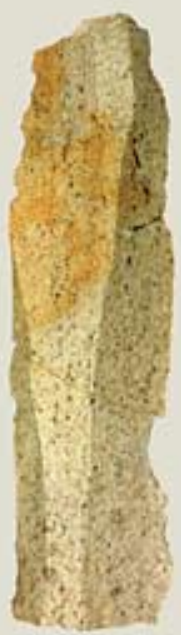

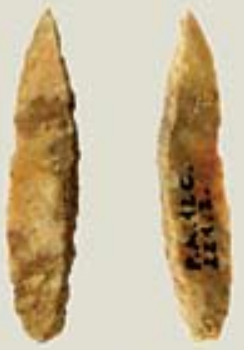

2

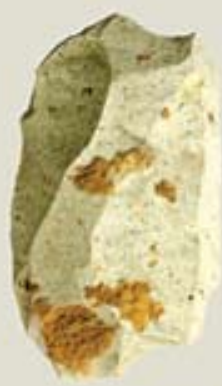

6

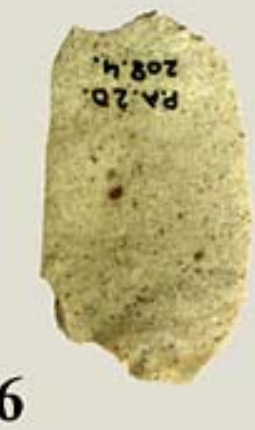

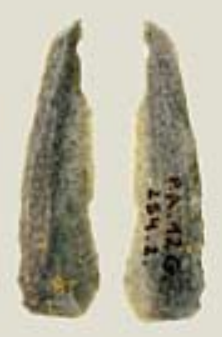

3

4
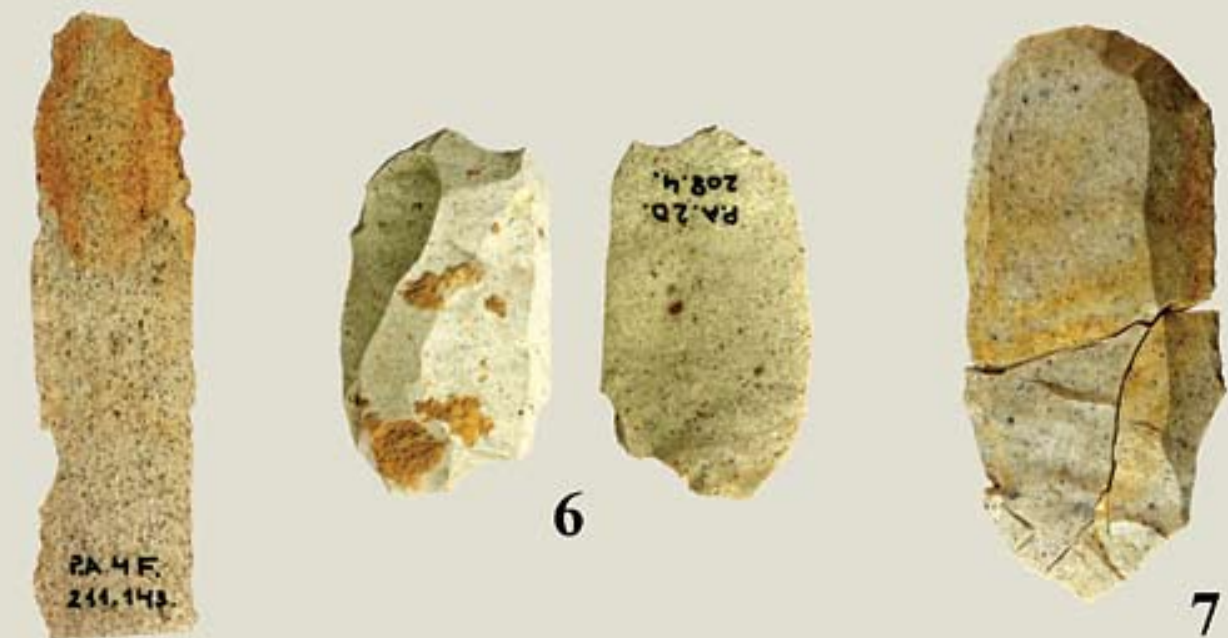

5

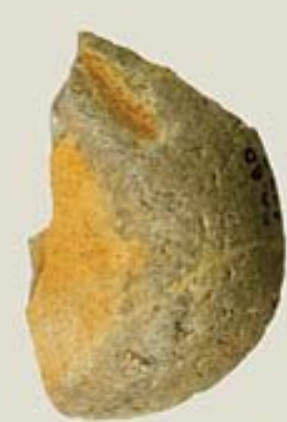

8
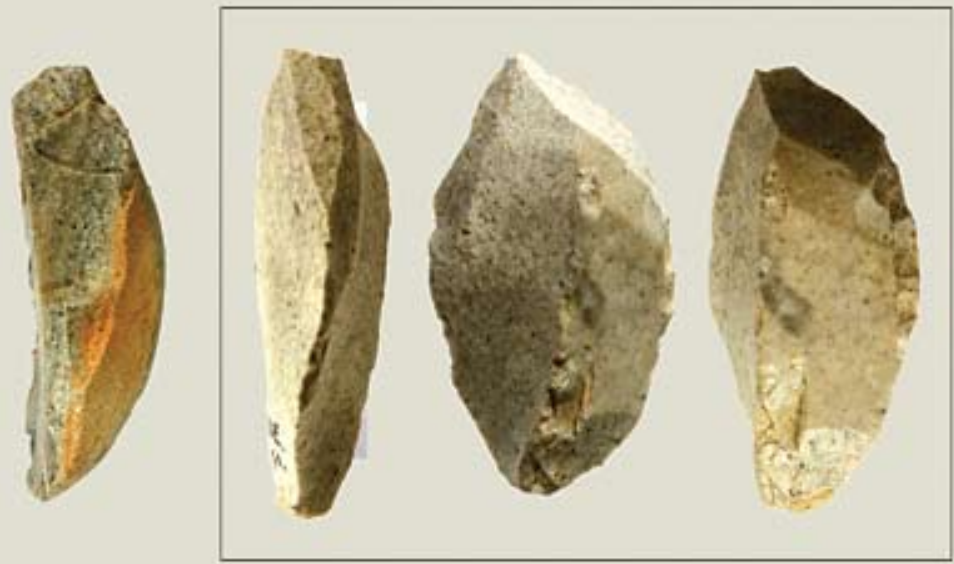

9

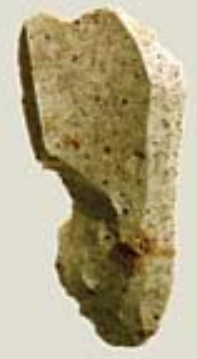

10

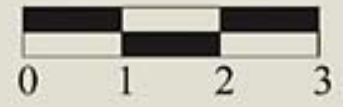

Fig. 5. Industria lítica del nivel II del vestíbulo. / Lithic industry from the level II of the vestibule. 
Fig. 6. Bastón perforado (X. Otero). / Perforated baton (X. Otero).

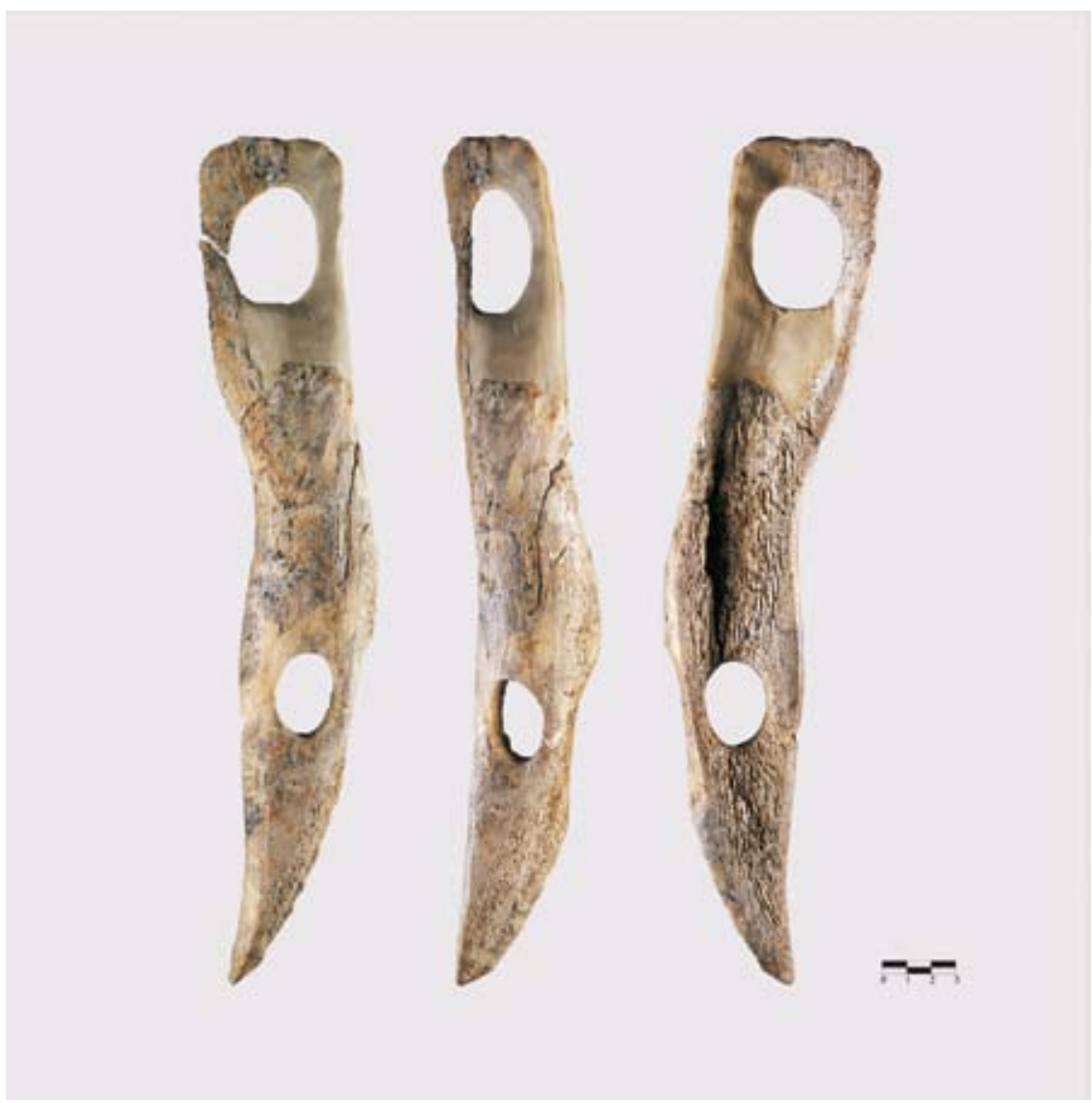

\subsubsection{Industria ósea}

La industria osea del nivel II del vestíbulo apenas ha aportado vestigios relacionables con ella ni con el proceso de fabricación. Con el fin de aproximarnos a la cronología de un excepcional bastón perforado, que además muestra en el extremo distal una amplia perforación de suspensión (P.A.10D.217.24), se envío una muestra de una esquirla ósea procedente del mismo cuadro y pro-

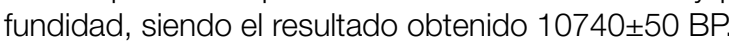

El bastón está fabricado sobre una ancha lengüeta de asta de ciervo, obtenida por aserramiento longitudinal paralelo, que presenta una forma general sinuosa asimétrica (P.A.10D.217.24: Figs. 6, 7 y 9 -detalle-). Sus dimensiones máximas son: $172 \times 28 \times 11,3 \mathrm{~mm}$. Su superficie cortical ha sido abrasionada casi totalmente, aunque se conserva parcialmente en dos zonas a modo de testigo y cuya presencia no es involuntaria.

Las zonas medial y distal del objeto son menos espesas, y además su cara ventral es cóncava a consecuencia de la pérdida del tejido esponjoso por su profunda alteración.

En el tercio distal, se localiza la perforación mayor encuadrada entre los lados rectilíneos, prácticamente paralelos, del soporte. Aquí, donde su espesor es de unos $3,5 \mathrm{~mm}$, la superficie cortical y el tejido esponjoso han sido profundamente raspados con el fin de eliminarlos hasta transformar esta zona en una delgada lámina. Las dimensiones del orificio, de forma ovalada, son aproximadamente $30 \times 20 \times 3,5$ mm. Su función, dado su débil espesor, fue distinta a las propias de un bastón (o de las que se les suponen más habitualmente), por lo que proponemos que su fin pudo ser la de facilitar su suspensión, aunque en este caso sus dimensiones serían inhabituales. Sin embargo, otra posibilidad es que fuera un trozo de un bastón con varias perforaciones, quizás en curso de fabricación, y que por su rotura -o abandono del proyecto mental inicial-, fuera reutilizado tras las modificaciones necesarias. También cabe la posibilidad de que se rompiera durante su uso, pero nos decidimos por la primera opción ya que estos objetos presentan por lo general decoraciones realizadas con profundas incisiones, de las cuales en este ejemplar no quedan rastros. Ciertamente, este tipo de piezas no son frecuentes, pero se conoce un ejemplar magdaleniense final en el cercano yacimiento de Aizkoltxo (MUJIKA, 2011).

Por otra parte, en los otros dos tercios del objeto sus bordes no corren paralelos, sino que son en cierta manera independientemente sinuosos, dando la impresión de que se desea configurar el cuello estirado -se produce un estrechamiento del soporte- y cabeza de un ave. En el tramo medio, el borde lateral correspondiente al dorso del cuello es rectilíneo, mientras que el otro -donde se situaría la hipotética garganta- es cóncavo. A continuación, 


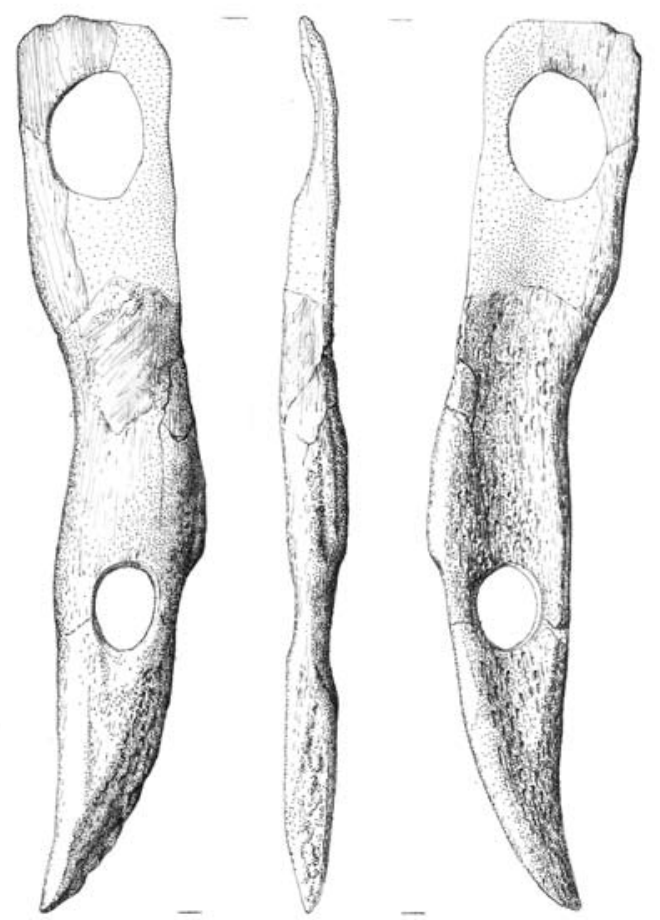

el borde dorsal se ensancha o abre hacia el exterior formando el pileo que quedará en relieve. Este es destacado, conservando la cortical del asta sin eliminar y mediante un profundo rebaje que configura la frente. Es de subrayar que esta escotadura que produce el estrechamiento de la lengüeta, se localice justo a la altura del orificio elíptico - de paredes oblicuas- del bastón, lo que la debilitaría para cualquier actividad que se ejerciese con cierta energía. El agujero ligeramente ovalado -que podría venir a representar el ojo del ave-, es asimilable al de los bastones perforados, siendo sus dimensiones 16,5 X $13 \times 5,5 \mathrm{~mm}$.

Finalmente, el extremo más próximo del soporte se estrecha progresivamente y se curva terminando en un apuntamiento romo y ligeramente desviado, que recuerda el potente pico de un ave -quizás un buitre-. En su parte superior conserva la cortical sin abrasionar, realzando dicha zona.

Este ejemplar de bastón perforado presenta algunas particularidades, como estar fabricado sobre una lengüeta (se conocen en Isturitz, La Vache, La Chora, La Pila, El Pendo), su forma sinuosa (se puede citar un objeto solutrense que muestra cierta semejanza en su silueta, la denominada "venus del Pendo" -CARBALLO, GONZÁLEZ ECHEGARAY, 1952; DELPORTE, 1982: 102-), y la presencia de dos orificios -uno de ellos de supensión y el otro funcional como bastón-. Se conocen bastones con varias perforaciones en yacimientos del Magdalenien-
Fig. 7. Bastón perforado (J. Alonso). / Perforated baton (J. Alonso).

se Final del entorno del golfo de Bizkaia: un fragmento con dos orificios sobre una lengüeta ancha en La Chora (CORCHÓN, 1987: 445), interpretada por el contrario como una plaqueta con dos orificios (GONZÁLEZ SÁINZ, 1989: 90); en El Pendo otro ejemplar con doble perforación, uno de ellos de mucho menor tamaño ¿de suspensión? (CORCHÓN, 1987: 418); en Isturitz (un bastón perforado presenta a lo largo de uno de los bordes al menos una decena de pequeñas perforaciones aparentemente no funcionales) (MUJIKA, 1993; SAINT-PÉRIER 1930, 1936), La Madeleine, Rochereil, Kesslerloch, etc.

Finalmente, con relación a la silueta general del objeto no podemos evitar señalar su similitud con otra excepcional pieza descubierta en la cueva de La Vache (Fig. 8), nos referimos al denominado "cetro" fabricado sobre un asta de cérvido y que muestra en sus caras varias repesentaciones, alguna no fácil de identificar, en relieve (un felino, un pez, un bóvido o cérvido y un caballo), y en el extremo apuntado la cabeza y cuello de un ave que recuerda al del bastón que tratamos. Por otra parte, la técnica de dejar en relieve algunas de las figuras que se desean destacar, rebajando para ello la cortical del asta se observa también en un asta perforada del mismo yacimiento, donde se representan un uro, tres cazadores y una cabra (BUISSON et al., 2003). Paralelos tipológicos de esta pieza se conocen en Isturitz (MUJIKA, 1993) y Santa Catalina (BERGANZA, RUIZ IDARRAGA, 2014). 


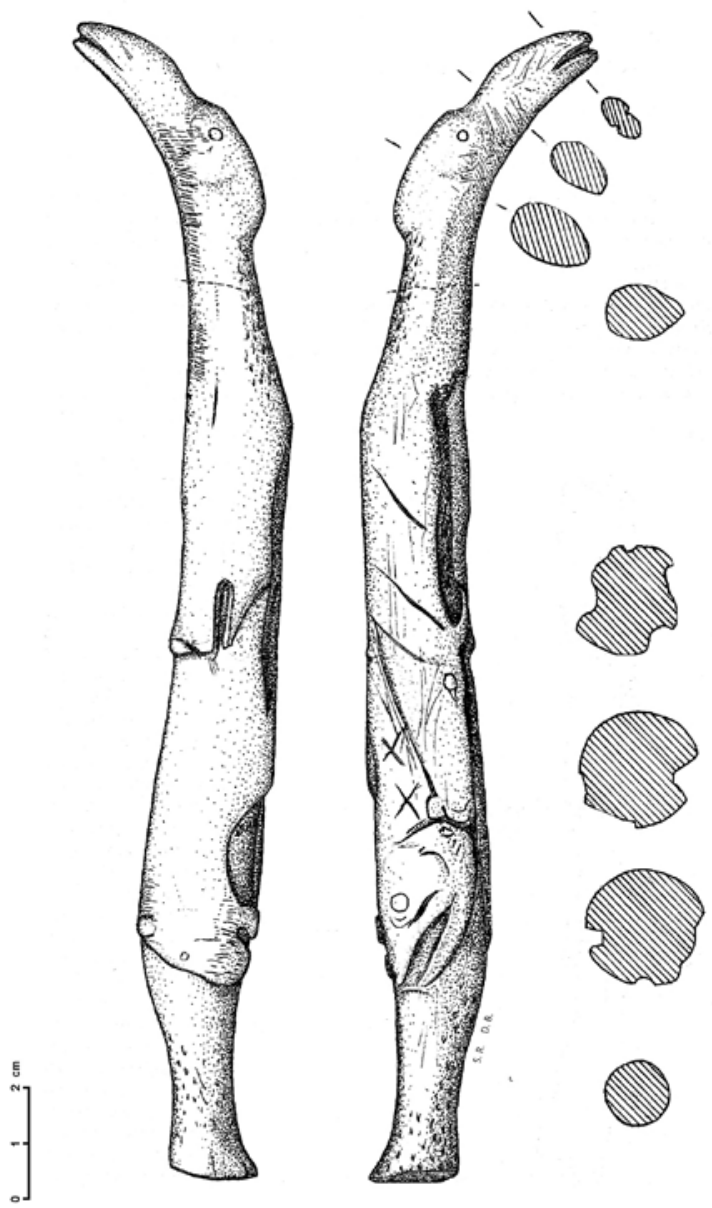

Fig. 8. "Cetro" de La Vache (BUISSON et al., 2003). / "Sceptre" from La Vache (BUISSON et al., 2003).

Entre el instrumental recuperado podemos citar un fragmento medial de biapuntado corto o anzuelo, fabricado en asta, y de sección circular en la zona central y aplanada hacia el extremo más completo (P.A.6F.230.15: Fig. 10). Sus dimensiones son: $52,3 \times 3,3 \times 3,3 \mathrm{~mm}$.

En resumen, los restos recuperados en este nivel proceden de un espesor de entre 65 y $80 \mathrm{~cm}$, lo que indica que son el resultado de la breve y recurrente ocupación de la cavidad. El número de efectivos es bajo, 94 líticos y 2 óseos, además de algunos cantos rodados de arenisca. Los productos líticos retocados (23) son poco característicos, pero la variedad tipológica es importante con raederas, raspadores, denticulados, truncaduras, elementos de dorso (LD, LDT, PD), buriles y astillados, lo que indica que no se trata de un nivel especializado. Destacaríamos la presencia de 2 puntas de dorso completas de morfología similar y tipometría, y de dos buriles, y en la industria ósea un bastón perforado de sugerente silueta. Este último, y acaso algunos otros objetos, habría que situarlos en el Magdaleniense Final, quizás en su extremo terminal, aunque no hay criterios para dicha

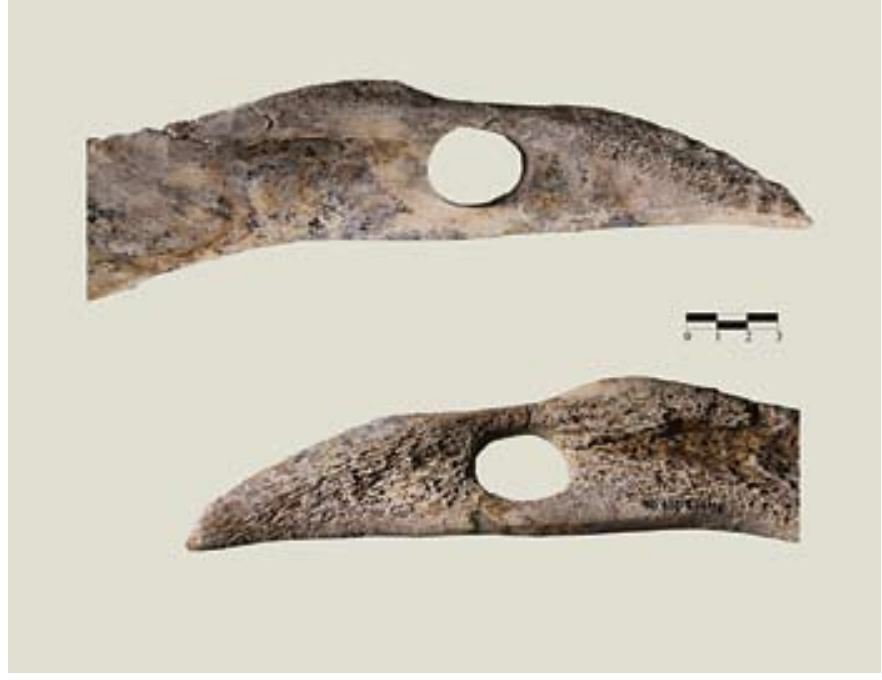

Fig. 9. Detalle de la hipotética cabeza del bastón perforado. / Detail of the perforated baton's hypothetical head.

Fig. 10. Biapuntado (J. Alonso). / Bipointed assegai (J. Alonso).

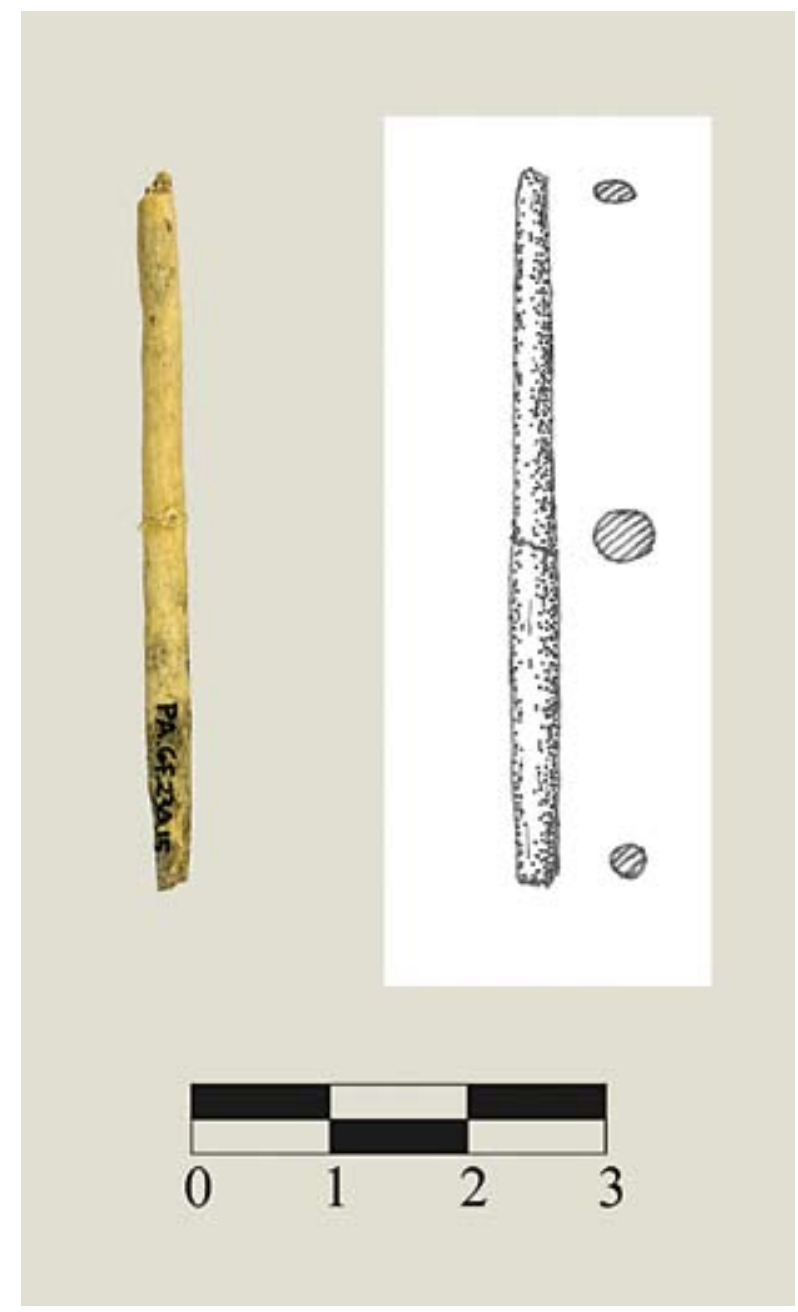


selección. El lento proceso de sedimentación y la irregularidad del suelo original dificultan dicha delimitación. Sin embargo, la datación aportada por la esquirla ósea y las procedentes de los hogares de la primera sala interior indicarían que a lo largo del Aziliense estos espacios han sido frecuentados por grupos humanos, aunque a nivel industrial no se conservan elementos característicos de estas cronologías (como las PDT triangulares de Ekain -MERINO, 1984- o Urtiaga).

\subsection{Nivel III}

\subsubsection{Industria lítica}

El lote principal lo constituye la industria de sílex, con 96 restos, pero podemos reseñar también la presencia de cuatro cantos rodados de arenisca, sin estigmas de utilización netos. De los 96 objetos, 82 (85,4\%) no están retocados y $14(14,6 \%)$ sí lo están. De los restos brutos de talla, $56(68,3 \%)$ son lascas y $26(31,7 \%)$, soportes laminares (P.A.2E.143.3: Fig. 11.13). 6 de ellos conservan restos de córtex. De las lascas, 8 están enteras, 18 corresponden a fragmentos proximales, 28 a mediales y distales, y dos son trozos informes. De las 26 láminas contabilizadas, 6 son completas, 8 fragmentos proximales y 12 mediales y distales. Entre los talones dominan los planos (27 efectivos), 7 diedros, 3 lineales, y finalmente un puntiforme, facetado y astillado.

Entre estos restos hay que señalar la presencia de algunas piezas de técnica, relacionadas con actividades de preparación de núcleos, reacondicionamiento de útiles, una veintena de fragmentos de reducidas dimensiones (denominados como grupo Z -MERINO, 1984-). Estos últimos fueron recuperados en un espacio muy reducido (cuadro $8 \mathrm{E}$ ) y a similar cota lo que indica actividad de acondicionamiento de soportes o de retoque. 4 fragmentos de láminas tienen denticulaciones irregulares, discontinuas, que interpretamos provisionalmente como huellas de uso (Fig. 11.5).

Entre los objetos retocados se han contabilizado 14 útiles (14,6\%) que atendiendo a los grupos tipológicos se distribuyen como sigue: 3 raspadores, 2 raederas, un écaillé, un buril, 3 truncaduras, 2 laminillas de dorso y una punta de dorso. A estos objetos, que presumiblemente pertenecen a las mismas ocupaciones superopaleolíticas, podemos añadir una punta musteriense (P1), o

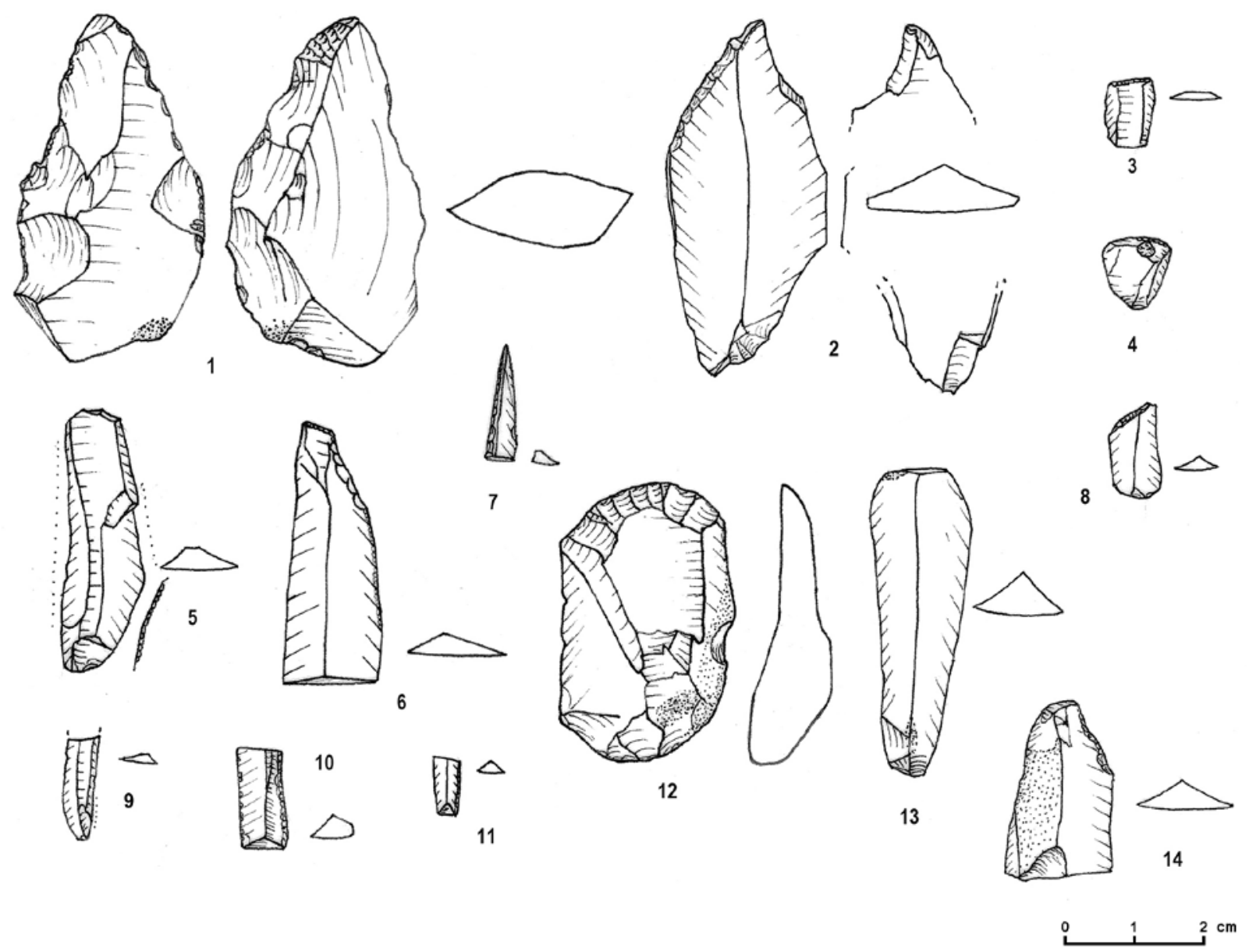

Fig. 11. Industria lítica del nivel III. / Lithic industry from the level III. 
Fig. 12. Industria lítica del nivel III. / Lithic industry from the level III.

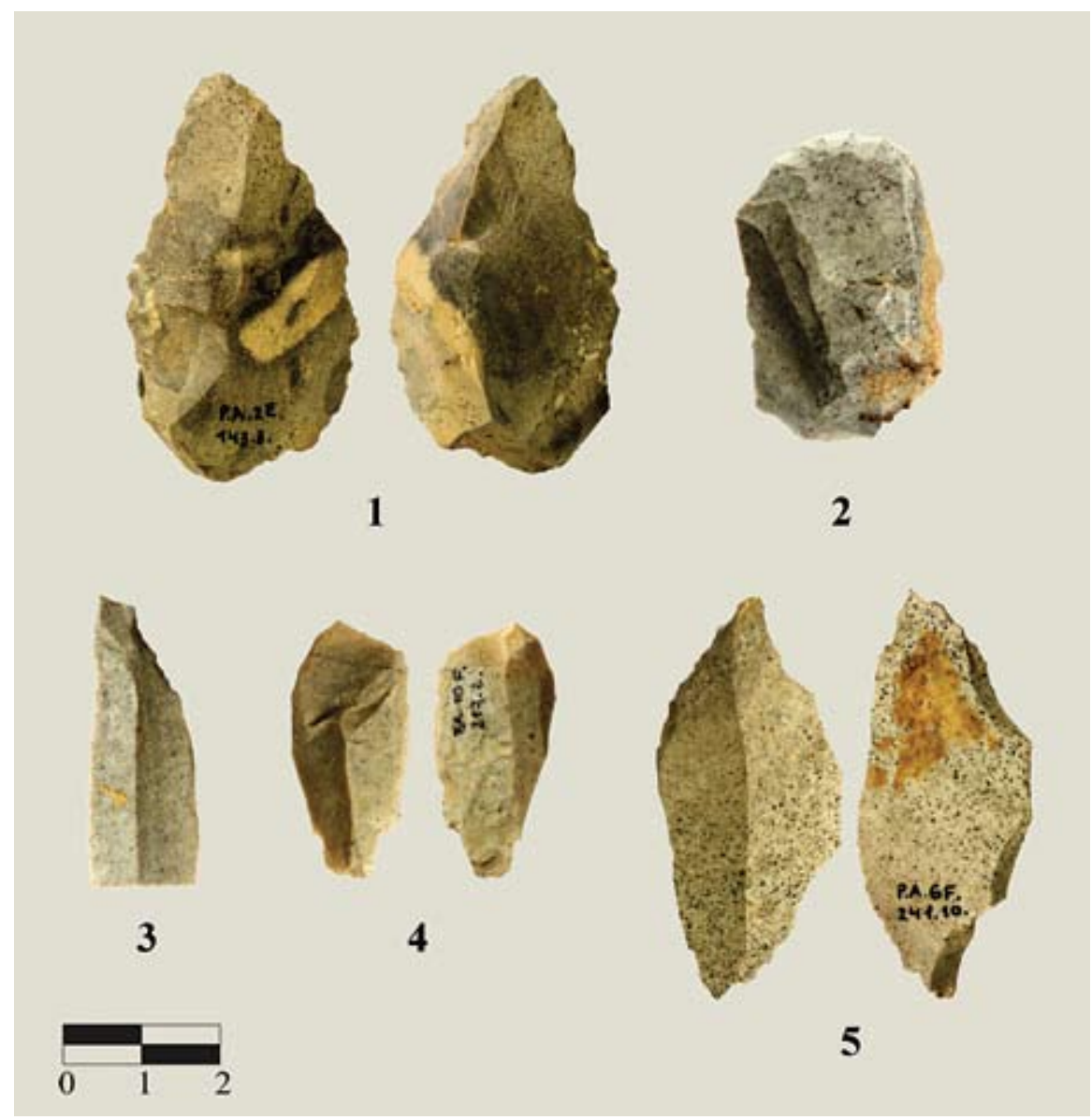

quizás raedera $(\mathrm{R} 3)$ fabricada sobre una gruesa lasca de bulbo pronunciado y talón facetado (P.A.2E.143.3: Figs. 11.1 y 12.1). Los retoques del talón son continuados con retoques simples inversos hasta el ápice, actualmente fracturado. Sus dimensiones son: 50,3 X 28,7 X 11,3 $\mathrm{mm}$. Esta pieza, al igual que algunas otras que se señalarán oportunamente, procedería de la galería noroeste.

En el grupo tipológico de los raspadores se han estudiado 3 ejemplares frontales (G11). Uno de ellos es una pieza doble (G11•G11) (P.A.10l.238.1: Figs. 11.12 y 12.2); otro, un raspador agotado fabricado sobre una lasca de decorticado, que desde el punto de vista tipométrico es carenada (G11k) y, finalmente, un ejemplar de dimensiones micro con el frente parcialmente retocado (Fig. 11.4).

En el grupo tipológico de las raederas se han incluido un fragmento de R1 parcial en extremo distal de lámina de decorticado (Fig. 11.14), y otro posible fragmento de raedera. En el grupo de los astillados o écaillés (E2) se ha clasificado un ejemplar (P.A.10F.217.2: Fig. 12.4).

En el grupo de los buriles se ha contabilizado un buril diedro doble (B31•B31) fabricado sobre un soporte laminar que presentaba una truncadura previa en ambos extremos (P.A.6F.241.10: Figs. 11.2 y 12.5). En las aris- tas laterales muestra retoques complementarios simples inversos.

En el grupo de las truncaduras se han incluido 3 piezas, una truncadura nomal (T1) (P.A.6F.241.5: Figs. 11.3 y 13.2) y otra oblicua (T2) (P.A.6F.241.13: Figs. 11.8 y 13.1), ambas fabricadas sobre fragmentos de láminas de pequeñas dimensiones $(13,5 \times 7,3 \times 2,3 \mathrm{~mm}$ y 9,8 $X 7,4 \times 1,5 \mathrm{~mm})$, y una T1m en fragmento distal de lámina con retoque complementario simple lateral distal (P.A.2E.222.1: Figs. 11.6 y 12.3).

El grupo tipológico de las láminas de dorso está representado por 2 fragmentos mediales de LD21 (Fig. 11.10 y 11.11) y el de las puntas de dorso por un fragmento distal de PD21 (Fig. 11.7).

Los restos recuperados en este nivel proceden de un espesor de entre 10 y $16 \mathrm{~cm}$. El número de efectivos es bajo, 96 de sílex, destacando entre los restos brutos de talla la elevada proporción de pequeñas lascas $(68,3 \%)$ frente a las láminas $(31,7 \%)$. Esto se explica por la presencia de lascas de retoque y de reavivado halladas en un reducido espacio y a similar cota, y que indicarían la existencia de un breve episodio de acondicionamiento de núcleos y de útiles.

El número de objetos retocados es muy discreto (14 efectivos $-14,6 \%-)$, pero la variabilidad es amplia, ya 


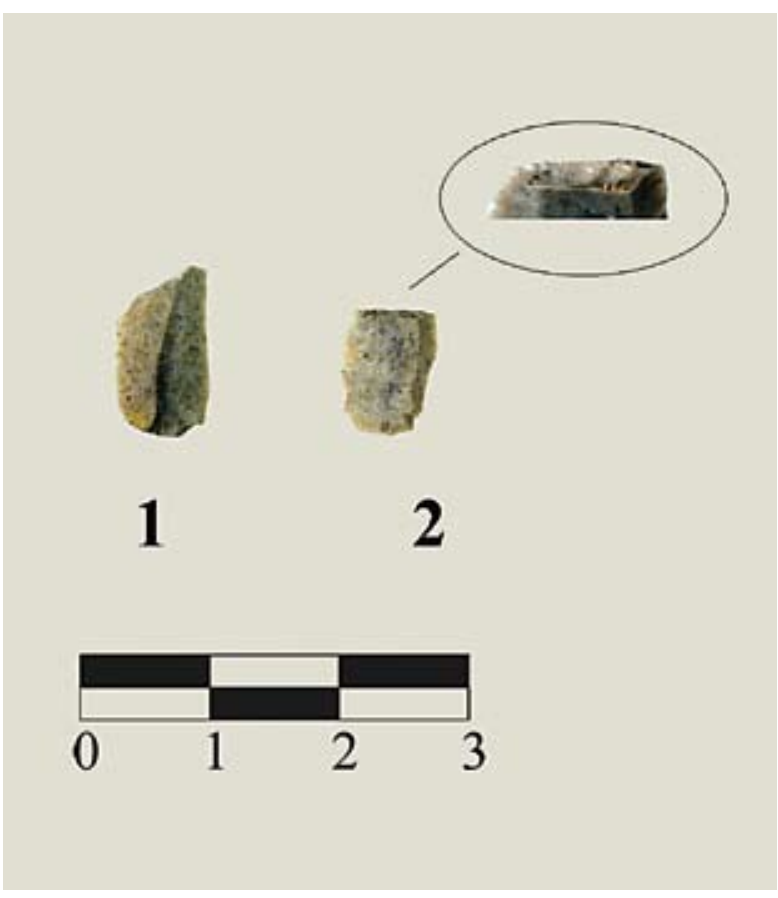

Fig. 13. Industria lítica del nivel III. / Lithic industry from the level III.

que se encuentran representados, aunque con un bajo número de efectivos, los raspadores, raederas, écaillé, buril, truncaduras y piezas de dorso (laminillas y punta). En este aspecto muestra similitud con el nivel II, aunque en el nivel III la proporción de útiles es netamente inferior. Por su posición estratigráfica y la presencia de un arpón en el pasillo, único instrumento óseo recuperado en el nivel, proponemos que estamos ante fugaces ocupaciones del Magdaleniense Superior-Final. Una referencia válida de esta ocupación en el vestíbulo podría ser una base de asta de matanza de reno (P.A.8F.211), datada en

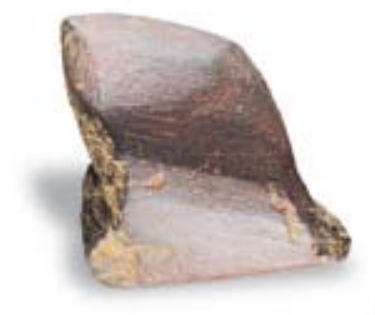

1
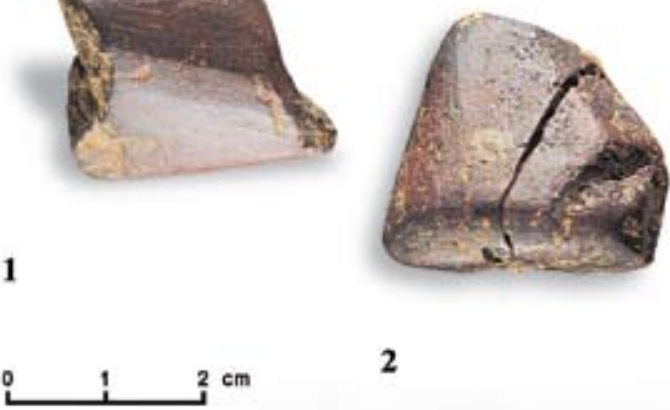

2

Fig. 14. Fragmentos de ocre con líneas de abrasión del nivel IV del vestíbulo (X. Otero). / Ochre fragments with abrasion lines from the level IV of the vestibule (X. Otero).
$12920 \pm 50$ BP, y hallada en el contacto entre los niveles II y III, y que por cierto se hallaba próxima al bastón de mando. Su presencia no parece obedecer a razones antrópicas si atendemos a sus características, pero podría ser una referencia para datar esta ocupación Magdaleniense.

\subsection{Nivel IV}

\subsubsection{Industria lítica}

Entre los restos de origen antrópico podemos señalar la presencia de 83 objetos de distinta naturaleza, concretamente 2 cantos rodados de arenisca, 7 fragmentos de ocre, 73 de sílex y uno de "vulcanita".

Entre los cantos rodados, uno de ellos un simple trozo, podemos destacar uno de arenisca de grano fino, que muestra ligeras manchas de ocre. Sus dimensiones son: $70,7 \times 44,7 \times 16,2 \mathrm{~mm}$.

De los 7 fragmentos de ocre, 4 no tienen indicios claros de utilización, a pesar de que alguno, aparentemente, es de buena calidad. Los otros trozos presentan distintos planos de abrasión, dándose la circunstancia de que dos de ellos pegan perfectamente (P.A.8D.279.13: Figs. 14.2 y 15.2). Además, uno de estos muestra numerosas incisiones longitudinales de abrasión en la cara dorsal y laterales, y en la ventral y en los extremos se observa que tras la fractura del bloque de ocre original se continuó utilizando como lápiz o núcleo de polvo de ocre, aunque en estas caras las incisiones son menos profundas (P.A.8D.283.12: Figs. 14.1 y 15.1).

La industria lítica de sílex la constituyen 73 elementos, a los que habría que sumar uno de "vulcanita". Entre los objetos líticos de origen antrópico no retocados contabilizamos $52(71,2 \%)$ restos, y entre los retocados
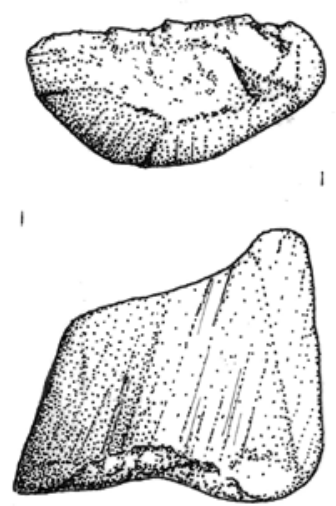

1
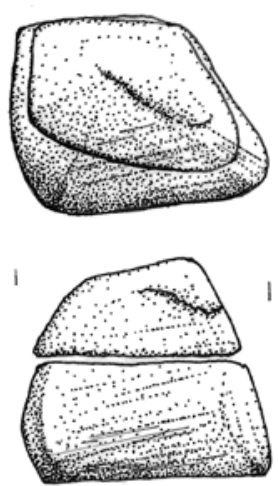

2

Fig. 15. Fragmentos de ocre del nivel IV del vestíbulo (J. Alonso). / Ochre fragments from the level IV of the vestibule (J. Alonso). 
21 (28,7\%). De los no retocados cuatro conservan córtex. Desde el punto morfológico y métrico 33 (63,5\%) de ellos son lascas (8 completas, 11 proximales y 14 mediales o distales), 17 (32,7\%) láminas (3 completas, 7 proximales y 7 mediales y distales) (P.A.12E.281.24: Fig. 16.6; P.A.12D.275.4: 16.9; P.A.12A.279.4: 16.10), y finalmente 2 (3,8\%) fragmentos. Entre los 29 talones conservados dominan los lisos o planos (18 items, que representan el 62\%), seguidos de los facetados con 5 $(17,2 \%)$, los lineales con $3(10,3 \%)$, los diedros con $2(6,9 \%)$ y los puntiformes con un ejemplar $(3,4 \%)$. La presencia de algunos de estos restos (por ejemplo 5 lascas de reavivado, una cuña) obedece a labores de acondicionamiento de nucleos y de útiles. Además, podemos señalar que una lasca muestra huellas de uso distales en su borde derecho.
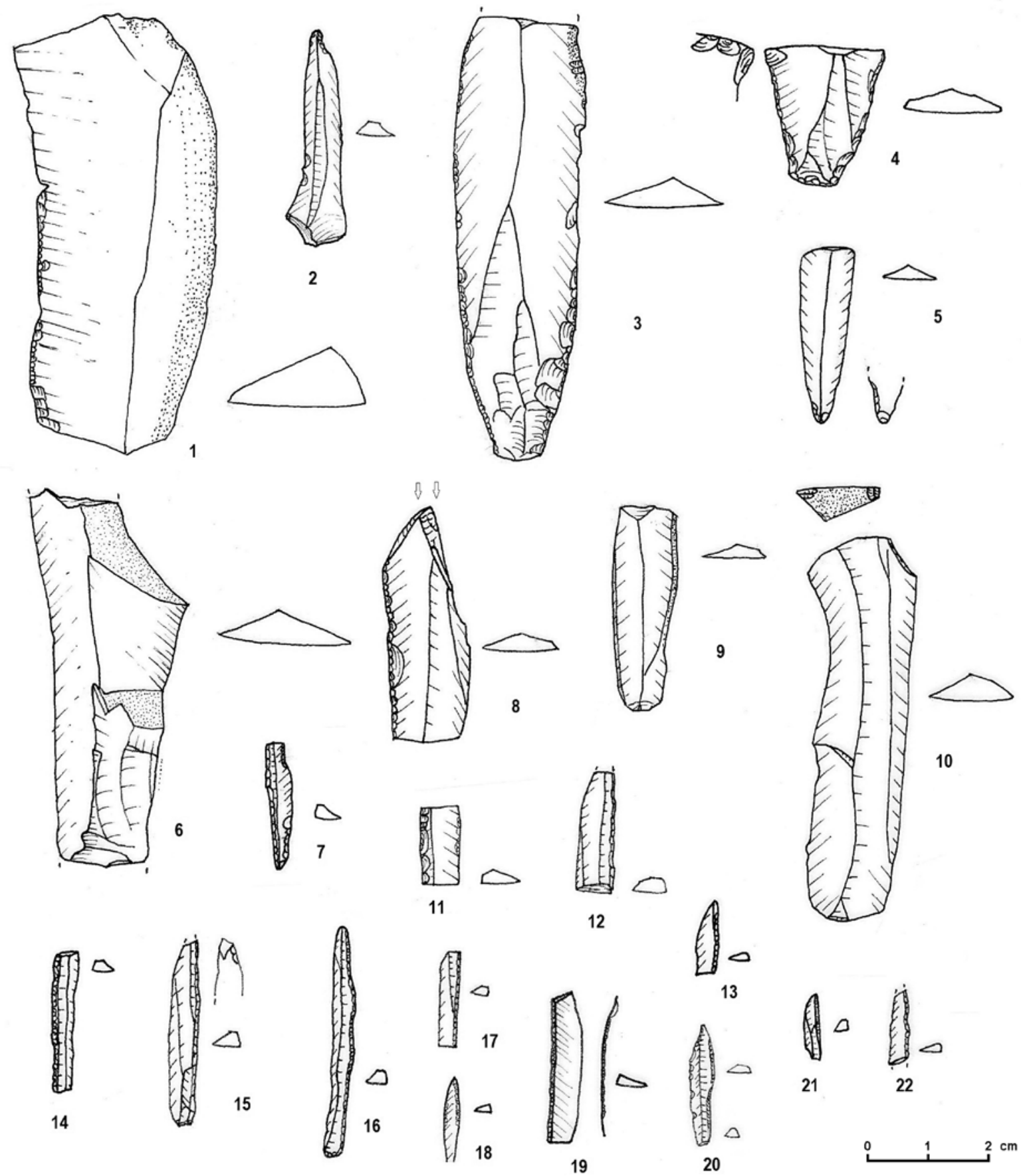

Fig. 16. Industria lítica del nivel IV del vestíbulo. / Lithic industry from the level IV of the vestibule. 


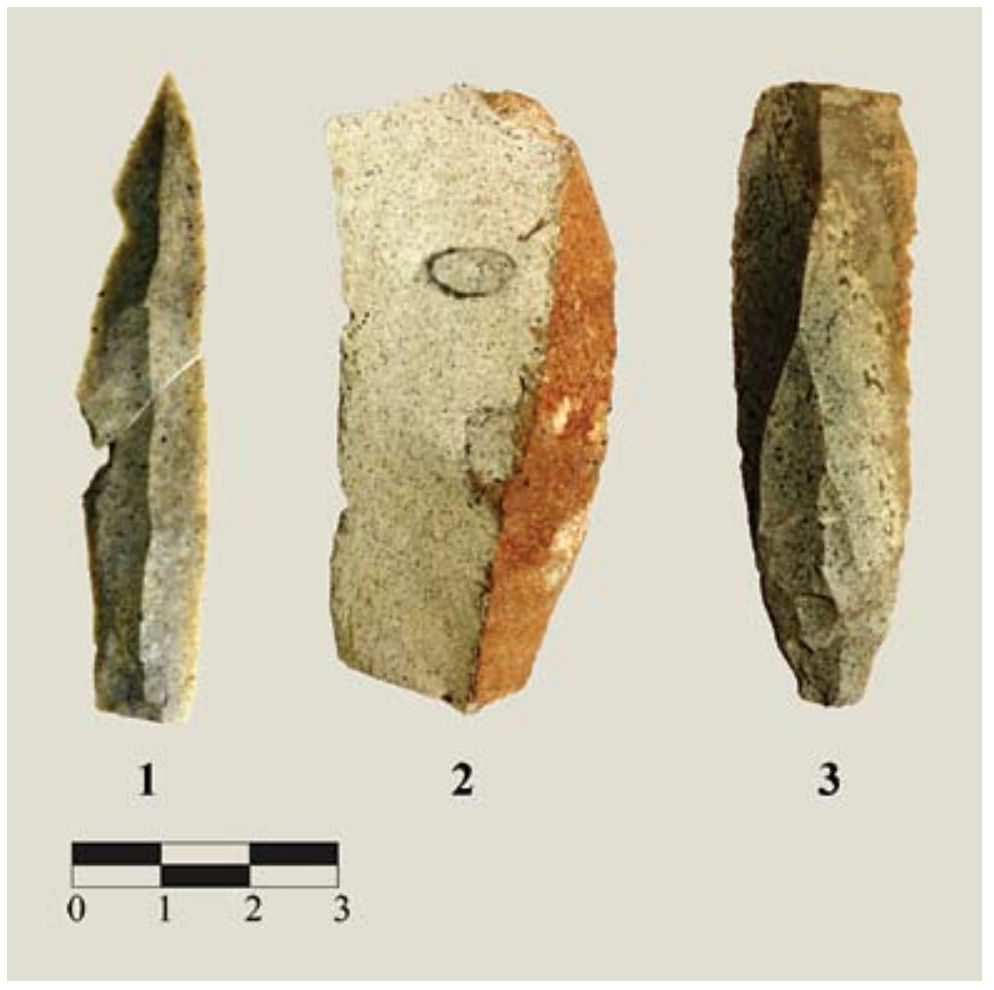

Fig. 17. Industria lítica del nivel IV del vestíbulo. / Lithic industry from the level IV of the vestibule.

El número de efectivos retocados se eleva a 21 (28,7\%). El grupo tipológico mejor representado es el de los dorsos con 13 piezas (6 laminillas de dorso y 6 puntas, y una punta de dorso y truncadura), seguidos de lejos por los bec con 3, raederas con 2 y ejemplares aislados de buril, denticulado y astillado.

En el grupo tipológico de las raederas se han clasificado 2 ejemplares de raederas laterales marginales parciales (R1), una de ellas (P.A.6C.276.2: Fig. 16.1, 17.2) sobre un fragmento medial de ancha lámina de decorticado (73,2 X 32 X 11,4 mm), y la otra (P.A.10G.256.10: Figs. 16.3 y 17.3$)$ un fragmento mesoproximal con retoques simples bilaterales (73,5 X 21,8 X 5,8 mm).

En el grupo de los denticulados se contabiliza una muesca simple (D1) dispuesta en la parte central del borde izquierdo de una lámina apuntada, punto a partir del cual se partió el soporte (P.A.12B.273.5: Fig. 17.1). La fractura es antigua y los trozos se localizaron en P.A.12B.273 y P.A.10C.277, lo que nuevamente confirma la práctica horizontalidad del sitio.

En el grupo de bec se han incluido 3 ejemplares (Bc2), 2 de ellos sumarios. Uno se localiza en el ápice de una lámina apuntada que presenta una muesca sumaria distal, y otro en el extremo proximal, junto al talón puntiforme de una lámina reflejada (P.A.12E.286.28: Figs. 16.2 y 18.1; P.A.8E.269.24: Figs. 16.5 y 18.2). El tercer ejemplar parece tratarse de un extremo proximal de raedera, del que se reutiliza el vértice que conforma el plano de fractura con la arista lateral (P.A.12E.265.3: Figs. 16.4, 18.3).
En el grupo tipológico de los astillados o écaillés se ha clasificado un solo objeto (E1). El de los buriles está representado por un fragmento distal de buril de paños laterales (B31) con retoques simples marginales en la arista izquierda. Sus dimensiones son: 40,4 X 14 X 5,1 mm (P.A.10F.271.3: Figs. 16.8 y 18.5).

El grupo de las láminas de dorso está representado por 6 fragmentos mediales de laminilla (LD21) (P.A.10F.276.5: Figs. 16.14 y 18.8; P.A.14G.303.2: 16.17; P.A.10G.265.236: 18.10 y P.A.12F.289.110: 16.22), uno de los cuales muestra además retoques simples discontinuos minimales en el borde opuesto al dorso (P.A.14E.291.73: Fig. 16.11, 18.4) y otro retoques simples marginales continuos inversos en el borde opuesto (P.A.12B.295.287: Figs. 16.19 y 18.6).

El grupo tipológico de las puntas de dorso (PD) está representado por 7 efectivos. La mayoría se conservan incompletas, pero existen elementos en su morfología que nos inclinan a clasificarlas aquí. Son tres los fragmentos distales -2 pequeños- (P.A.16F.310.14: Figs. 16.12; P.A.12F.289.110: 18.14; P.A.16F.310.14: 18.13; P.A.10F.269.4: 16.13 P.A.2D.195.2:).

El ejemplar más completo de PD21 no conserva el ápice, donde muestra un plano helicoidal originado, probablemente, por impacto. En el borde opuesto al dorso se observan retoques simples inversos sumarios (P.A.2F.304.221: Figs. 16.15 y 18.7). Sus dimensiones son: $30,6 \times 5,1 \times 2,8 \mathrm{~mm}$.

Otra punta de dorso también prácticamente completa (P.A.8C.287.124: Figs. 16.20 y 18.11), pero de di- 

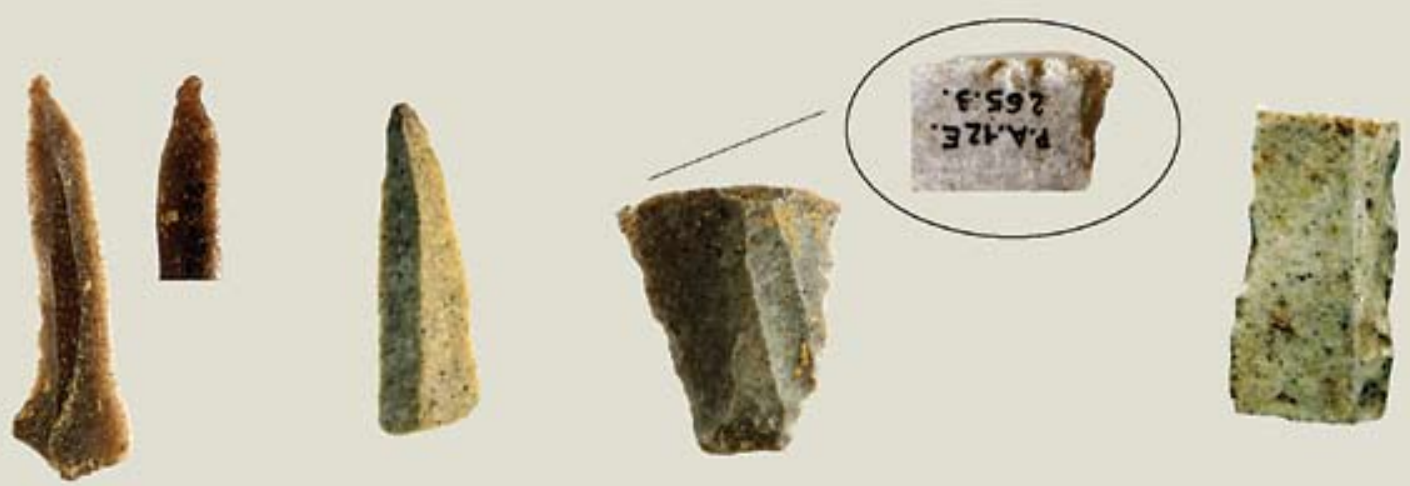

1

2

3

4
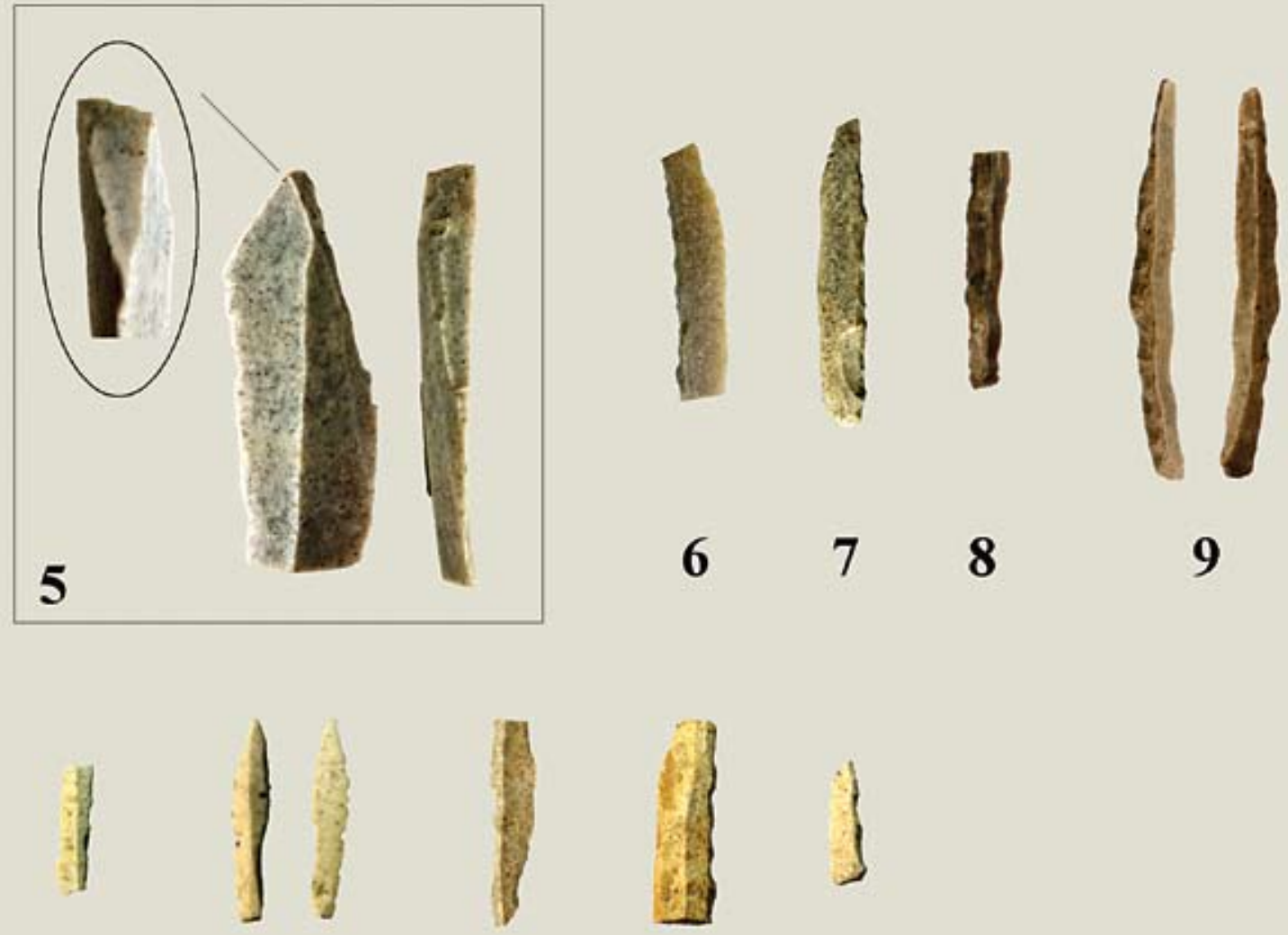

1

10

11

12

13

14

Fig. 18. Industria lítica del nivel IV del vestíbulo. / Lithic industry from the level IV of the vestibule. 


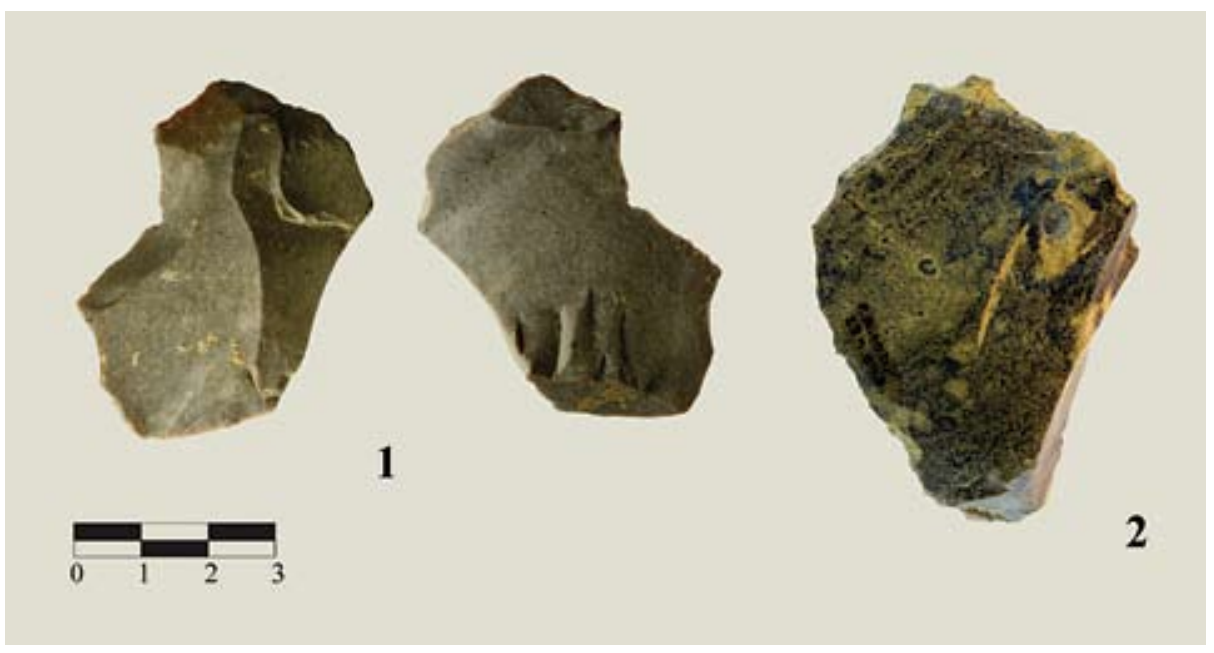

Fig. 19. Industria lítica del nivel IV del vestíbulo. / Lithic industry from the level IV of the vestibule.

mensiones más discretas, muestra en la mitad proximal un golpe burinoide que ha eliminado la arista derecha, y un lascado proximal ventral, originados probablemente por impacto. Conserva el talón plano. Sus dimensiones son: $20 \times 3,7 \times 1,8 \mathrm{~mm}$.

Además, se ha clasificado como fragmento de LD21 (o de PD21) -de dimensiones micro- en extremo de laminilla (P.A.14F.287.13: Fig. 16.18) que muestra retoques complementarios en la arista opuesta.

En el grupo de las puntas de dorso y truncadura se ha incluido un ejemplar (PDT1) fabricado sobre una laminilla muy estrecha (P.A.10F.267.7: Figs. 16.16 y 18.9). Sus dimensiones son: $38,4 \times 4,3 \times 2,9 \mathrm{~mm}$.

Se ha clasificado como fragmento proximal de PD32 o LD32 sobre lámina (P.A.14E.294.9: Figs. 16.7 y 18.12).

Por otra parte queremos señalar la presencia de 2 objetos de aspecto musteriense, localizados en el contacto del vestíbulo y la galería noroeste de la que podrían proceder. Uno de ellos es una lasca de reavivado de talón plano $\left(120^{\circ}\right)$ que muestra una muesca simple (D1) (P.A.10G.260.13: Fig. 19.1). Sus dimensiones son: $50 \mathrm{X}$ $33,6 \times 11 \mathrm{~mm}$. El segundo ejemplar es una espesa y ancha lasca de decorticado, bulbo pronunciado y talón plano (P.A.10D.289.343: Fig. 19.2) fabricada sobre sílex de Flysch de la variedad Gaintxurizketa. Sus dimensiones son: $45 \times 61,2 \times 21 \mathrm{~mm}$.

\subsubsection{Industria ósea}

La colección de industria ósea del nivel IV está constituida por 5 objetos, concretamente 3 azagayas, un trozo de costilla decorado y 3 incisivos de cabra con doble perforación en su raíz y trazos transversales paralelos en su cara vestibular.

Entre las azagayas destaca un ejemplar de monobisel corto y aplanamiento central, que está fabricada sobre una lengüeta de asta. Sus dimensiones son: 132,5 X 9,5 X 7,4 mm (P.A.10F.274.32: Figs. 20 y 21).

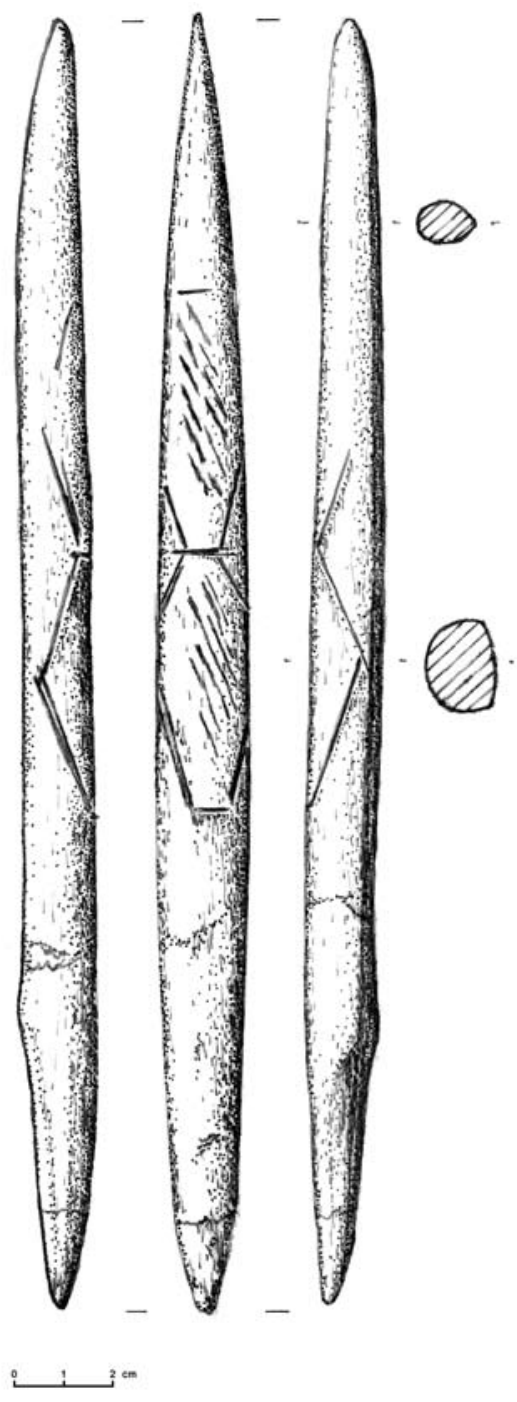

Fig. 20. Azagaya decorada del nivel IV del vestíbulo (J. Alonso). / Decorated assegai point from the level IV of the vestibule (J. Alonso). 


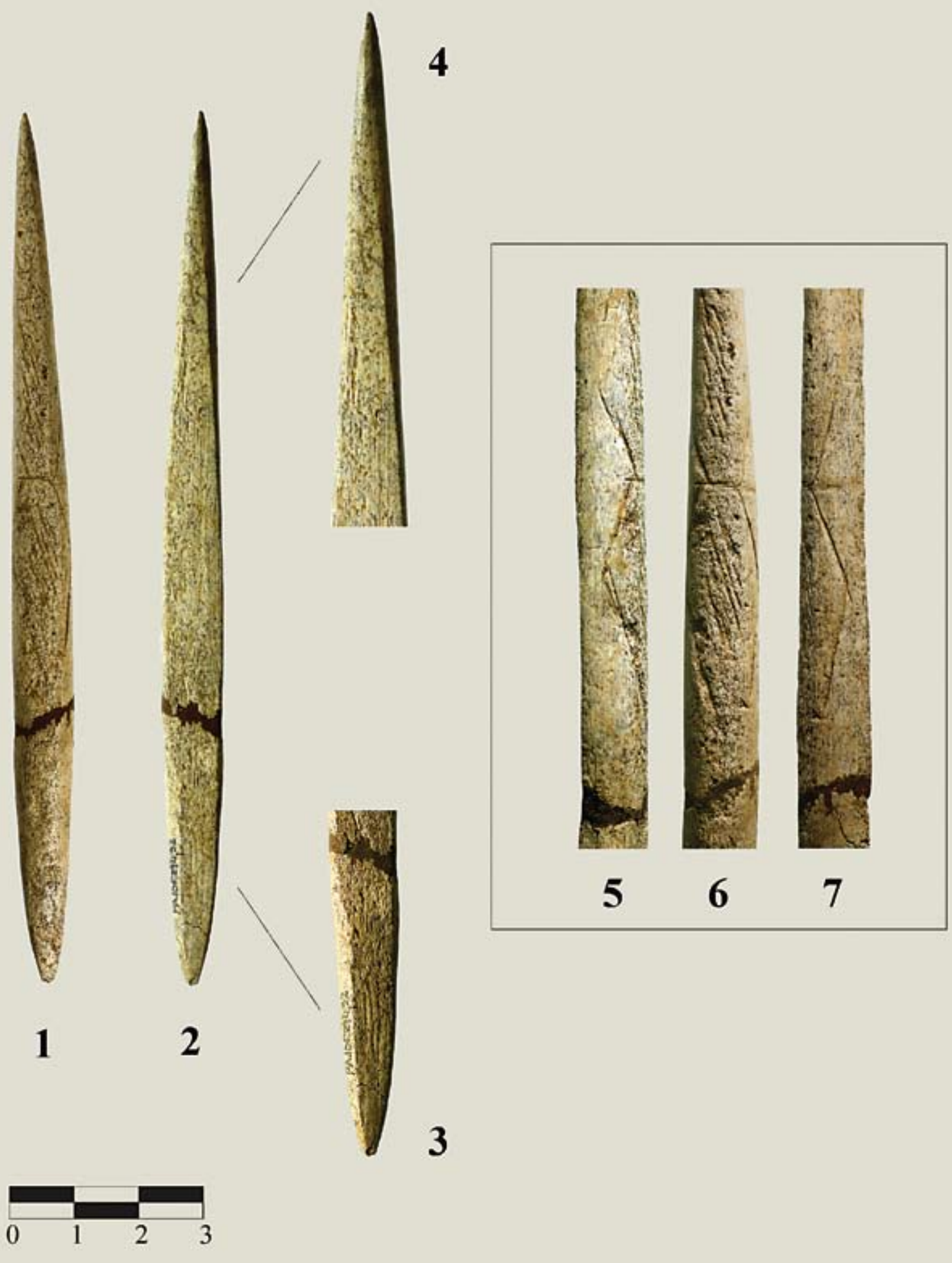

Fig. 21. Azagaya decorada del nivel IV del vestíbulo. / Decorated assegai point from the level IV of the vestibule. 
En su extremo distal, en los últimos 20 mm, su sección es biconvexa-aplanada. En la zona medial -a lo largo de unos $80 \mathrm{~mm}$-, presenta una amplia superficie plana obtenida tras abrasionar el tejido esponjoso, por lo que aquí su sección transversal es aproximadamente semicircular. A continuación se aprecia un suave resalte que se sitúa en el contacto de la zona medial con un corto (de $31 \mathrm{~mm}$ ) bisel liso que se va apuntando hacia el extremo proximal.

En la zona medial de la azagaya se disponen, en paralelo a ambos lados (Fig. 21.2 y 4), un zig-zag formado por tres trazos en uno de los lados y por cuatro trazos en el opuesto, y cortados en los ángulos en los que convergen las líneas quebradas por otros 3 cortos perpendiculares (situados en la cara cortical). De esta manera se conforman 2 hexágonos contiguos (casi rombos) muy alargados. El espacio interior de dichas representaciones está rellenado por dos series de profundas incisiones oblicuas muy agrupadas (Fig. 21.5, 6 y 7).

Hay que subrayar que sus características tipológicas no son frecuentes, recordando por un lado a las azagayas de bisel central del Solutrense Final y del Magdaleniense Inicial Cantábrico, pero en la que estudiamos dicha superficie se prolonga a modo de un neto monobisel. Por otra parte, se aprecia cierta similitud con las azagayas de bisel muy largo, aunque en la de Praileaitz I hay una ruptura neta entre el bisel y la superficie medial plana, o incluso con aquellas varillas planoconvexas en cuyo extremo distal la sección es más robusta (aplanada o biconvexa). Da la impresión de que se trata de ensayos en los tipos de enmangamiento, en la búsqueda de una mayor eficacia, ya que en estas fechas conviven las azagayas monobiseladas de bisel corto y de bisel muy largo, las varillas planoconvexas y las puntas-varillas (PEÑALVER, MUJIKA, 2003; MUJIKA, PEÑALVER, 2012).

Otra azagaya que destaca por su sigularidad es una de base hendida de sección circular de la que no se conserva el ápice ni el extremo proximal de los labios (P.A.10D.291.362: Figs. 22 y 23). Sus dimensiones son: $78 \times 6,8 \times 6,3 \mathrm{~mm}$. Se distingue de las azagayas auriñacienses de base hendida y sección aplanada (ovalada), además de por su sección por la decoración en el caso del ejemplar de la azagaya de Santimamiñe (PEÑALVER, MUJIKA, 2005).

Además, hay también otro fragmento medial de azagaya de sección aplanada (P.A.10D.291.362: Fig. 24)
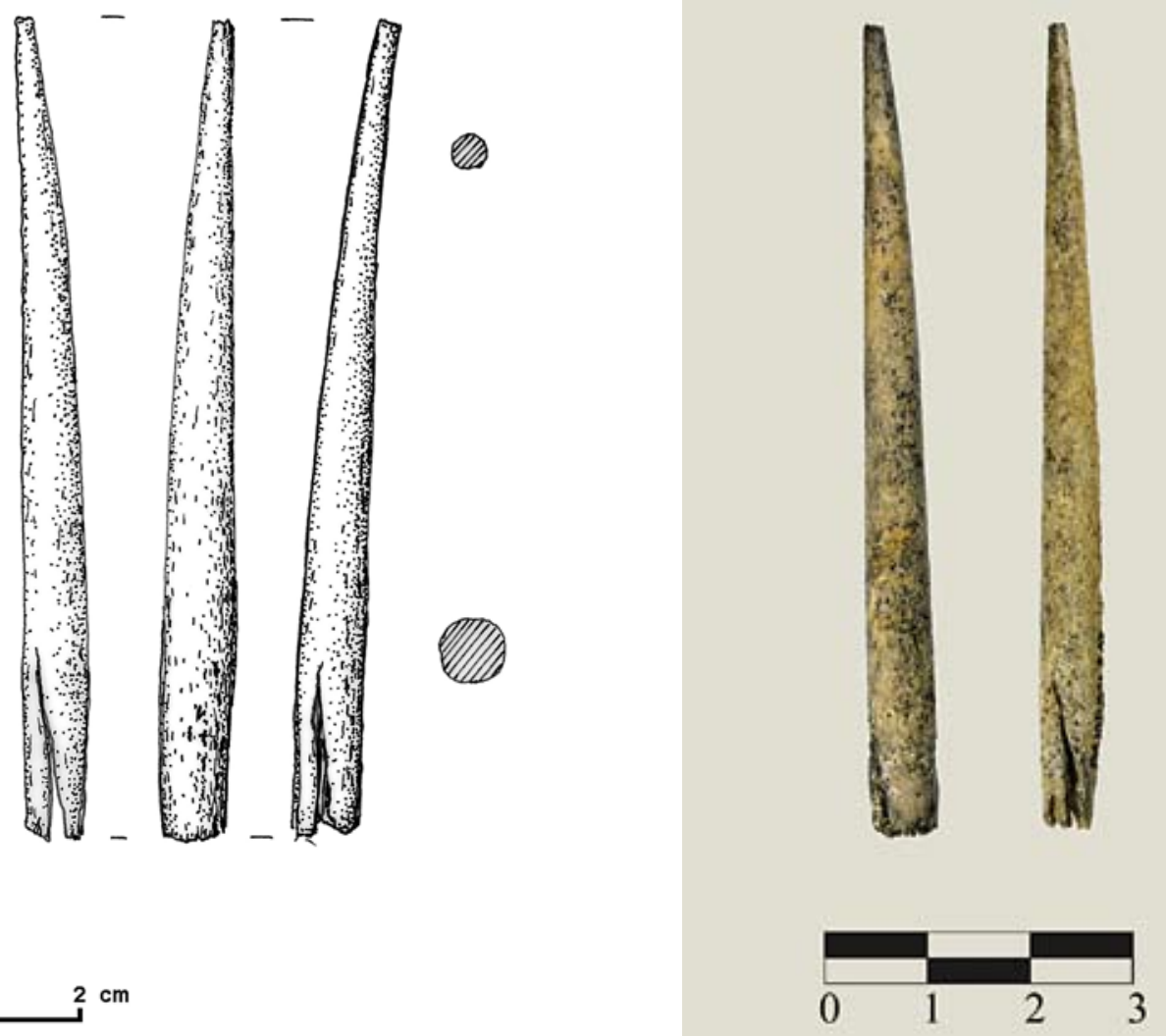

Figs. 22-23. Azagaya de base hendida del nivel IV del vestíbulo (Dibujo: J. Alonso). / Assegai point from the level IV of the vestibule (Drawing: J. Alonso). 

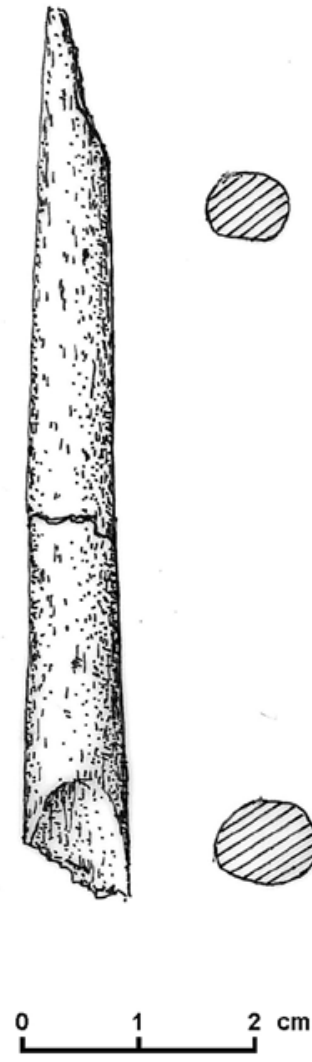

Fig. 24. Fragmento de azagaya del nivel IV del vestíbulo (J. Alonso). / Fragment of assegai point from the level IV of the vestibule (J. Alonso) que muestra el tejido esponjoso deteriorado en algunas zonas. Sus dimensiones son: $74,7 \times 8,9 \times 7,1 \mathrm{~mm}$.

Finalmente, tenemos un fragmento medial de costilla de un animal de pequeña o mediana talla (cabra, sarrio, etc.) que no conserva las dos aristas laterales (P.A.6C.271.3: Fig. 25), por lo que no puede descartarse que sea un fragmento de alisador. El mayor o menor desgaste en las aristas laterales de los alisadores sobre costillas completas es un hecho muy frecuente. En una de las caras mayores presenta un haz de profundas incisiones paralelas oblicuas que partiendo del lateral van a parar a la fractura transversal. En la fractura opuesta quedan restos de otra incisión de las mismas características. Sus dimensiones son: $21,7 \times 11,7 \times 4 \mathrm{~mm}$.

Fig. 25. Fragmento de costilla decorada del nivel IV del vestíbulo (Dibujo: J. Alonso). / Fragment of decorated rib from the level IV of the vestibule (Drawing: J. Alonso).
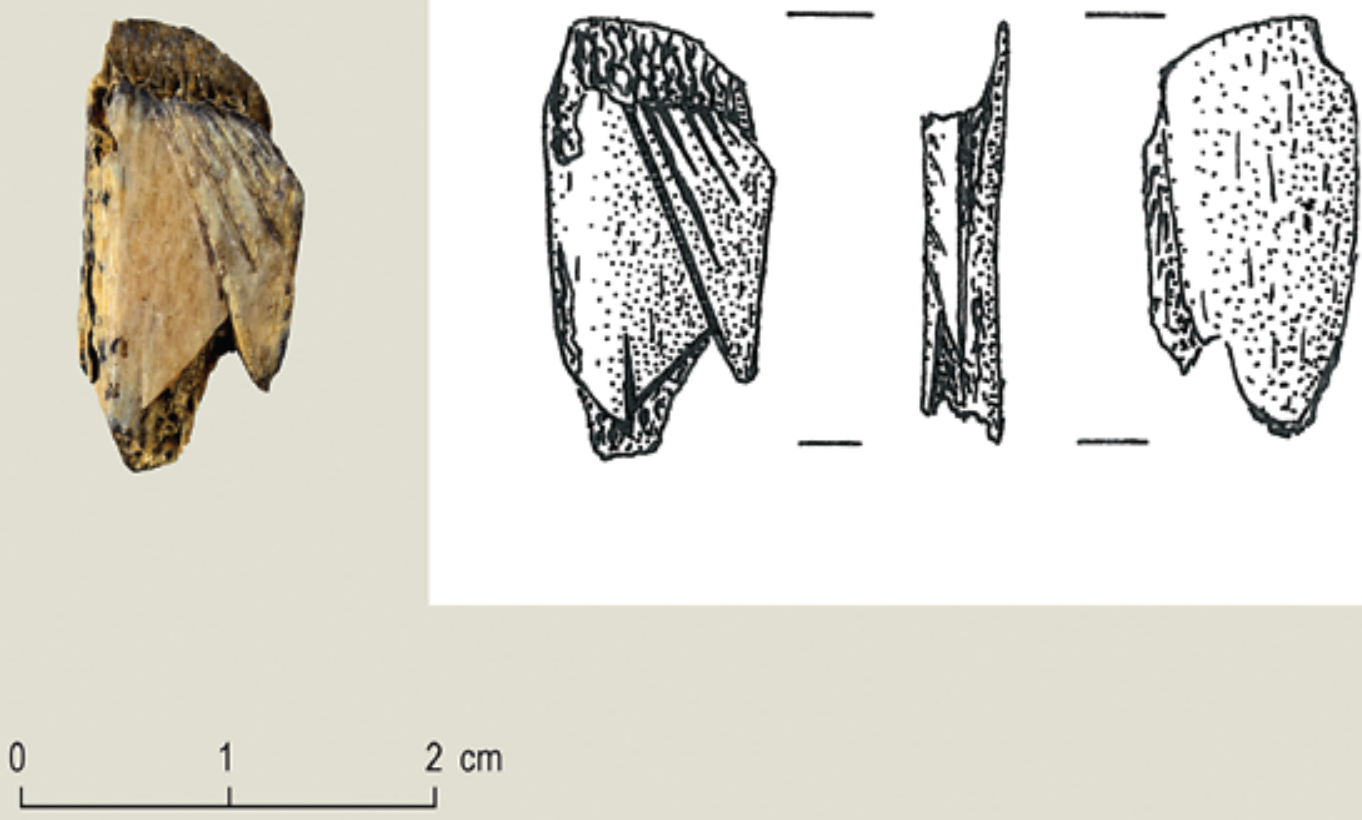

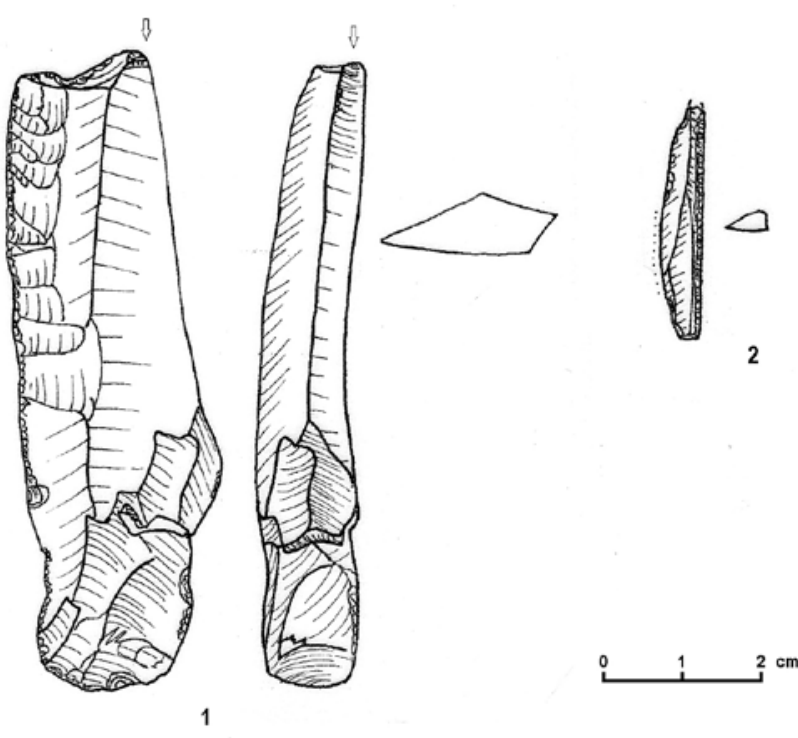

Fig. 26. Industria lítica del nivel $V$ del vestíbulo. / Lithic industry from the level $\vee$ of the vestibule.

Este nivel presenta los restos de la ocupación más importante y singular de Praileaitz I, concretamente varios trozos de ocre -alguno con huellas de abrasión-, un lote de colgantes constituido por 26 de piedra y 3 piezas dentarias, y un discreto conjunto industrial lítico y óseo, además de restos de fauna, sobre un suelo de origen antrópico constituido por pequeños cantos calizos sobre el cual se dispuso un hogar situado en el centro del vestíbulo, y junto al cual había un bloque que hacia las veces de banco o asiento.

Entre los 74 objetos líticos subrayaríamos la baja proporción de los soportes laminares en comparación con el nivel II, y su semejanza con el III, aunque en la ocupación del IV no se ha observado una presencia llamativa de lasquitas de retoque o de reavivado, sino más bien simples fragmentos de soportes, lo que interpretamos como que estos y los útiles eran aportados ya fabricados.

Destaca también la elevada proporción de productos retocados (21 efectivos, $28,7 \%$ respecto del total), entre los cuales es muy llamativa la elevada proporción de elementos de dorso (6 LD, 6 PD y 1 PDT) que representan el $61,9 \%$, y que habrá que asociar a las actividades cinegéticas practicadas, labores de preparación de las armas, etc. La presencia de 3 becs pudiera obedecer a la necesidad de preparar la perforación de los colgantes, aunque para el elevado efectivo de estos sería necesario un mayor número de perforadores por lo que la mayoría serían aportados ya fabricados. Los restantes instrumentos son 2 raederas y ejemplares aislados de buril, de denticulado y de pieza astillada.

En cuanto a la industria ósea hay que señalar la presencia de 4 objetos, si bien no hay indicios de fabricación por lo que serían aportados ya acabados.

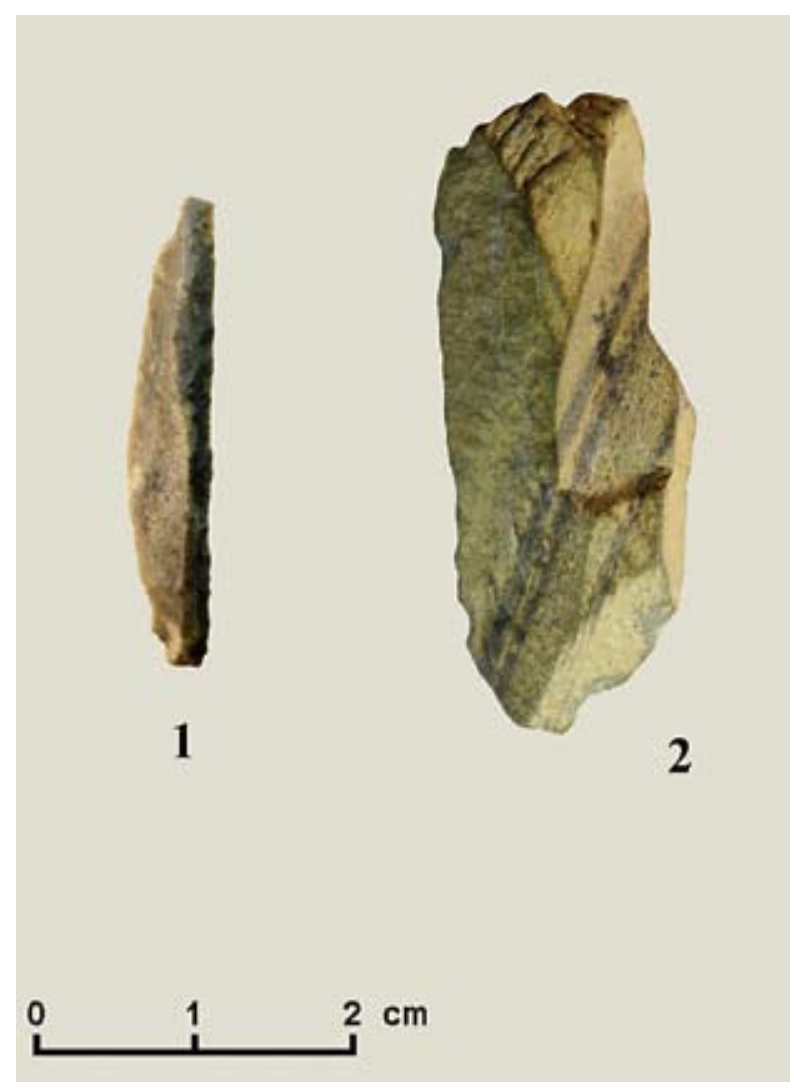

Fig. 27. Industria lítica del nivel $\vee$ del vestíbulo. / Lithic industry from the level $\vee$ of the vestibule.

\subsection{Nivel V}

\subsubsection{Industria lítica}

La industria lítica está representada por 11 objetos, siendo la materia prima utilizada para su fabricación el sílex en nueve casos y en dos la "vulcanita".

Desde el punto de vista tecnotipológico se han contabilizado 8 fragmentos no retocados (72,7\%): 3 de lasca (un proximal, un medial y un distal), un fragmento proximal de lámina de decorticado, 3 de láminas -2 de ellas de "vulcanita"- y un posible recorte de buril. Los talones son dos planos, un astillado y otro lineal (Fig. 27.2).

La industria lítica retocada atribuida a este nivel está constituida por 3 utensilios (27,3\%). En el grupo de los denticulados se ha clasificado una muesca (D1) sobre una irregular lasca de reavivado. Sus dimensiones son: $34 \times 14,4 \times 11,7 \mathrm{~mm}$.

En el grupo tipológico de las puntas de dorso se contabiliza un ejemplar (PD21) que no conserva el ápice (P.A.12A.304.168: Figs. 26.2 y 27.1). Sus dimensiones son: $29,7 \times 5,5 \times 2,6 \mathrm{~mm}$.

En el grupo de los foliáceos se ha incluido una raedera con retoques planos dorsales en el lado izquierdo (F11), y que en su extremo distal presenta un buril sobre 


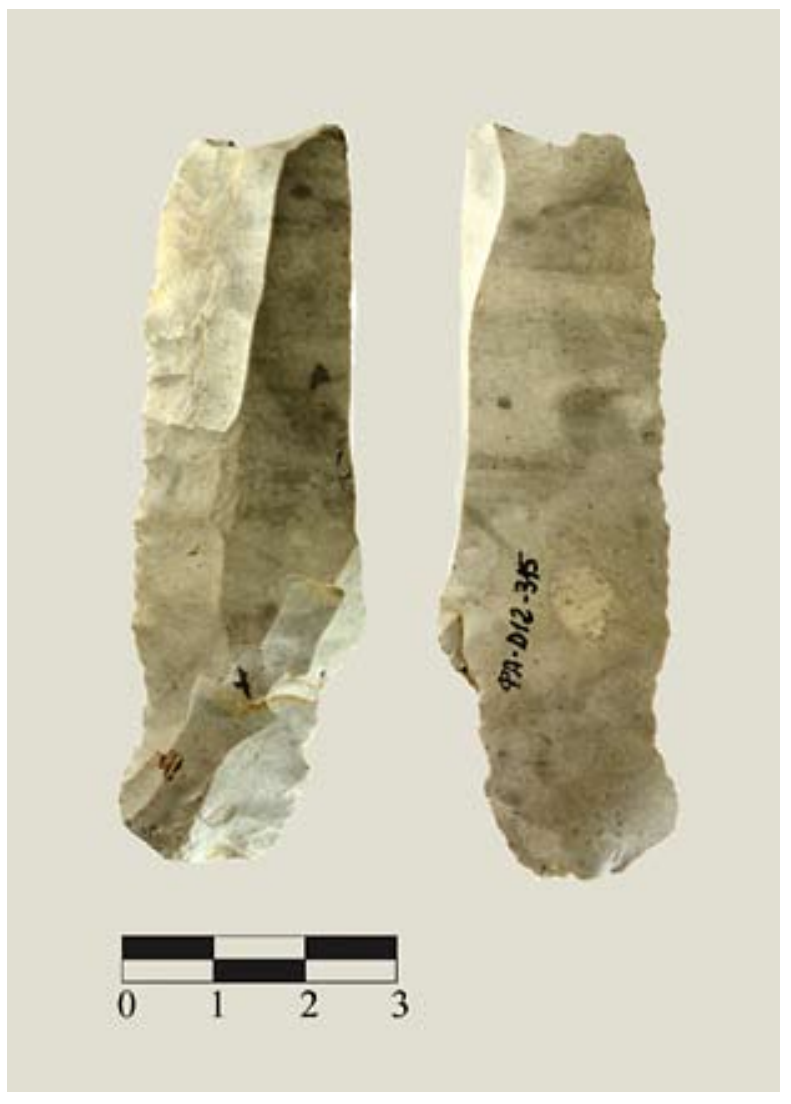

Fig. 28. Industria lítica del nivel $\vee$ del vestíbulo. / Lithic industry from the level $\mathrm{V}$ of the vestibule. truncadura transversal (B22). El soporte es una lámina de talón plano. Sus dimensiones son: 81,7 X 25 X 7,6 mm (P.A.12D.315.363: Figs. 26.1 y 28).

\subsubsection{Industria ósea}

La industria ósea está representada únicamente por un fragmento proximal de azagaya monobiselada de sección circular que muestra sus superficies alteradas (P.A.8E.301.26: Fig. 29). El bisel es corto -de unos 25 mm- para la presumible longitud total de la pieza, siendo además su anchura inferior a la del fuste $(<9 \mathrm{~mm})$, ya que se estrecha ligeramente hacia el extremo proximal. Sus dimensiones son: 50,3 X9 $\times 7,7 \mathrm{~mm}$.

\section{3.- GALERÍA NOROESTE}

La estratigrafía de la galería noroeste tiene características propias debido al proceso de formación de su depósito, consecuencia en parte de episodios de avenidas de aguas. En ella se han identificado siete niveles, pero su correlación directa con el vestíbulo no es fácil por la escasa industria característica, así como porque los procesos de sedimentación del depósito varían sustancialmente. Por otra parte, incluso dentro de la misma galería pueden distinguirse desde el punto de vista sedimentológico y de distribución de los restos dos sectores:

1. El sector más interior de la galería, coincidente con las bandas $\mathrm{J}$ y $\mathrm{K}$, y que aparentemente sería su extremo final.
Fig. 29. Industria ósea del nivel $V$ del vestíbulo. / Osseous industry from the level $\mathrm{V}$ of the vestibule.

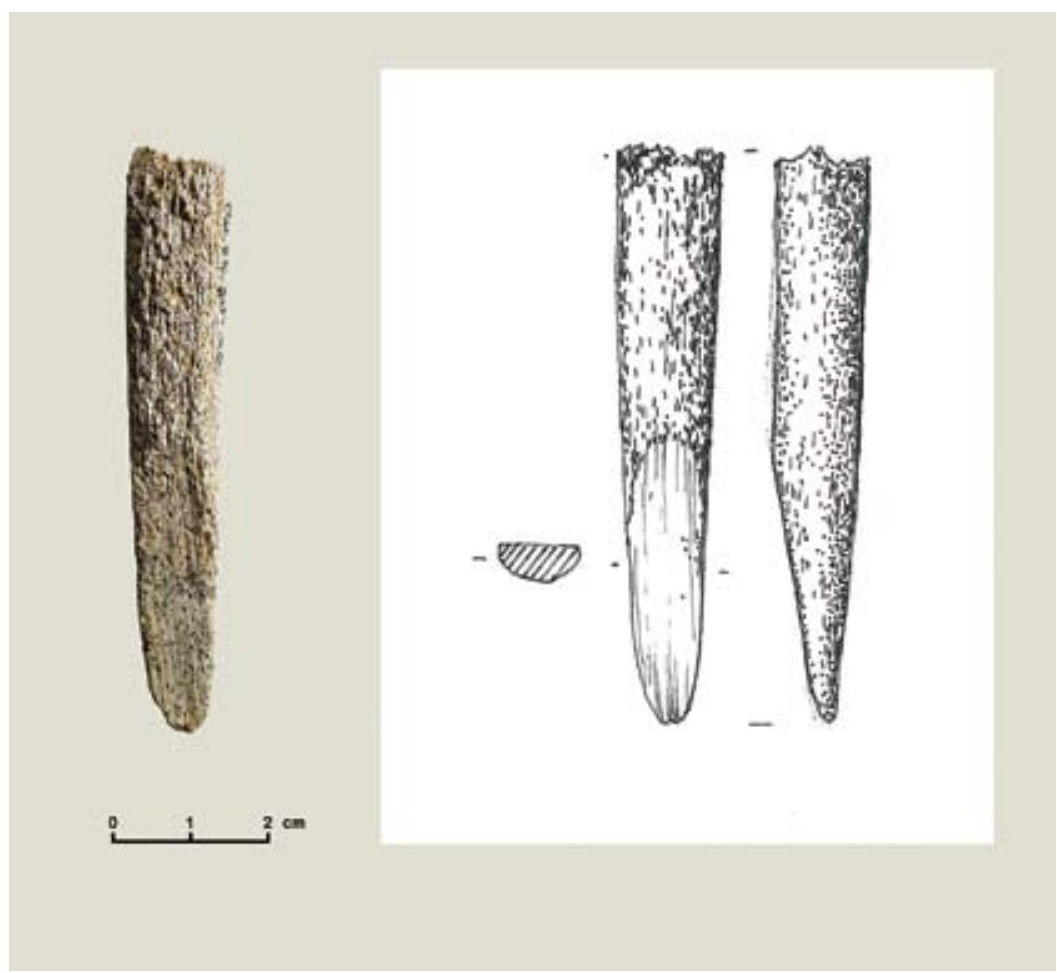


2. El sector correspondiente a las bandas $\mathrm{G}$ y $\mathrm{H}$ ha aportado mayor número de evidencias industriales (el $50 \%$ en el primero y el $29 \%$ en el segundo) que $\mathrm{J}$ y $\mathrm{K}$ (casi un 21\%) por estar en contacto con la zona del vestíbulo, o ser en cierta manera una prolongación del área de habitación de éste. Por otra parte, mientras en el nivel de bloques (lechos 10-14) de la banda 3 escasea la fauna, en la 4 aumenta de forma considerable, quizás por haber sido acarreada y arrinconada por el agua contra la pared. Avenidas de agua más o menos ocasionales podrían explicar la presencia de objetos descontextualizados de aspecto musteriense en la galería (un bifaz en 2G-246, y quizás también un fragmento de vulcanita 4G-242) o en el vestíbulo, siempre con restos más modernos. Además habría otros restos menos significativos desde el punto de vista cronocultural -fauna, etc.- que podrían entorpecer el estudio del depósito al no poder ser distinguidos y aportar fechas que poco tienen que ver con la cronología real. Estos procederían de cotas superiores de la galería noroeste o de otra entrada totalmente colmatada o colapsada. En la campaña de 2013 se han detectado nuevas evidencias líticas más al interior de la galería, y

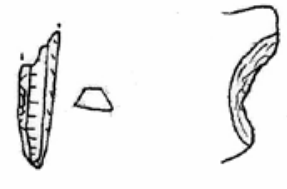

1

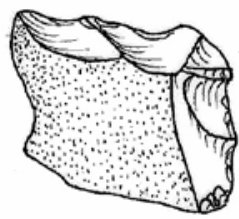

2

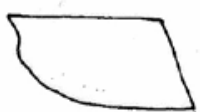

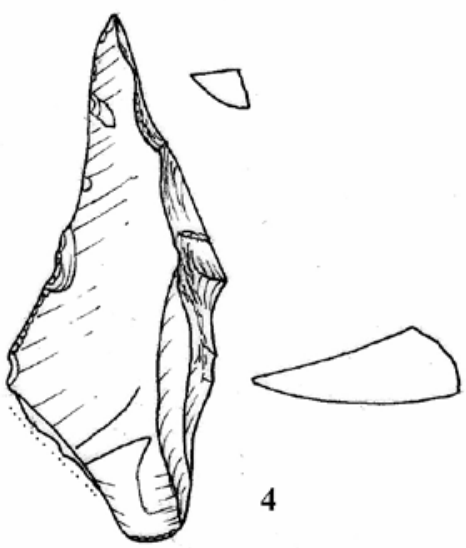
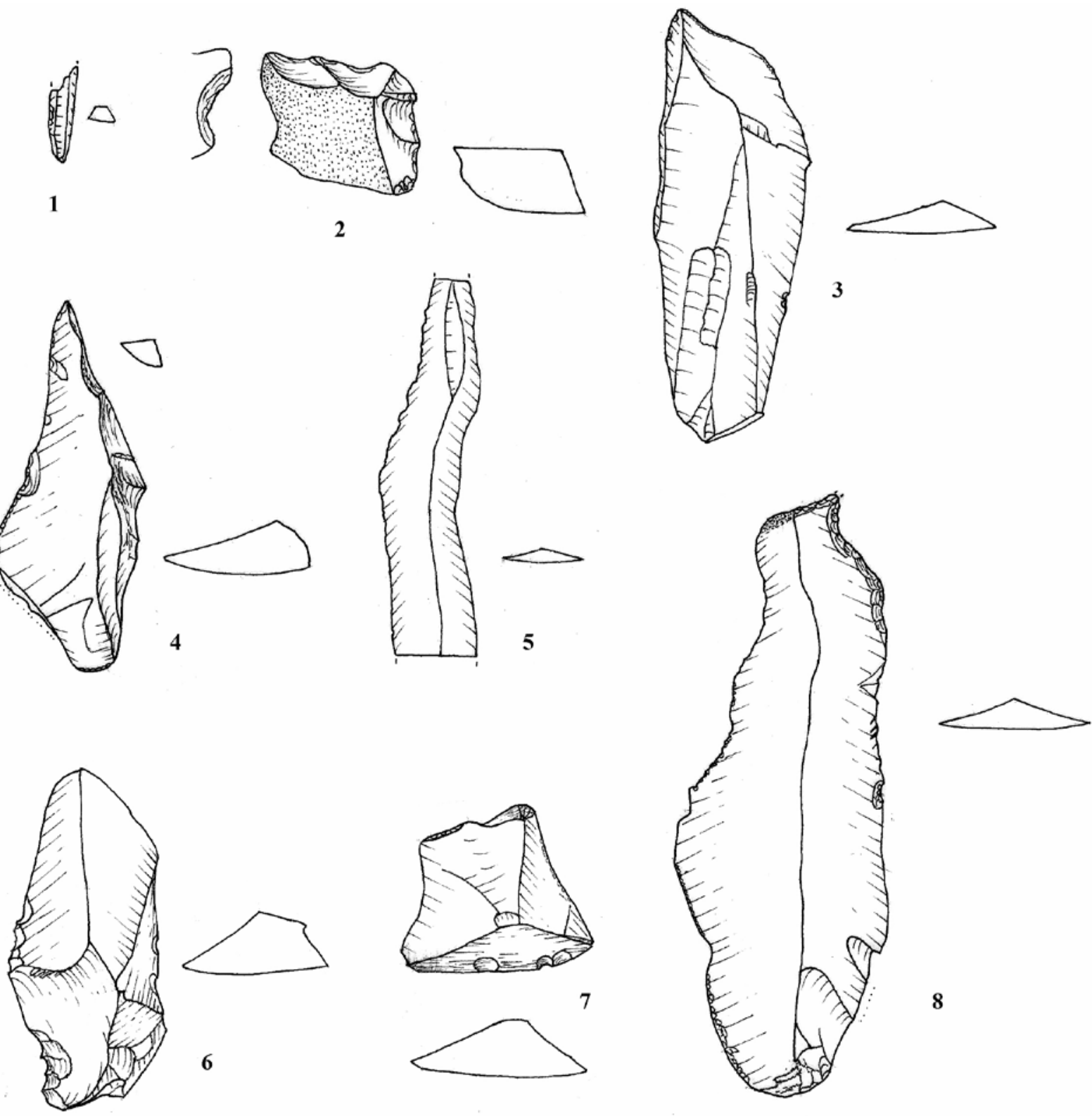

8

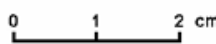

Fig. 30. Industria lítica de la galería noroeste. / Lithic industry from the northwest gallery. 
Fig. 31. Industria lítica de la galería noroeste. / Lithic industry from the northwest gallery.

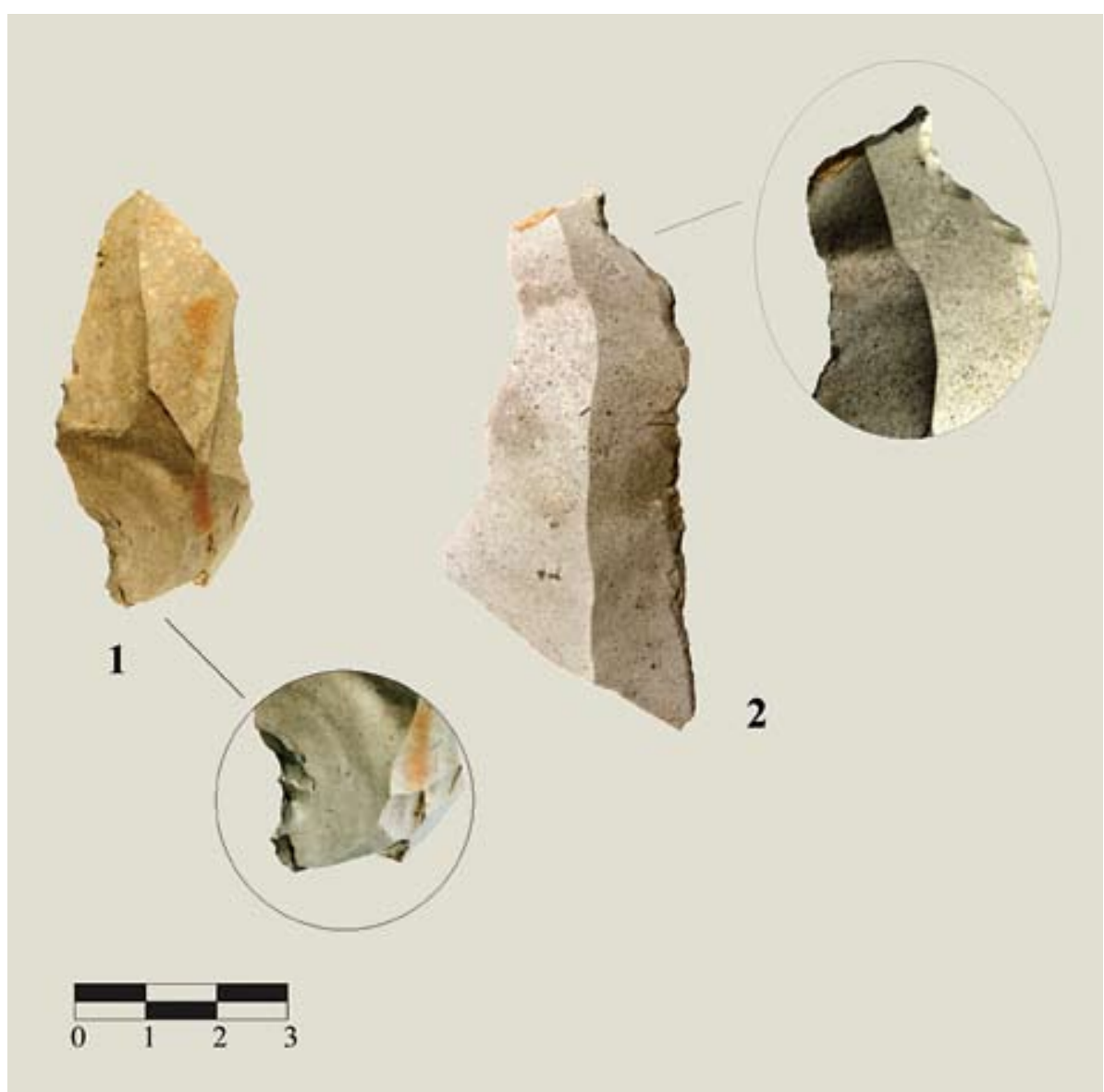

en la campaña de 2014 se ha confirmado la hipótesis de la existencia de otra entrada en un extremo más alejado de la misma (PEÑALVER, 2013 y 2015). No obstante, hay que señalar que los ensamblajes efectuados con fragmentos industriales indican la escasa removilización de algunos objetos, al menos si atendemos a su localización: P.A.2G.217.70 + P.A.2G.222.102, P.A.1H.204.57 + P.A.1H.219.82, P.A.2G.222.102 + P.A.2G.217.70, P.A.1H.219.90 +P.A.1G.223.78yP.A.2I.186.4 +P.A.4E.212.2. La mayoría de ellos se localizan en el mismo cuadro y por lo general la diferencia en sus cotas es mínima.

\subsection{Nivel II}

Entre las evidencias industriales se han contabilizado 18 objetos, de los cuales 5 (27,7\%) corresponden a soportes retocados y los restantes 13 a restos brutos de talla $(72,2 \%)$.

De los productos brutos de talla, cinco $(38,5 \%)$ son lascas (una lasca escama, una de retoque y tres fragmentos) y ocho $(61,5 \%)$ láminas (una completa $-52 X$ $12,7 \times 4,1 \mathrm{~mm}-$, 3 fragmentos proximales, 3 mediales y un distal con restos de córtex). Algunos de los restos (lasca de reavivado y de retoque) indican que en el lugar se han llevado actividades de acondicionamiento de los núcleos y talla de útiles. Por otra parte, queremos mencionar que en 2 fragmentos mediales de láminas de sección triangular se aprecian huellas de uso en uno de los bordes laterales. Sus dimensiones son: $65 \times 14,6 \times$ $3,7 \mathrm{~mm}$ y $35,5 \times 8 \times 3,3 \mathrm{~mm}$. De los 8 talones conservados 4 son planos, un diedro, un facetado, un lineal y un astillado.

En cuanto a los objetos retocados su número se eleva a 5 ejemplares. En el grupo tipológico de las raederas se ha clasificado un fragmento proximal sobre lámina ancha (R1) y en el de los denticulados un raspador denticulado (D5k) sobre lasca de decorticado (P.A.1H.204.57: Figs. 30.2 y 32.2), que al menos parcialmente fue trabajado en la propia cavidad, ya que una lasca de retoque se ensambla con él. Sus dimensiones son: 20,1 X 27,2 $\mathrm{X} 12,2 \mathrm{~mm}$.

En el grupo de los becs se clasifican 2 ejemplares: un Bc2 fabricado en el extremo distal de un soporte laminar de avivado de núcleo que muestra huellas de uso hacia el ápice del borde izquierdo (P.A.1H.192.8: Fig. 30.4). $63,7 \times 25 \times 8,8 \mathrm{~mm}$

Un fragmento distal de Bc2 en extremo proximal de lámina de talón punctiforme (P.A.2G.211.243: Fig. 32.1). Sus dimensiones son: $17,8 \times 12 \times 2,1 \mathrm{~mm}$. 


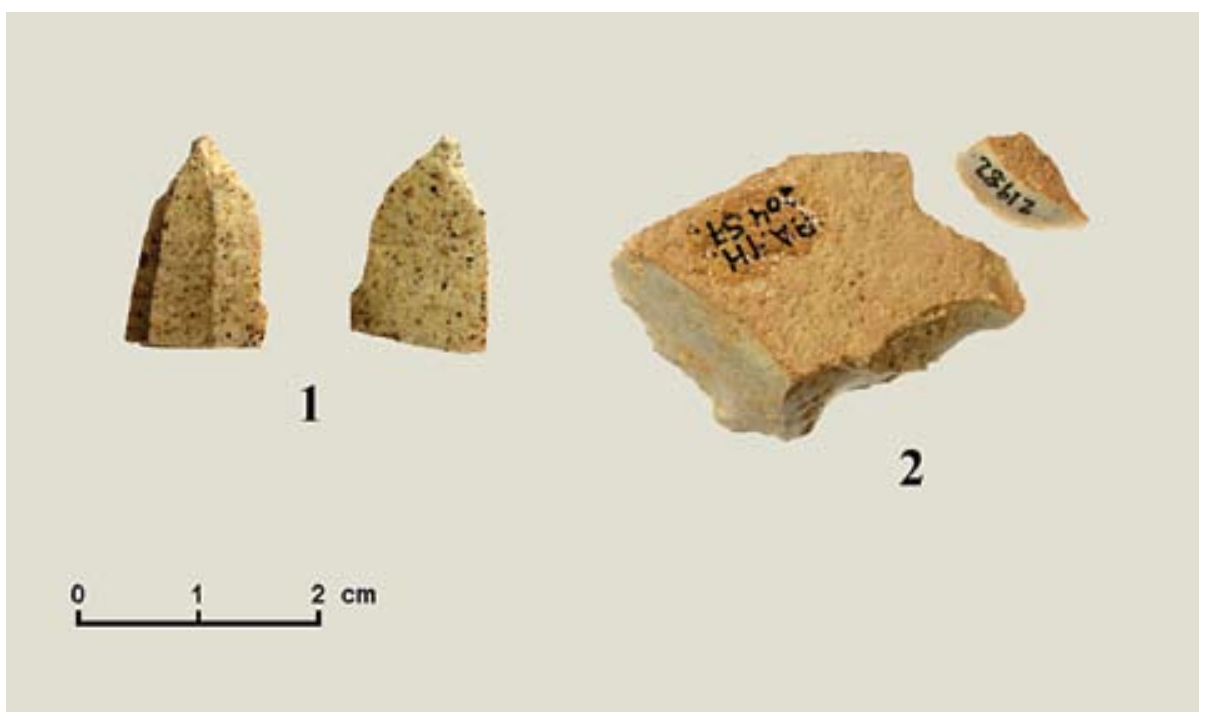

Fig. 32. Industria lítica de la galería noroeste. / Lithic industry from the northwest gallery.

Finalmente, en el grupo tipológico de las láminas de dorso se contabiliza un fragmento proximal de LD21m parcial (P.A.2J.210.1: Fig. 30.1) de sección trapezoidal, que además muestra retoque simple inverso complementario.

\subsection{Nivel IV}

El número de objetos líticos recuperados en el nivel IV asciende a 6 ejemplares de sílex, de ellos 5 son restos brutos de talla, concretamente 2 láminas, 2 lascas y un fragmento pequeño. Los talones son 2 planos, un puntiforme y otro facetado. Finalmente, una lasca laminar muestra un microdenticulado a modo de huellas de uso en el lateral izquierdo y en la zona proximal del borde opuesto.

\subsection{Nivel V}

Entre las evidencias industriales líticas se han contabilizado 8 objetos, 7 de ellos de sílex y un fragmento laminar de "vulcanita", que es posible que no corresponda al mismo momento cultural que el resto del conjunto. Desde el punto de vista tipológico 6 (75\%) son restos brutos y 2 (25\%) retocados. Entre los primeros se han clasificado 2 fragmentos proximales de láminas de talón plano, 2 mediales y 2 fragmentos menores -uno con córtex-. Los 2 fragmentos mediales de lámina presentan microdenticulado en una o 2 aristas laterales, que interpretamos como posibles huellas de uso (P.A.2G.217.70+P.A.G.222.102: Fig. 30.5).

Entre los objetos retocados se identifican una muesca parcial (D1) sobre un fragmento medial de lámina afectada por fractura distal y un bec-truncadura (Bc1) sobre una lámina retocada de cara de lascado cónca- va y de notables dimensiones -102 X 35,5 X 6,4 mm(P.A.1G.223.78: Figs. 30.8 y 31.2 -detalles-).

\subsection{Nivel VI}

El número de objetos líticos recuperados en el nivel VI asciende a 8 ejemplares, de ellos 5 son de sílex, 2 de arenisca y uno de vulcanita. De los 8 objetos, 4 (40\%) son soportes brutos, concretamente una lasca completa, un fragmento proximal de talón plano, uno de vulcanita, y un fragmento distal de lámina.

Entre los útiles hemos clasificado tipológicamente un bec (Bc2) sobre una lámina de talón diedro (P.A.2H.220.119: Fig. 30.3) y una profunda muesca proximal (D1) en extremo de lámina (P.A.1G.236.99: Figs. 30.6 y 31.1), además de un objeto excepcional, concretamente un bifaz parcial sobre arenisca calcárea (P.A.2G.246.244: Fig. 33 y 34). Sus dimensiones son: $160 \times 101 \times 28 \mathrm{~mm}$. Este, al igual que el fragmento de lasca de vulcanita, podría proceder de una ocupación musteriense. Sin embargo, una esquirla ósea cercana datada por AMS ha aportado una fecha (25320 \pm 140 BP) que habría que situar en el Gravetiense. Creemos necesario subrayar la presencia de estos objetos que tipológicamente desentonan con el contexto en el que han sido hallados (además de otros no característicos -esquirlas óseas...-), y que en nuestra opinión, como hemos ya señalado anteriormente, proceden del otro extremo de la misma galería.

Otro elemento interesante es un percutor sobre canto rodado de arenisca que se halla partido aproximadamente por su mitad. En cada una de sus caras mayores, junto a la fractura, muestra una cúpula, así como piqueteados concentrados en el polo conservado (P.A.1G.229.85: Fig. 35). Sus dimensiones son: $55,3 \times$ $68,4 \times 59,4 \mathrm{~mm}$. 


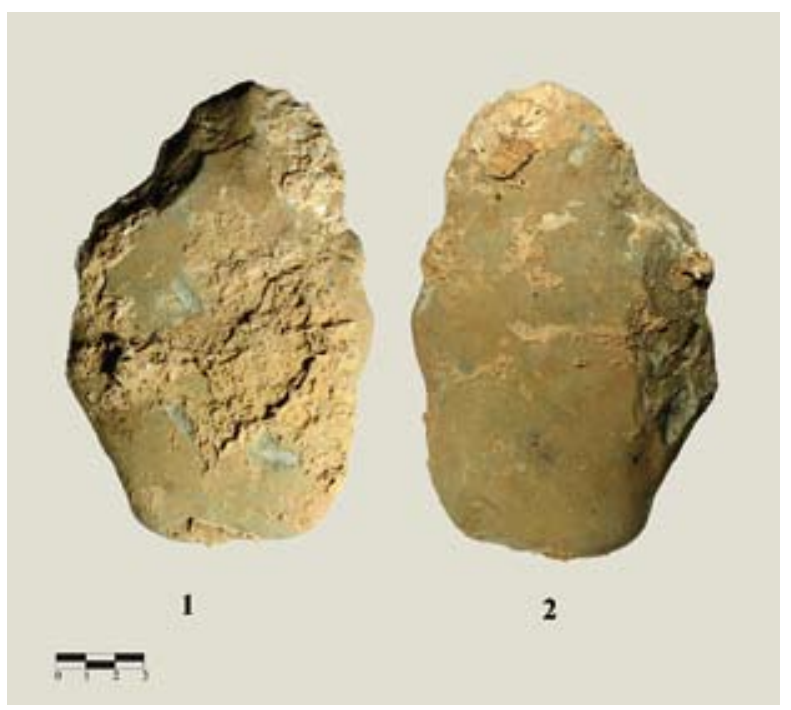

Figs. 33-34. Bifaz (Dibujo: J. Alonso). / Biface (Drawing: J. Alonso).

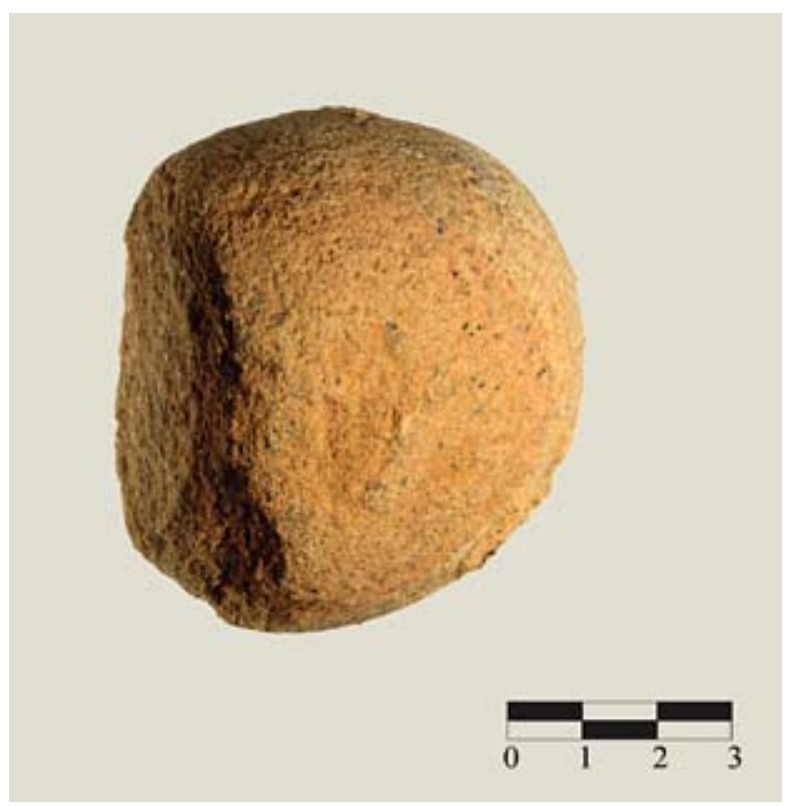

Fig. 35. Industria lítica de la galería noroeste. / Lithic industry from the northwest gallery.

\subsection{Nivel VII}

Son 2 los objetos líticos recuperados, siendo uno de ellos un fragmento informe de sílex y el otro un fragmento de gruesa lasca con un denticulado sumario (D3) en los planos de fractura transversales (Fig. 30.7).

En resumen, los niveles descritos en la galería noroeste no son correlacionables con los detectados en el vestíbulo por la falta de continuidad estratigráfica. Aquí, los complejos procesos sedimentológicos son distintos y a la vista de algunos objetos (bifaz, etc.) no existen ga-
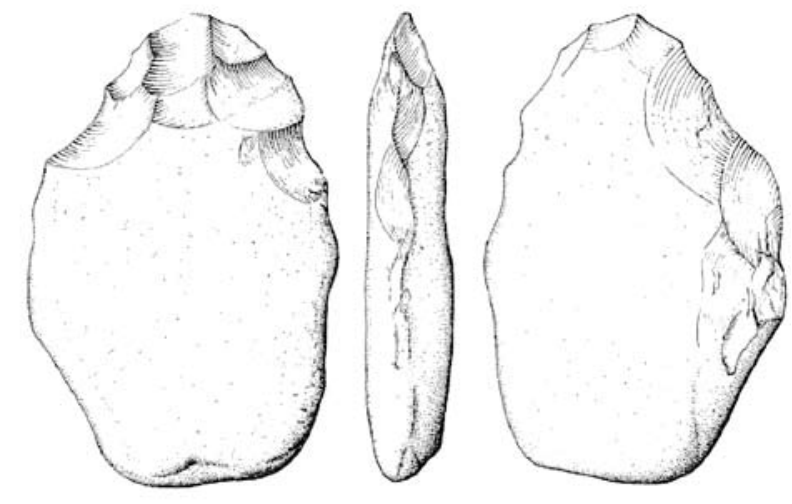

rantías sobre su emplazamiento original, sospechando que buena parte de los restos están en posición secundaria, aunque no se puede concretar cuales de ellos por ser la mayoría poco característicos.

\section{4.- PASILLO}

Se trata de un corto, estrecho y bajo tramo que conecta el vestíbulo con la primera sala interior, existiendo una diferencia de cotas en su superficie de entre 20 y $30 \mathrm{~cm}$, con la pendiente descenciente hacia el interior de la cavidad. Los restos recuperados aquí difícilmente pueden considerarse como resultado de la ocupación de este espacio, sino que probablemente han llegado de forma involuntaria.

\subsection{Nivel Ic, Ila y Ilb}

El número de efectivos recuperados en ambos niveles es escaso. En Ic sólo podemos mencionar una laminilla de reavivado de talón lineal y en llb 10 restos brutos (6 soportes laminares y 4 lascas). Los objetos son: un recorte de buril, 2 láminillas completas -de reavivado-, y otra -de 65,6 X 20,5 X 4,8 mm- con discretas huellas de uso bilaterales y tres fragmentos proximales; una lasca de reavivado y 3 fragmentos distales de lasca. Los talones más abundantes son los planos (4 ejemplares), aunque hay un puntiforme y otro lineal. Estos escasos restos, por su posición estratigráfica, podrían atribuirse al Magdaleniense Final y Epipaleolítico.

\subsection{Nivel III}

La identificación y delimitación estratigráfica de esta efímera ocupación en la zona del pasillo es prácticamen- 


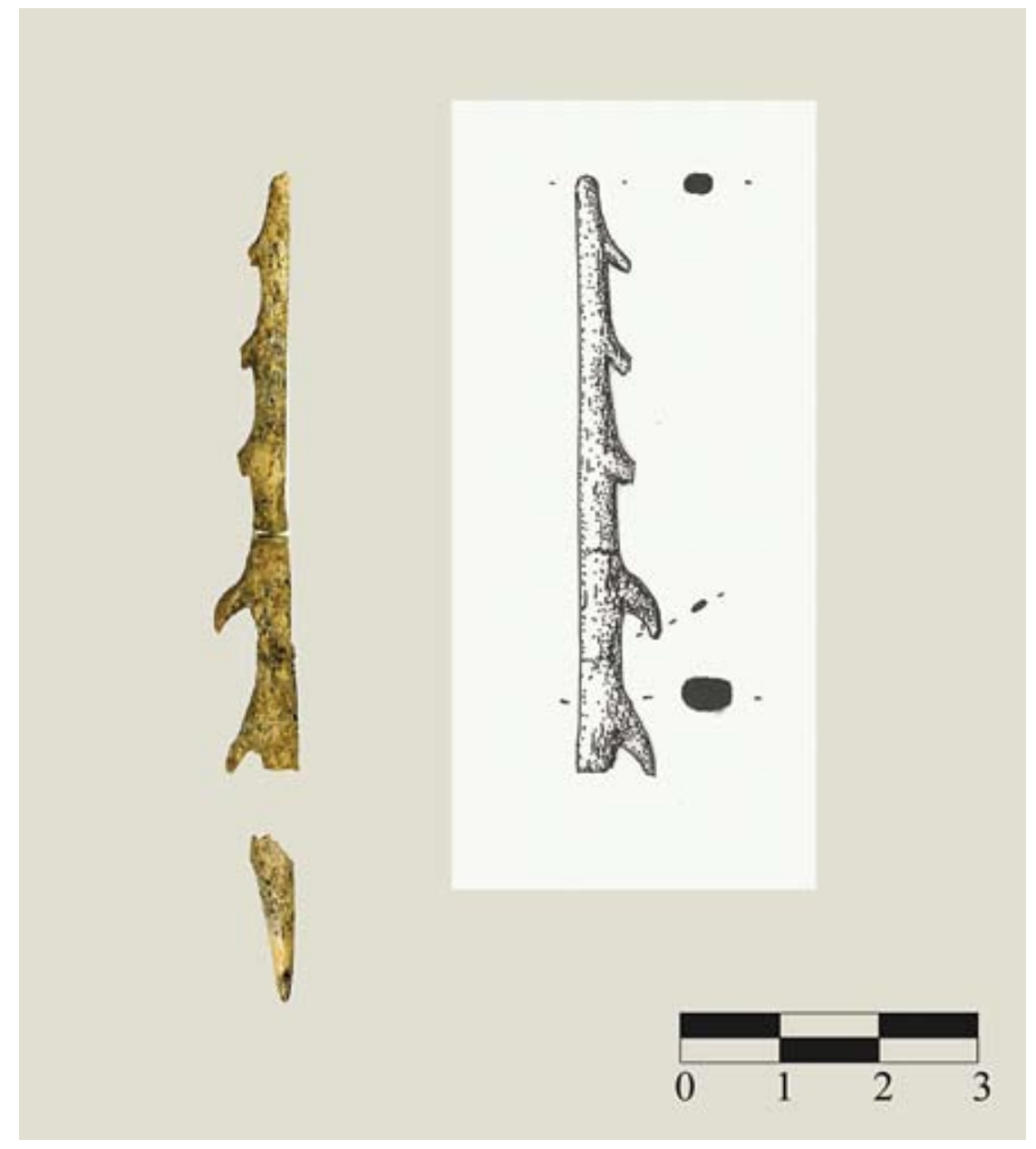

Fig. 36. Fragmento de arpón procedente del pasillo (Dibujo: J. Alonso). / Fragment of harpoon coming from the corridor (Drawing: J. Alonso).

te imposible. Sin embargo, la presencia de un fino arpón, recogido en 2 trozos y de superficies bastante alteradas, permite identificar esa ocupación del Magdaleniense Superior/Final, aunque es difícil su contextualización con los restos del vestíbulo. Su fragmento distal conserva una hilera de dientes, bien despejados del fuste, de sección ligeramente aplanada. Su longitud total es de $59,3 \mathrm{~mm}$ y su anchura máxima a la altura de los dientes es de 8,1 mm. La anchura máxima del fuste es de $4,1 \mathrm{~mm}$ y su espesor de $3,7 \mathrm{~mm}$. Se tienen indicios de 5 dientes, aunque de los tres distales sólo se conservan las bases. Los otros 2 están completos, uno de estos es recto o ligeramente curvo, y el otro netamente curvado, ganchudo. Sus superficies están bastante alteradas (P.A.6A'.289.46: Figs. 36).

El otro trozo se trata de un cuerpo alargado apuntado de asta, de sección aplanada, que en el extremo proximal presenta un engrosamiento a modo de un abultamiento basilar. Sus dimensiones son: 12,5 X 4,2 X 3 mm.

\subsection{Nivel IV}

El número de objetos líticos recuperados asciende a 15 ejemplares de sílex (4 con córtex), de ellos nueve
(60\%) son restos brutos de talla (6 láminas y 3 lascas), aunque en 3 de ellos se aprecian huellas que interpretamos como de uso, y 6 (40\%) productos retocados.

De las láminas 2 están completas y 3 son fragmentos, de ellos uno distal y 2 proximales -uno de estos de $77 \mathrm{~mm}$ de longitud-, y una punta de esquina, aparentemente con estigmas de uso. Las lascas son 2 de decorticado -una completa y un fragmento distal- y la 3, un fragmento distal de lasca de reavivado. Los talones conservados son mayoritariamente planos (5 ejemplares) y un astillado. Hay que indicar también que 3 de los soportes presentan lascados simples discontinuos en algunos de los bordes laterales.

El conjunto de los restos retocados (6) está representado por los grupos tipológicos de las raederas (1) y de los dorsos (5). En el grupo de las primeras se ha clasificado una raedera denticulada (D3) sobre una lámina casi completa (P.A.8A'.306.109: Fig. 37.1). 64,6 X 22,3 X $112 \mathrm{~mm}$.

En el grupo de las laminas de dorso contabilizamos 4 fragmentos mediales (uno marginal sumario, y otro quizás un fragmento de LD32) y uno proximal de LD21 


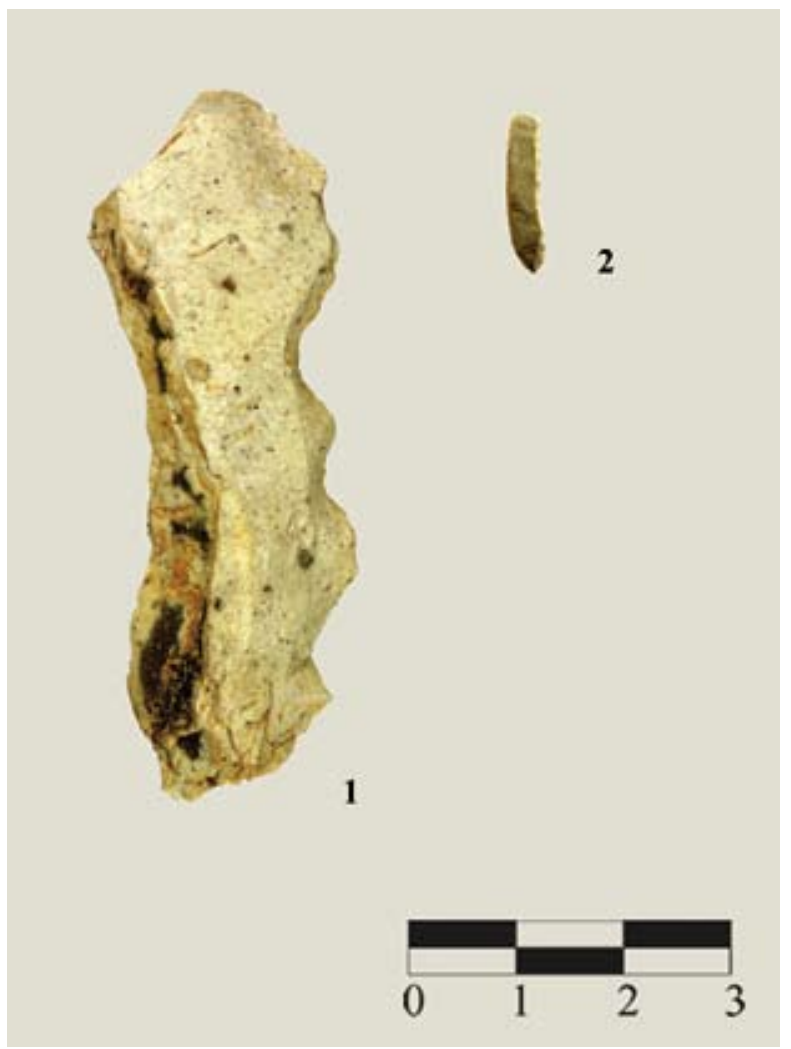

Fig. 37. Industria lítica del pasillo. / Lithic industry from the corridor.
(P.A.8A'.294.107: Fig. 37.2), todos ellos de una longitud inferior a los $15 \mathrm{~mm}$.

\subsection{Nivel V}

El número de objetos líticos recuperados en el nivel asciende a 3 ejemplares, concretamente una lámina de sílex de talón punctiforme, una truncadura oblicua (T2) y un voluminoso prisma de cuarzo con aristas embotadas por rodado y una extracción fresca (P.A.2E.269.4: Fig. 38). Sus dimensiones son: $35 \times 35,7 \times 12 \mathrm{~mm}$.

\section{5.- PRIMERA SALA INTERIOR}

Una vez traspasado el restringido espacio que permite el acceso desde el vestíbulo al interior de la cavidad se abre una sala más o menos circular de $43 \mathrm{~m}^{2}$ y de una altura de entre 2 y 2,25 m, que fue puntualmente ocupada al menos en tres períodos: Epipaleolítico, Magdaleniense Inferior y Solutrense Superior.

\subsection{Nivel II}

\subsubsection{Industria lítica}

En la industria lítica se contabilizan 21 objetos de sílex -3 de los cuales conservan restos de córtex-, 16 $(76,2 \%)$ de ellos son soportes no retocados y cinco $(23,8 \%)$ útiles.
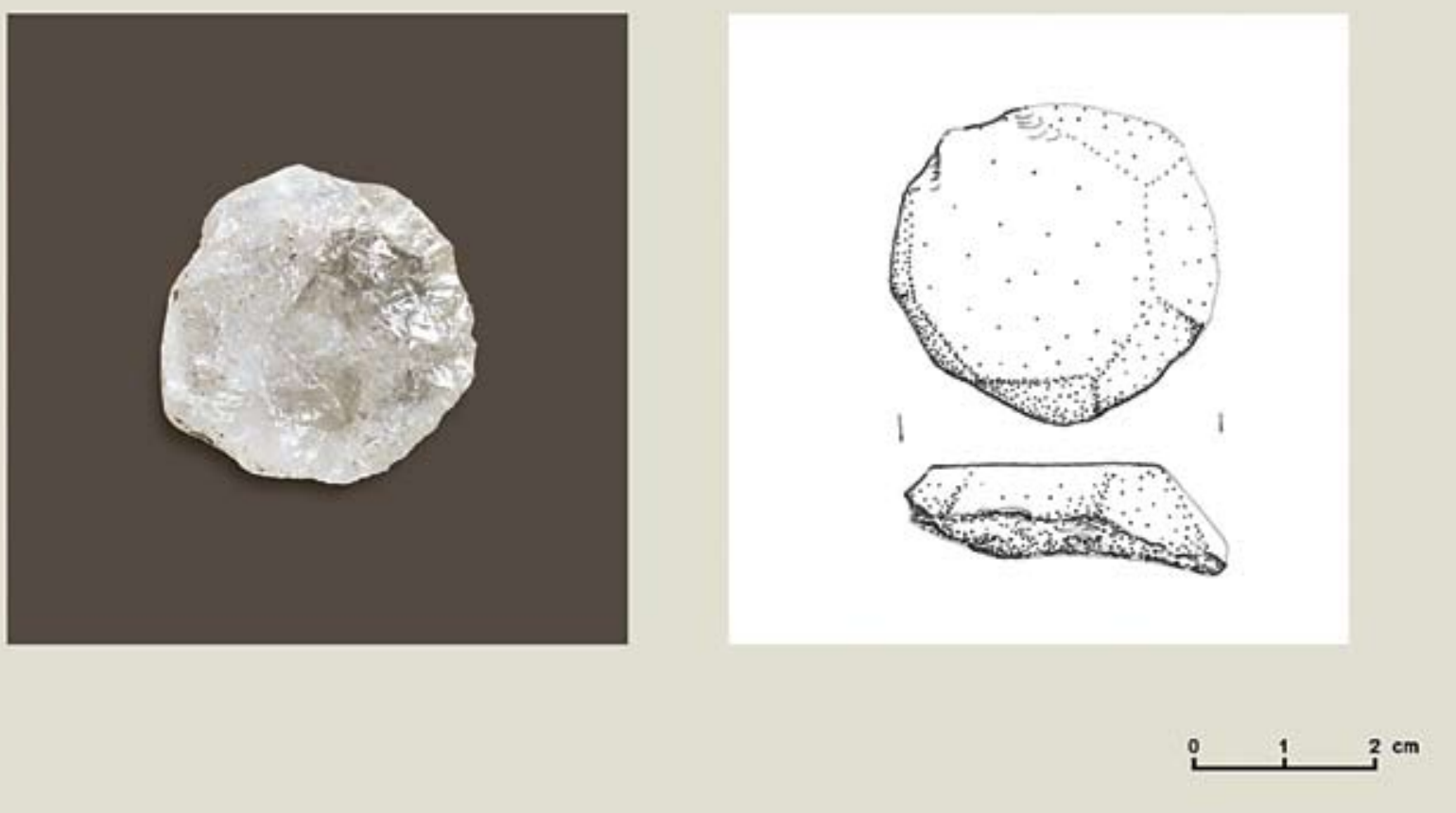

Fig. 38. Prisma de cuarzo del nivel $V$ del pasillo. (Fotografía: $X$. Otero; dibujo: J. Alonso). / Quarz prism from the level $\vee$ of the corridor. (Fotografía: X. Otero; dibujo: J. Alonso). 


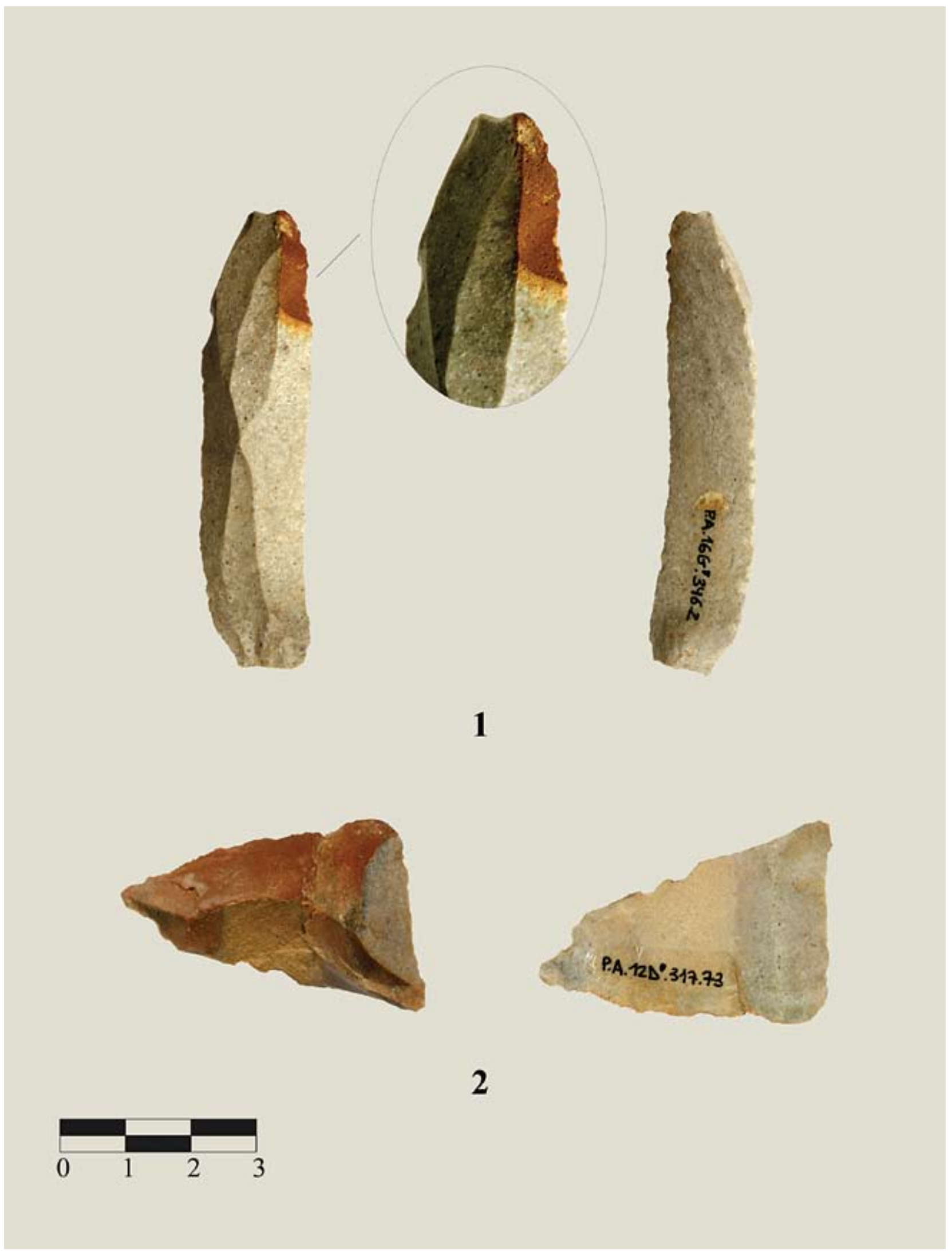

Fig. 39. Industria lítica de la primera sala interior. / Lithic industry from the first inner room. 
Fig. 40. Industria lítica de la primera sala interior. / Lithic industry from the first inner room.

Entre los restos brutos se clasifican 10 $(62,5 \%)$ láminas y $6(37,5 \%)$ lascas, que se han clasificado como sigue: una lasca de decorticado, 2 lascas completas y un trozo; y 4 fragmentos proximales de lámina, 2 mediales y 2 distales. Además, algunos de estos restos se relacionan con actividades de talla o reacondicionamiento: 2 lascasescama, una laminilla de reavivado y un recorte de buril primario. Entre los talones predominan los planos (8 ejemplares), estando representados con uno de cada los diedros, puntiformes y lineales. Finalmente, podemos señalar la presencia de un fragmento distal de lámina de decorticado con huellas de uso bilaterales.

Entre los objetos retocados se han contabilizado 5 ejemplares. En el grupo de las raederas se ha clasificado un fragmento medial de laminilla ( $R 1$ con tendencia LD21) y en el de los denticulados 2 espinas (D2) en extremo de ápice triédrico, uno en un fragmento distal de lasca de decorticado (P.A.12D'.317.73: Fig. 39.2) (31,2X $43,4 \times 10,3 \mathrm{~mm}$ ) y el otro, muy sumario, en el ápice de un soporte laminar de cara ventral muy cóncava.

En el grupo de las truncaduras se ha clasificado una truncadura cóncava (T1) en extremo distal de una lámina que en sus bordes laterales muestra desconchados profundos discontinuos que atribuimos al uso (P.A.16G'.346.2: Fig. 39.1). Sus dimensiones son: 68,8 $\mathrm{X} 17,7 \times 7,7 \mathrm{~mm}$.

Finalmente, se ha clasificado un fragmento medial de LD21 en el grupo de las láminas de dorso.

\subsection{Nivel IV}

\subsubsection{Industria lítica}

En el nivel IV de la primera sala interior se han estudiado 19 objetos líticos, de los cuales 16 son de sílex (12 $-75 \%$ - restos brutos y $4-25 \%$ - soportes retocados) y 3 de vulcanita. Además podemos mencionar 2 objetos de hueso y un lote de 20 colgantes de piedra y un fragmento perteneciente a otro localizado anteriormente en el vestíbulo.

Entre los elementos no retocados se han estudiado 4 lascas: un fragmento proximal con restos de córtex y 3 fragmentos, uno de estos con aparentes huellas de uso en la charnela de flexión y otro de reavivado. De las 8 láminas 2 están enteras, 5 son fragmentos proximales y un distal. Se han contabilizado un fragmento proximal de recorte de buril primario y un distal secundario. Entre los 6 talones predominan los planos (4), siendo los otros 2 lineales.

Son 4 los objetos retocados. En el grupo de las raederas se ha estudiado una fabricada sobre lámina ancha (R1). Sus dimensiones son: $62,8 \times 30 \times 7,2 \mathrm{~mm}$.

En el grupo de las truncaduras se ha incluido un fragmento (T2) fabricado sobre una pequeña laminilla (de 7,6 X 2,6 X 0,8 mm) (P.A.16G'.342.1: Fig. 40.2).

Finalmente, en el grupo de las láminas de dorso se han clasificado 2 piezas: 1 fragmento medial de LD21 (LD32) y otro proximal sobre lámina ancha (LD21 parc). Sus dimensiones son: 34,6 X 22,5 X 4,9 mm.

En este contexto se han recogido también 3 objetos de vulcanita de aspecto musteriense (P.A.18G'.341.1: Fig. 40.1). En nuestra opinión, al igual que otros restos, procederían de la galería noroeste, y son: 2 lascas -una entera y 1 fragmento- $y$ una dudosa raedera parcial sumaria (R1m) de 43,2 X 74,2 X 15,3 mm. 2 de las piezas tienen en común que presentan un amplio talón plano, cuyo ángulo respecto de la cara de lascado es de aproximadamente $120^{\circ}$.

\subsubsection{Industria ósea}

La industria ósea ha aportado 2 utensilios: un fragmento medial de azagaya de sección ovalada muy deteriorada, de 40,6 X11 X 9,3 mm, y un punzón que conserva parte del inicio de la epífisis de la pieza anatómica (quizás un metapodio). En uno de los laterales se aprecia un plano de aserrado parcial, testimonio del surco practicado longitudinalmente a lo largo de la diáfisis para posteriormente fracturarla de forma controlada (P. A.12D'.343.122+P.A.12E'.340.84: Fig. 41). En el tercio distal presenta un plano de abrasión a modo de bisel que llega hasta el ápice. Sus dimensiones son: 125 X 16,5 X $9,5 \mathrm{~mm}$ 


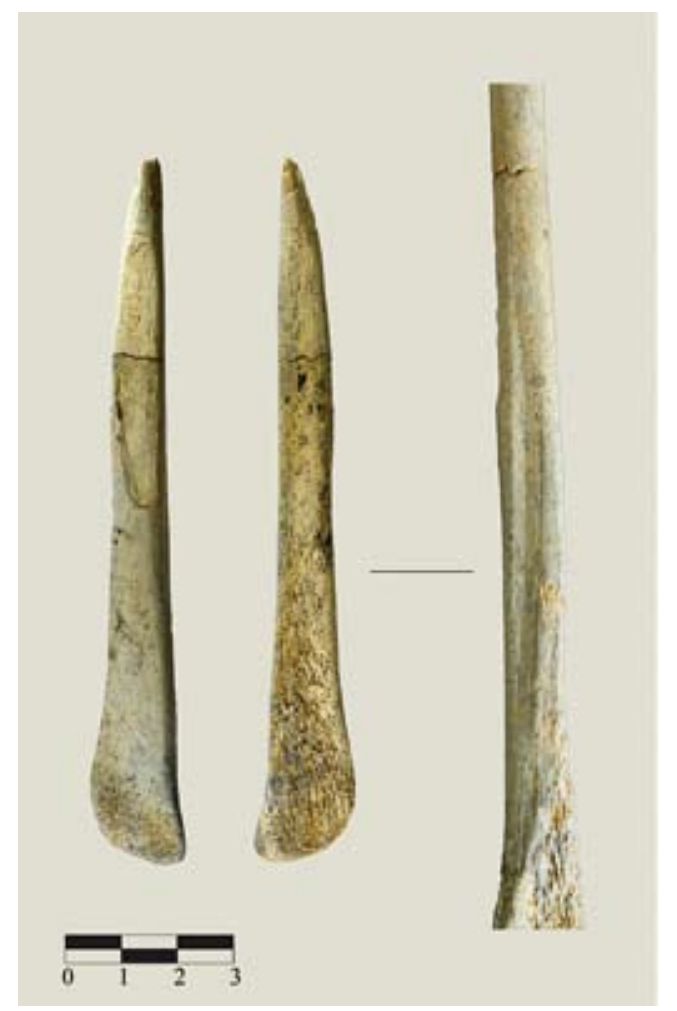

\subsection{Nivel V}

\subsubsection{Industria lítica}

De este nivel proceden 8 objetos de origen antrópico, 5 de ellos líticos y 3 óseos. La industria lítica está constituida por 5 piezas de sílex, de las cuales uno es un

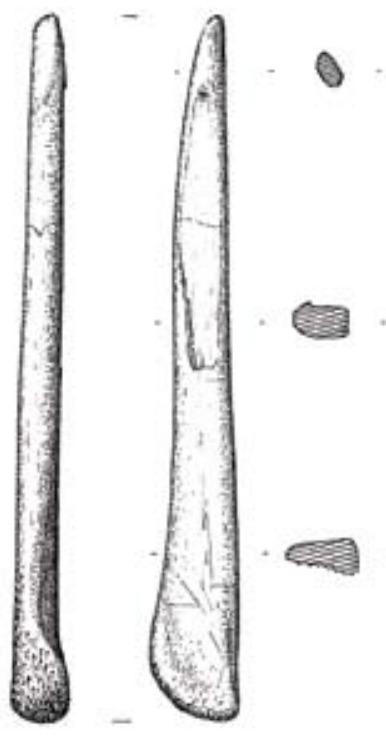

Fig. 41. Industria ósea de la primera sala interior (Drawing: J. Alonso). / Osseous industry from the first inner room (Drawing: J. Alonso)

producto bruto de talla (un fragmento proximal de laminilla de talón plano) y 4 están retocadas.

En el instrumental se han clasificado un fragmento distal de raedera marginal $(\mathrm{R} 1 \mathrm{~m})$ sobre lasca reflejada en el grupo tipológico de las raederas.

En el grupo de los foliáceos se han incluido 2 fragmentos mediales de una raedera foliácea $(F 11)$ y de una punta foliácea (F32) (P.A.10F'.332.18: Fig. 42.1; P.A.10G'.345.45: 42.2) y, finalmente, en el de las láminas

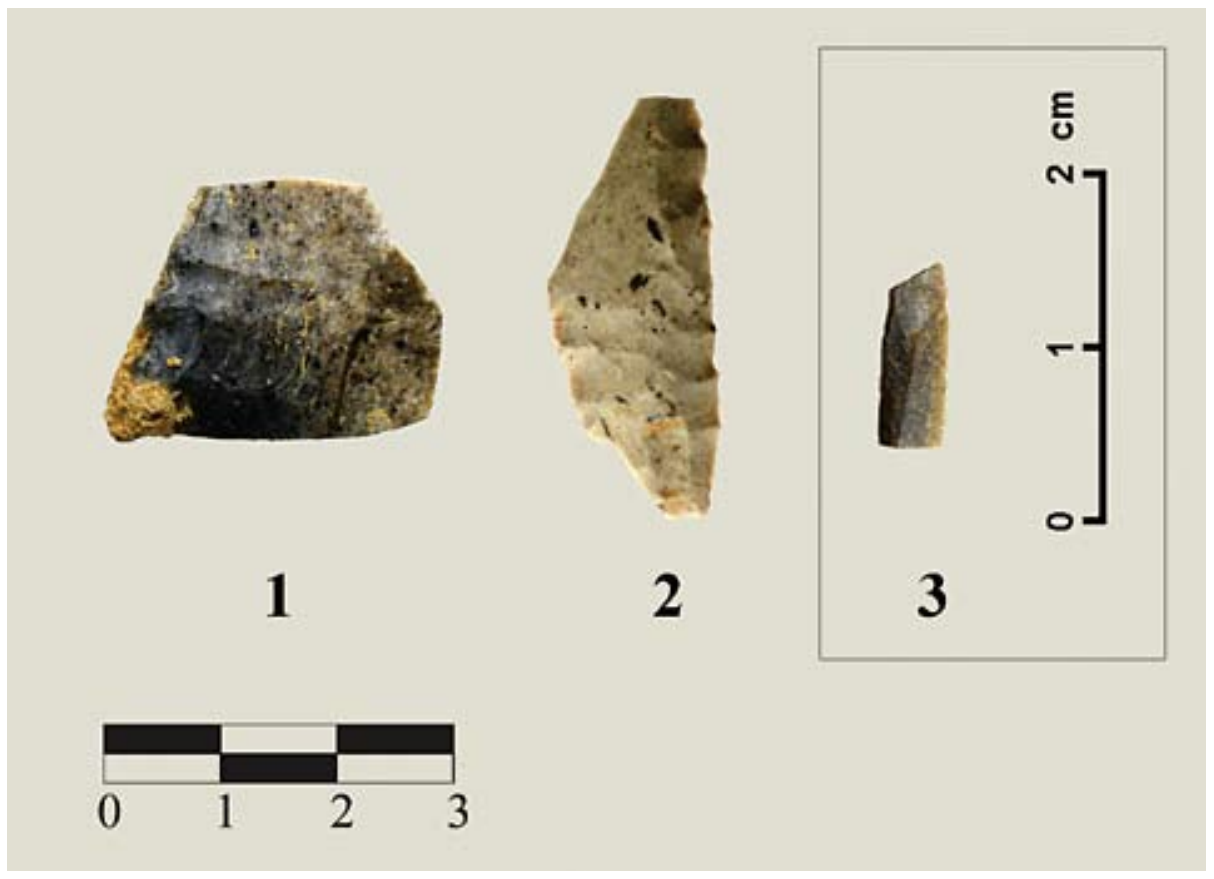

Fig. 42. Industria lítica del nivel $V$ de la primera sala interior. / Lithic industry from the level $\mathrm{V}$ of the first inner room. 


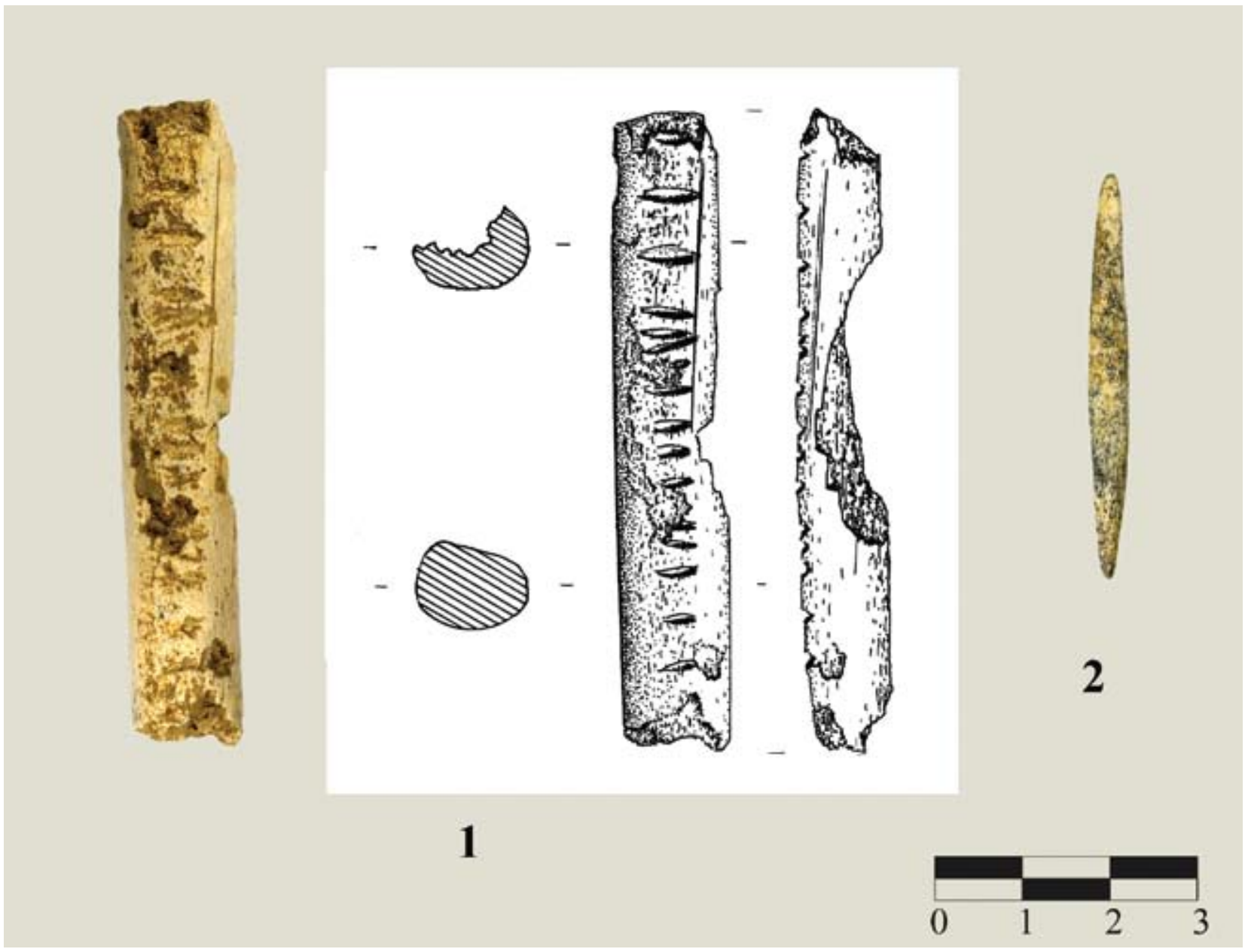

Fig. 43. Industria ósea del nivel $\mathrm{V}$ de la primera sala interior (Dibujo: J. Alonso). / Osseous industry from the level $\mathrm{V}$ of the first inner room (Drawing: J. Alonso).

de dorso, un fragmento medial de LD21 (P.A.10F'329.15: Fig. 42.3).

\subsubsection{Industria ósea}

En la industria ósea se han contabilizado 3 instrumentos:

- Un biapuntado corto de asta -anzuelo- de sección aplanada con las superficies notablemente alteradas (P.A.8D'.329: Fig. 43.2). Sus dimensiones son: 46,5 $\times 4,8 \times 3,4 \mathrm{~mm}$.

- Un fragmento medial de azagaya de sección circular ligeramente aplanada. La superficie ventral está muy deteriorada y sobre la superficie cortical muestra cortos pero profundos y anchos trazos transversales irregulares (P.A.10F'.339.20: Fig. 43.1). Sus dimensiones son: 72,5 $X 13 \times 10,6 \mathrm{~mm}$. Se conocen varios ejemplares similares sin contexto claro procedentes de la excavación de Aitzbitarte IV por el Conde de Lersundi (Ait.IV-Ind-3, 7 y 29) (MUJIKA, 1983 y 1993).
- Un fragmento distal de varilla de seccción planoconvexa, que hacia el extremo apuntado es prácticamente biconvexa (P.A.10G'.345.66: Fig. 44). Sus dimensiones son: 118,6 X 14,6 X 5,7 mm. Si bien este tipo de útiles son frecuentes en la primera mitad del Magdaleniense, no lo son tanto en fases más antiguas ni más recientes. Sin embargo, en la cercana cueva de Ermittia existen al menos 2 ejemplares solutrenses (Er-IV-2 y 4) (MUJIKA, 1983; 1993).

En resumen, la presencia humana en la primera sala interior es recurrente, pero fugaz, y quizás con distintos objetivos. En el nivel más antiguo, atribuible al Solutrense, el número de restos es muy discreto (5 líticos y 3 óseos), pero hay que subrayar que prácticamente en su totalidad se trata de instrumentos, y además 2 de ellos (piezas foliáceas) muy significativos desde el punto de vista cronocultural.

Indicios de una ocupación más importante y compleja han quedado reflejados en el nivel IV. Destaca un interesante lote de 14 colgantes, que pueden ponerse en relación con los recuperados en el vestíbulo, que han 


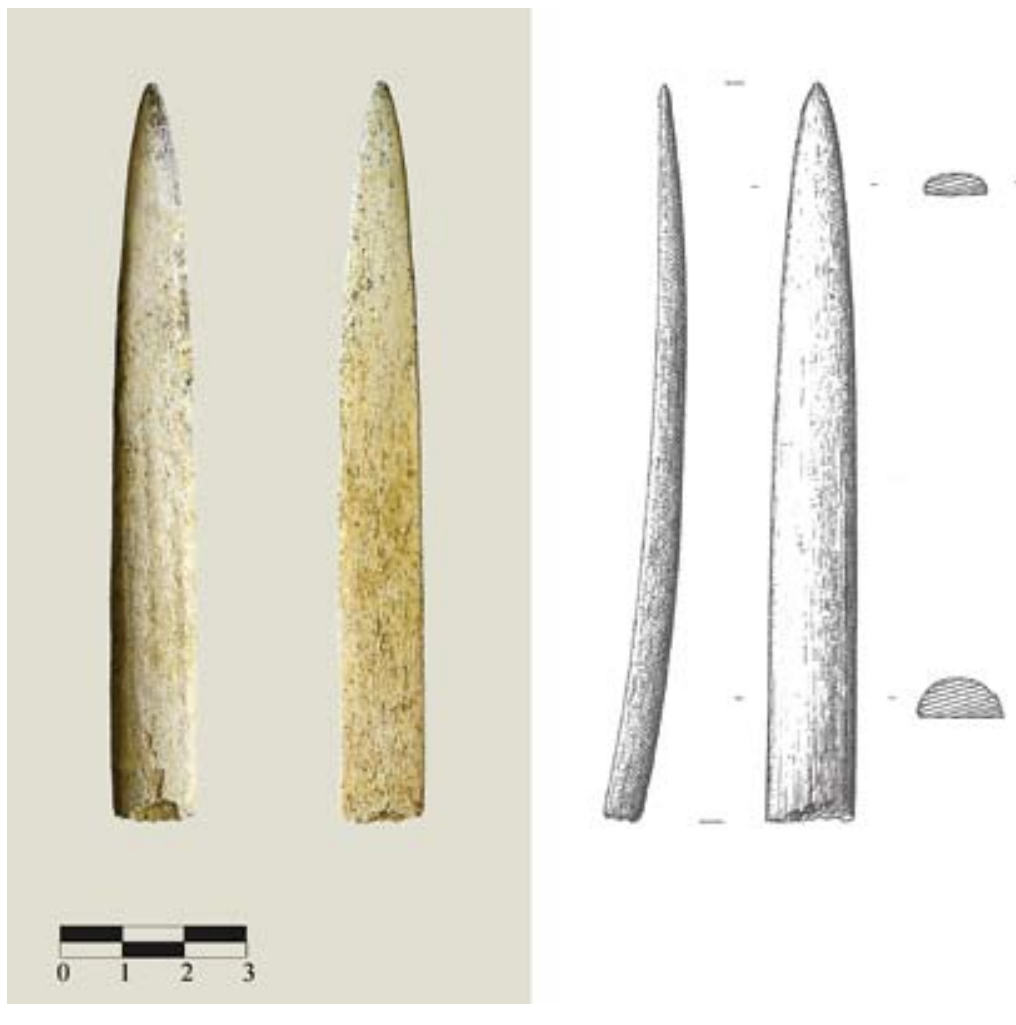

Fig. 44. Industria ósea del nivel $V$ de la primera sala interior (Fotografía: X. Otero; dibujo: J. Alonso). / Osseous industry from the level $V$ of the first inner room (Picture: X. Otero; drawing: J. Alonso)..

minosidad y amplitud, como es el vestíbulo. Sin embargo, en ella hay evidencias de industrias líticas y óseas que prueban que era visitada o frecuentada por razones que desconocemos, aunque no se puede asegurar que todas ellas sean coetáneas.

Los restos líticos recuperados ascienden a 13 objetos, entre los que contabilizamos algunos, sin seguridad de que su presencia obedezca efectivamente a razones de carácter antrópico, Éste es el caso de 2 nodulitos de ocre, aparentemente de buena calidad, pero sin rastros de abrasión, así como el de un pequeño canto rodado con incisiones involuntarias $(33 \times 12 \times 6,7$ $\mathrm{mm})$, de materia prima similar a la de los colgantes.

Los objetos de sílex ascienden a 9; de ellos 8 son soportes brutos y una pieza retocada. Entre los primeros identificamos 3

sido aportados al lugar ya fabricados. En el instrumental lítico se observa una disminución proporcional del número de instrumentos, ya que de 16 restos de sílex tan solo lo son 4 (2 dorsos, una truncadura y una raedera), 3 lascas de vulcanita probablemente en posición secundaria, y además 2 instrumentos óseos.

Finalmente, las ocupaciones del Magdaeniense FinalEpipaleolítico del vestíbulo no parecen haber dejado restos característicos estratificados en la primera sala interior, siendo principalmente la serie de fechas (en torno a 9000 BP) obtenida a partir de los carbones procedentes del nivel fértil más superficial (II) el criterio utilizado para su diagnóstico cronocultural. Destaca la presencia de 237 conchas no perforadas, mayoritariamente Littorina obtusata, y 21 objetos de sílex, de los cuales 5 son útiles (una raedera, 2 espinas, una truncadura y una laminilla de dorso).

\section{6.- SEGUNDA SALA INTERIOR}

\subsection{Industria lítica}

La segunda sala interior se trata de un espacio alejado (a una docena metros) del área de habitación más acogedor por su lu-

Fig. 45. Industria lítica hallada en la segunda sala interior. / Lithic industry from the second inner room.
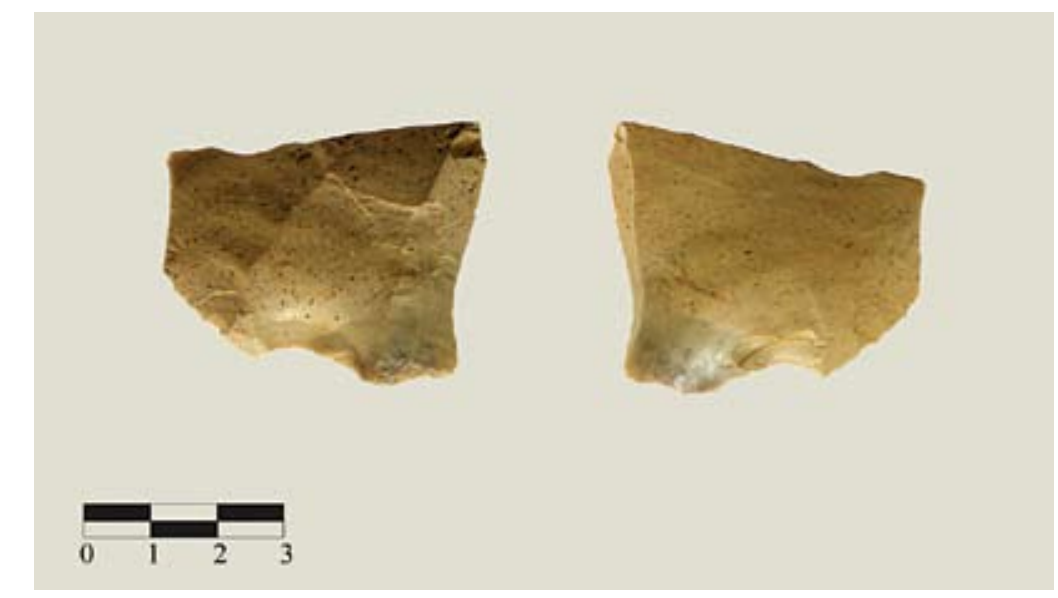
fragmentos de laminillas (2 proximales -de talón plano y puntiforme- y uno medial), 2 fragmentos menores (uno de ellos una escama) y 3 cachos. Hay que señalar, además, la presencia de un fragmento medial de lámina con estigmas que interpretamos como de uso.

Entre los objetos retocados se ha clasificado un ancho buril lateral (plano) sobre fractura transversal distal -B12- (P.A.12J'.356.136: Fig. 45).

\subsection{Industria ósea}

La industria ósea está representada por 2 objetos. El más significativo es un fragmento de bastón de mando 
Fig. 46. Fragmento de bastón perforado hallado en la segunda sala interior. / Perforated baton fragment found at the second inner room.

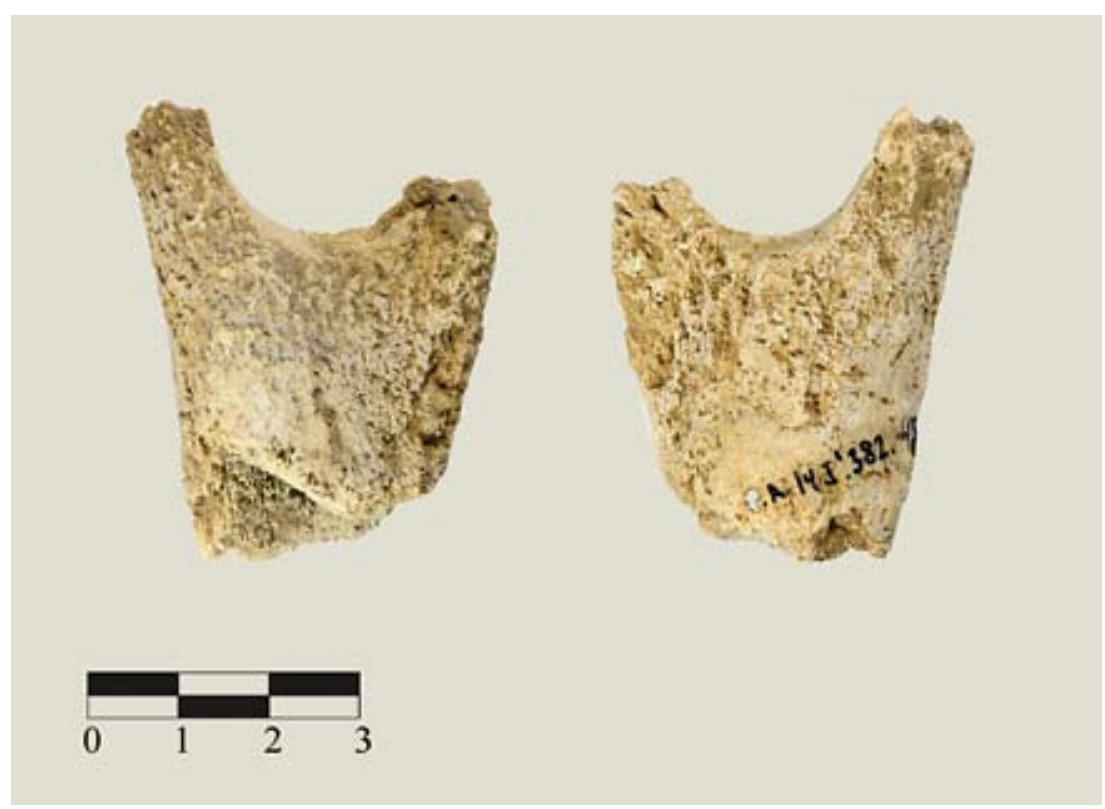

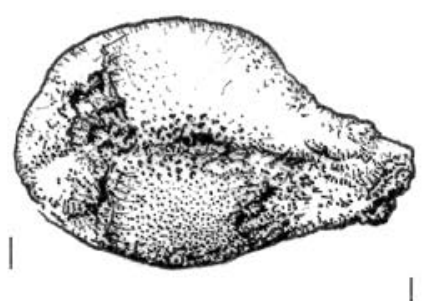
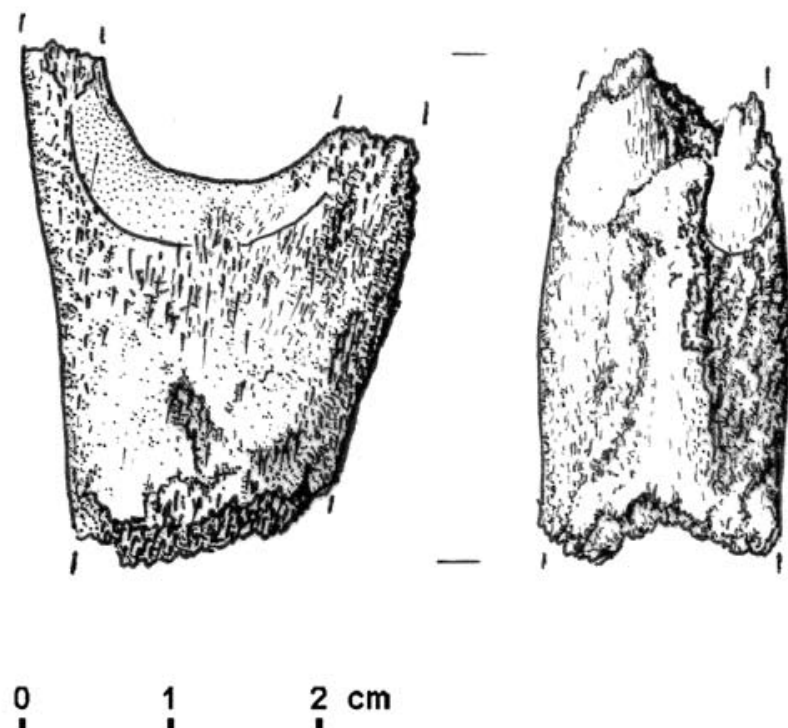

$2 \mathrm{~cm}$

Fig. 47. Fragmento de bastón perforado hallado en la segunda sala interior (J. Alonso). / Perforated baton fragment found at the second inner room (J. Alonso).

perforado fabricado sobre un asta de reno. Sus superficies están muy alteradas y se conserva únicamente la parte correspondiente a la vara -en una zona próxima a la bifurcación de un candil- que muestra la mitad de una perforación bipolar (P.A.14J'.382.45: Figs. 46 y 47). Sus dimensiones son: $51,2 \times 37,2 \times 23,2$ mm. Calculamos que el diámetro del orificio del bastón pudo ser de unos $20 \mathrm{~mm}$.

Con el fin de conocer la cronología de estos restos tan poco característicos se dató directamente el bastón perforado, obteniéndose la fecha de 17530 $770 \mathrm{BP}$, que correspondería al Solutrense. Entre los paralelos contemporáneos podemos citar el ejemplar de Aitzbitarte IV, decorado con profundos motivos lineales, y los de Cueto de La Mina y El Pendo, entre otros.

La segunda pieza es un fragmento medial de una larga y estrecha tira de sección aplanada preparada para su transformación en una aguja (o bien un fragmento de aguja). Sus dimensiones son: $66 \times 3,5 \times 2,4 \mathrm{~mm}$ (P.A.20K'.355.39: Fig. 48)

\section{7.- EL RELLANO EXTERIOR}

Además, de las ocupaciones humanas que se sucedieron en las distintas áreas del interior de la cavidad hay algunos escasos vestigios industriales que prueban la esporádica presencia humana en el reducido rellano existente al abrigo de la roca situada a la izquierda de la entrada. Los restos recuperados se han agrupado en 3 niveles.

Del nivel I proceden 2 piezas, concretamente un posible reavivado de núcleo y un fragmento medial de una lámina de doble dorso marginal (LDD21) (P.A.3A'.38.1: Figs. 49.1 y 50.1).

En el nivel III se recuperaron 3 objetos de sílex, 2 fragmentos de lascas - uno medial y otro distal- (P.A.3C.99.4: Figs. 49.2 y 50.2) y otra con córtex.

Finalmente, se han estudiado 6 objetos del nivel IV: un canto rodado de arenisca, una lasca de basalto (?), una lasca de reavivado y 1 de decorticado, una lasca de 


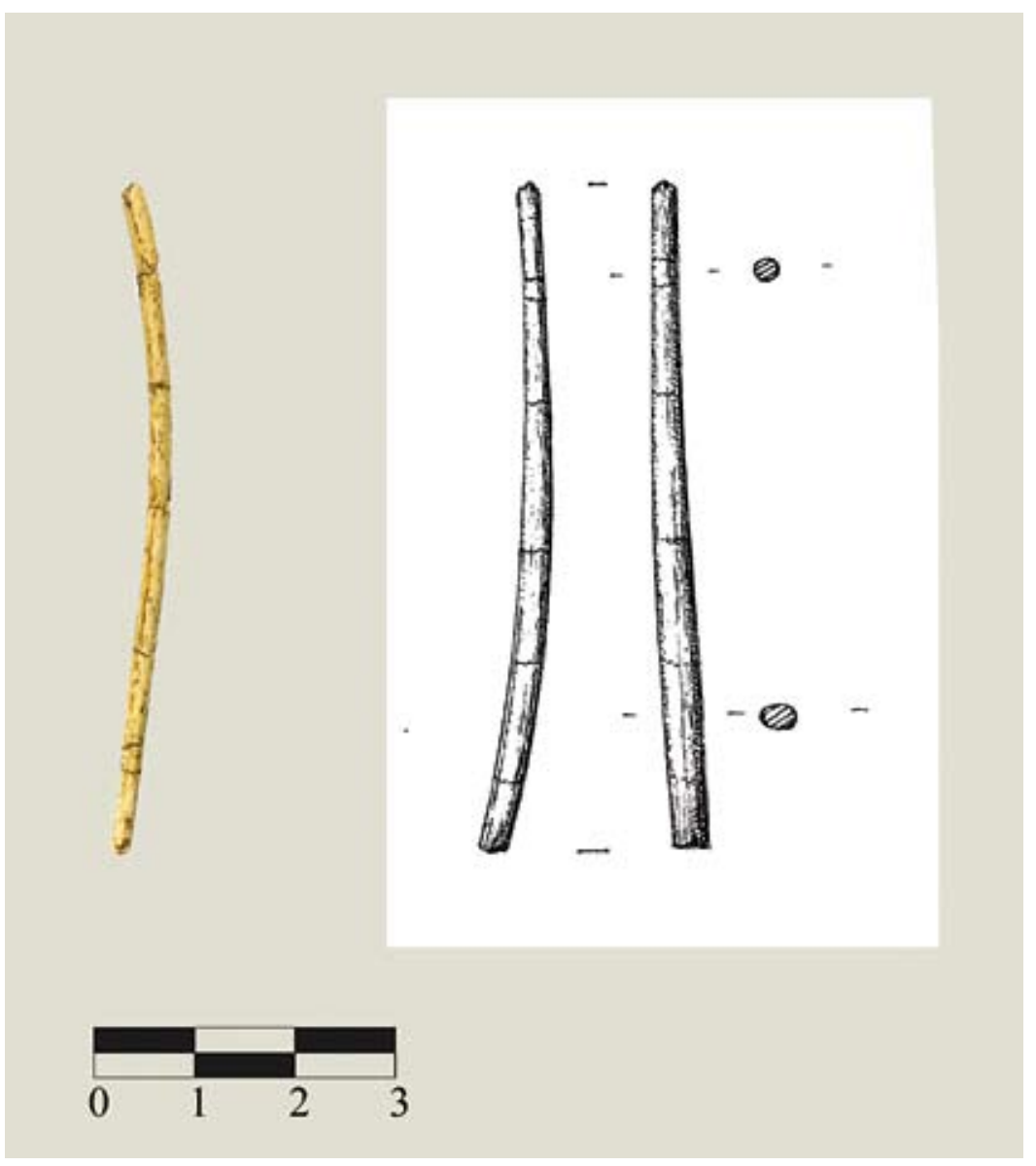

Fig. 48. Industria ósea hallada en la segunda sala interior (Dibujo: J. Alonso). / Osseous industry at the second inner room (Drawing: $J$. Alonso).

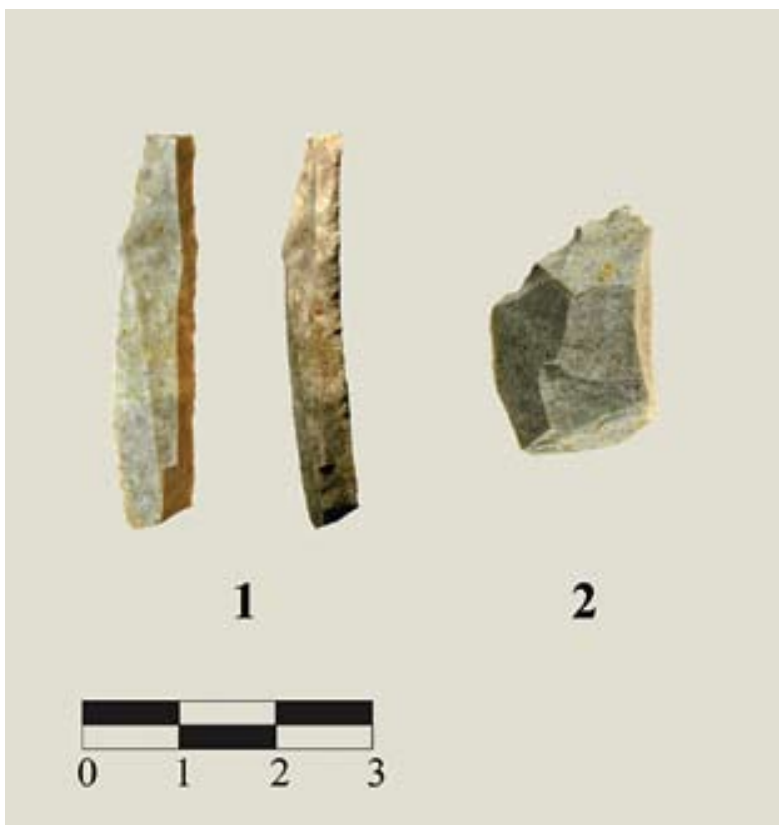

Fig. 49. Industria lítica del rellano exterior. / Lithic industry from the outside area.
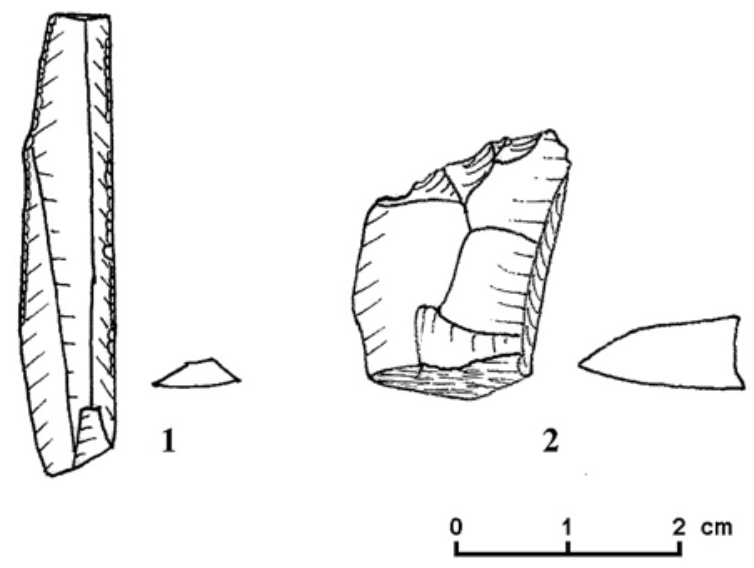

Fig. 50. Industria lítica del rellano exterior. / Lithic industry from the outside area. 
avivado de núcleo y un fragmento de lasca con huellas de uso.

En resumen, en el depósito sedimentario del rellano exterior la escasa y poco característica industria lítica recuperada indica únicamente la fugaz y recurrente ocupación de este espacio. Parece lógico pensar que los individuos que habitaron ocasionalmente el interior de la cavidad efectuaban ocasionalmente actividades de poca entidad fuera de la misma, o simplemente no se conservan. Sólo las fechas radiocarbónicas permiten una aproximación a su cronología.

\section{8.- VISIÓN GENERAL}

Los restos recuperados en los distintos niveles de Praileaitz I son el resultado de fugaces ocupaciones de grupos humanos constituidos por un muy reducido número de individuos a lo largo de diferentes períodos de su secuencia: Solutrense (Ermittia, Urtiaga), Magdaleniense Inferior (Ermittia, Urtiaga, Ekain y Erralla) y Superior/Final (además de los citados Iruroin, Langatxo, Aizkoltxo, Agarre, Santa Catalina, etc.) y Epipaleolítico, prácticamente en todos los señalados.

Entendemos que el papel de Praileaitz I fue a lo largo de la formación de su depósito un asentamiento secundario -quizás sólo un alto- dependiente, o con relación a otros próximos, también temporales de carácter estacional, pero que aportaron vestigios arqueológicos (restos industriales y faunísticos de origen antrópico) más abundantes. Además, el contexto sedimentológico en el que se recuperaron dichos restos era muy orgánico, de coloración muy oscura, como sucedía en Ermittia, Urtiaga o Aizkoltxo, mientras que otros proceden de contextos menos orgánicos (Erralla y Ekain).

Se han distinguido 5 niveles que de abajo arriba son los siguientes:

- El nivel V, del cual se ha excavado su techo, es atribuible al Solutrense por las piezas características halladas tanto en el vestíbulo como en la primera sala interior, así como por las dataciones del vestíbulo (17760 $\pm 70 \mathrm{BP})$ y del bastón de la segunda sala (17530 $\pm 70 \mathrm{BP})$.

- El nivel IV es el de más entidad de Praileaitz I, que ha podido ser bien identificado en el vestíbulo y primera sala, gracias a los conjuntos de colgantes y elementos asociados (hogar, azagayas, ocres etc.). Las fechas obtenidas a partir de los restos hallados en ese contexto del vestíbulo han sido: 14700 $\pm 100,15190 \pm 50,15460 \pm 100$, $15530 \pm 100$ y $15810 \pm 110 \mathrm{BP}$.

- Los niveles III y II aportan también un bajo número de efectivos, siguiendo la tónica observada en los niveles inferiores, ya que en ninguno de ellos se alcanza el centenar de restos. A pesar de ello, analizando los niveles II, III y IV del vestíbulo se observan ligeras diferencias entre ellos, que deben de ser tomadas en consideración con cierta prevención. Así se observa, que el nivel II y el IV tienen más semejanza entre si que con el III. En los dos primeros la proporción de los objetos retocados respecto del total de la industria de sílex se sitúa en torno al 25$30 \%$, mientras que en el nivel III la proporción disminuye al 15\%. Parece que en todos los niveles la mayoría de los soportes y el instrumental lítico se aportan ya fabricados. Hay indicios que indican una actividad de talla de baja intensidad en el nivel II (hay núcleos agotados, etc.) y restos de un episodio de talla en el nivel III.

Las dataciones disponibles para datar este periodo son escasas en el vestíbulo, pudiendo ser válidas la procedente del asta de reno $(12920 \pm 50$ BP) y la de una esquirla ósea (10740 $\pm 50 \mathrm{BP})$, además de las obtenidas a partir de los moluscos (10560 \pm 50 y $9320 \pm 40$ BP) existentes bajo dos amplios hogares en cubeta. Los carbones relacionados con éstos han aportado varias fechas que se sitúan entre el $8800 \pm 35$ y 9225 $440 \mathrm{BP}$.

Entre los yacimientos próximos estudiados destacaríamos Ekain, excavado con una metodología más próxima a la utilizada en Praileaitz I que con la practicada en los excavados en la década de los 20 y 30 del s. XX. Aquí, J. M ${ }^{a}$ Merino (1984) señala que la proporción entre los útiles y los restos de debitado se sitúa entre el 7,71\% y $14,3 \%$ en sus ocupaciones epipaleolíticas, en $14,05 \%$ durante el Aziliense y entre el 10,16\% y $10,72 \%$ en las magdalenienses. El desequilibro entre los recortes de buril y número de restos etc. le lleva a proponer que parte del utillaje no fue trabajado in situ, salvo que lo fuera en el exterior, o en una zona no excavada de las proximidades. Comparando los datos de ambos yacimientos se observa que la proporción de los útiles respecto del total debitado es notablemente mayor en Praileaitz I que en Ekain. Únicamente el nivel III, donde se constata cierta actividad de talla, con el $14,6 \%$ se aproxima a los niveles azilienses y epipaleolíticos de Ekain. Sin embargo, estas proporciones se alejan de las contabilizadas en Aizkoltxo, donde se documentan todas las fases del proceso de talla. En el estudio parcial de la colección del Magdaleniense Final de esta cueva, de 6797 objetos de sílex sólo el 4,72\% está retocado (GARCÍA ROJAS, 2014), aunque también hay que advertir que el cribado del sedimento se ha realizado con agua, lo que ha permitido recoger numerosísimos fragmentos mínimos, parte de los cuales indudablemente se hubieran perdido en un cribado en seco (el 84,2\% de los restos es inferior a $<8 \mathrm{~mm}$ ).

En cuanto a la industria retocada se observa que en Praileaitz I el retoque dominante es el Abrupto en los niveles II (60\%) y IV (62\%), seguidos del Simple, con una proporción del 30\%, mientras que en el III la proporción de Abruptos y Simples es similar, aproximadamente el $42 \%$. A nivel de grupos tipológicos se constata, como es lógico, que en los niveles II y IV predominan los elementos de dorso, por el contrario en el III la distribución de los distintos tipos es más homogénea.

En definitiva, Praileaitz I se trataría de una cavidad recurrentemente ocupada en periodos temporalmente muy breves, por grupos procedentes de otros asentamientos del entorno. Entre ellos destacaríamos Ermittia y Urtiaga, los más próximos, y Ekain que presentan indicios de ocupaciones contemporáneas. También pudiera haber tenido alguna vinculación puntual con Erralla durante el Magdaleniense Inferior y con Aizkoltxo, Agarre (Mendaro) y Santa Catalina durante el Magdaleniense Final y el Aziliense. 


\begin{tabular}{|c|c|c|c|}
\hline VESTIBULO & PASILLO & $1^{\text {a }}$ SALA & $2^{\text {a }}$ SALA \\
\hline $\begin{array}{l}\text { Nivel II } \\
\text { Industria lítica: } 94 \\
\text { No retocado: } 71 \text { (75,5\%) } \\
\text { Láminas: } 44 \text { (61,9\%). C: } 3, \text { P: 18, M/D: } 23 \text { Lascas: } 27 \\
\text { (38,0\%). C: 5, P: 4, M/D: } 18\end{array}$ & $\begin{array}{l}\text { Nivel lc+lla+llb } \\
\text { Industria lítica: } 11 \\
\text { No retocado: } 11 \\
\text { Láminas: 7. C: } 5, \text { P: } 2 \\
\text { Lascas: 4. C: } 1, \text { M/D: } 3\end{array}$ & $\begin{array}{l}\text { Nivel II } \\
\text { Industria lítica: } \mathbf{2 1} \\
\text { No retocado: } 10 \text { (62,5\%) } \\
\text { Láminas: } 10 \text { (62,5\%). C: } 2, \mathrm{P}: 4, \mathrm{M} / \mathrm{D}: 4 \\
\text { Lascas: } 6 \text { (37,5\%). C: 5, M/D: } 1\end{array}$ & \multirow{12}{*}{$\begin{array}{l}\text { Nivel indet. } \\
\text { Industria lítica: } 94 \\
\text { No retocado: } 8 \\
\text { Láminas: } 3 . \text { P: } 2, \text { M: } 1 \\
\text { Lascas: } 2 \\
\text { Chunck: } 2 \\
\text { Retocado: } 1 \\
\text { - Buril } \\
\text { Industria ósea: } \\
\text { - Bastón perforado } \\
\text { - Aguja? }\end{array}$} \\
\hline $\begin{array}{l}\text { Retocado: } 23(24,5 \%) \\
\text { - Simples } 7(30,4 \%) \text {, Abruptos } 14 \text { (60,8\%), Buriles } 2 \text { (8,7\%). } \\
\text { - } 2 \text { raederas, } 1 \text { raspador, } 4 \text { denticulados, } 4 \text { truncaduras, } 5 \\
\text { láminillas de dorso, } 1 \text { laminilla de dorso y truncadura, } 3 \\
\text { puntas de dorso, } 2 \text { buriles y } 1 \text { astillado. }\end{array}$ & & $\begin{array}{l}\text { Retocado: } 5 \\
-1 \text { raedera (LD21), } 2 \text { espinas, } 1 \text { truncadura, } 1 \\
\text { laminilla de dorso }\end{array}$ & \\
\hline $\begin{array}{l}\text { Índustria ósea: } \\
\text { - Biapuntado/Anzuelo. } \\
\text { - Bastón perforado }\end{array}$ & & & \\
\hline $\begin{array}{l}\text { Nivel III } \\
\text { Industria lítica: } 96 \\
\text { No retocado: } 82(85,4 \%) \\
\text { Láminas: } 26(31,7 \%) \text {. C: 6, P: 8, M/D: } 12 \\
\text { Lascas: } 56(68,3 \%) . \text { C: } 8, \text { P: 18, M/D: 28, Chunck: } 2\end{array}$ & $\begin{array}{l}\text { Nivel III } \\
\text { Industria ósea: } \\
\text { - Arpón }\end{array}$ & & \\
\hline $\begin{array}{l}\text { Retocado: } 14(14,6 \%) \\
\text { - Simples } 6(42,8 \%) \text {, Abruptos (42,8 \%), Buriles (7,1\%) y } \\
\text { écaille (7,1\%) } \\
\text { - } 2 \text { raederas, } 3 \text { raspadores, } 1 \text { écaillé, } 3 \text { truncaduras, } 2 \\
\text { laminillas de dorso, } 1 \text { puntas de dorso, } 1 \text { buril. } 1 \text { punta/ } \\
\text { raedera musteriense. }\end{array}$ & & & \\
\hline $\begin{array}{l}\text { Nivel IV } \\
\text { Industria lítica: } 73 \\
\text { No retocado: } 52 \text { (71,2\%) } \\
\text { Láminas: } 17 \text { (32,7\%). C: } 3 \text {, P: 7, M/D: } 7 \\
\text { Lascas: } 35 \text { (63,5\%). C: 8, P: 11, M/D: 14, Chunck: } 2 \text { (3,8\%) }\end{array}$ & $\begin{array}{l}\text { Nivel IV } \\
\text { Industria lítica: } 15 \\
\text { No retocado: } 9(60 \%) \\
\text { Láminas: 5. C: } 2, \text { P: } 2, \text { M/D: } 1 \\
\text { Lascas: 4. C: } 2, \text { P: } 2\end{array}$ & $\begin{array}{l}\text { Nivel IV } \\
\text { Industria lítica: } 16 \text { (+3 vulcanita) } \\
\text { No retocado: } 12-75 \% \text { - Láminas: 8. C: 2, P:5, } \\
\text { M/D: } 1 \text { Lascas: 4. P: } 1, \text { M/D: } 3\end{array}$ & \\
\hline $\begin{array}{l}\text { Retocado: } 21(28,7 \%) \\
\text { - Simples }(28,6 \%) \text {, Abruptos }(61,9 \%) \text {, Buriles (4,8\%) y écaillé } \\
(4,8 \%) \text {. } \\
\text { - } 2 \text { raederas, } 3 \text { becs, } 1 \text { écaillé, } 6 \text { laminillas de dorso, } 6 \\
\text { puntas de dorso, } 1 \text { punta de dorso y truncadura, } 1 \text { buril, } 1 \\
\text { denticulado }\end{array}$ & $\begin{array}{l}\text { Retocado: } 6(40 \%) \\
-1 \text { raedera } \\
-5 \text { dorsos }\end{array}$ & $\begin{array}{l}\text { Retocado: } 4(25 \%) \\
-1 \text { raedera, } \\
-1 \text { truncadura } \\
-2 \text { laminillas de dorso }\end{array}$ & \\
\hline $\begin{array}{l}\text { Instrumentos óseos: } \\
\text { - Azagaya monobisel corto } \\
\text { - Azagaya base hendida } \\
\text { - Alisador? Costilla decorada }\end{array}$ & & $\begin{array}{l}\text { Industria ósea: } \\
\text { - Azagaya } \\
\text { - Punzón }\end{array}$ & \\
\hline Diversos: 9 colgantes (6 líticos y 3 óseos), 2 ocres & & Diversos: 20 colgantes líticos & \\
\hline $\begin{array}{l}\text { Nivel V } \\
\text { Industria lítica: } 11 \\
\text { No retocado: } 8(72,7 \%) \\
\text { Láminas: } 5 \\
\text { Lascas: } 3 . \text { C: } 1, \text { P: } 1, \text { M/D: } 1\end{array}$ & $\begin{array}{l}\text { Nivel V } \\
\text { Industria lítica: } 3 \\
\text { No retocado: } 8(72,7 \%) \\
\text { - Lámina: } 1\end{array}$ & $\begin{array}{l}\text { Nivel V } \\
\text { Industria lítica: } 5 \\
\text { No retocado: } 1 \\
\text { - Lámina: } 1 . P: 1 .\end{array}$ & \\
\hline $\begin{array}{l}\text { Retocado: } 3(\mathbf{2 7 , 3 \% )} \\
-1 \text { muesca, } 1 \text { punta de dorso, } 1 \text { buril + raedera foliácea }\end{array}$ & $\begin{array}{l}\text { Retocado: } 1 \\
-1 \text { truncadura }\end{array}$ & $\begin{array}{l}\text { Retocado: } 4 \\
-1 \text { raedera, } 1 \text { raedera foliácea, } 1 \text { punta foliácea, } \\
1 \text { lámina de dorso }\end{array}$ & \\
\hline $\begin{array}{l}\text { Industria ósea: } \\
\text { - Azagaya monobisel }\end{array}$ & & $\begin{array}{l}\text { Industria ósea: } \\
\text { - Azagaya monobisel } \\
\text { - Varilla planoconvexa } \\
\text { - Biapuntado }\end{array}$ & \\
\hline
\end{tabular}

Tabl. 3. Tabla simplificada en la que se recogen los restos más significativos hallados en los distintos sectores de la Praileaitz I. C: completa; P: proximal; M/D: distal. / Simplified table in which there are gathered the most significant remains found in the different zones at Praileaitz I. C: complete; P: proximal; M/D: distal. 


\section{9.- AGRADECIMIENTOS}

Este trabajo ha sido desarrollado en el Grupo de Investigación del Sistema Universitario Vasco IT-622-13.

\section{0.- BIBLIOGRAFÍA}

BERGANZA, E., RUIZ IDARRAGA, R.

2014 Candil de ciervo decorado magdaleniense del yacimiento de Santa Catalina (Bizkaia, España). Tecnología y funcionalidad. Munibe Antropologia-Arkeologia 65, 25-36.

BUISSON, D., DELPORTE, H., KANDEL, D., WELTE, A.-C.

2003 Bois de cervidés, en CLOTTES, J.; DELPORTE, H. (Eds.). La grotte de la Vache (Ariège). I. - Les occupations du Magdalénien. II. - L'art mobilier, 395-411. Comité de Travaux Historiques et Scientifiques. Éditions de la Réunion des Musées Nationaux. Paris.

CARBALLO, J., GONZÁLEZ ECHEGARAY, J.

1952 Algunos objetos inéditos de la Cueva de El Pendo. Ampurias XIV, 37-48.

CORCHÓN, Ma S

1987 El arte mueble paleolítico cantábrico: contexto y análisis interno. Centro de Investigación y Museo de Altamira. Santander.

DELPORTE, $H$.

1982 La imagen de la mujer en el arte prehistórico. Istmo. Madrid.

FERNÁNDEZ ERASO, J.

1985 Las culturas del Tardiglaciar en Vizcaya. UPV/EHU. Bilbao.

2006 Los productos brutos de talla bajo el prisma de la Tipología Analítica. Dialektikê : Cahiers de Typologie Analytique 2006, 70-80

FERNÁNDEZ ERASO, J., GARCÍA ROJAS, M.

2013 Tipología analítica, en GARCÍA-DIEZ, M., ZAPATA, L. Métodos y técnicas de análisis y estudio en arqueología prehistórica. 481-510. UPV/EHU. Gasteiz.

GARCÍA ROJAS, M

2010 Propuesta de descripción y clasificación de los productos de debitado desde la tipología analítica. Zephyrus LXVI, 93-107.

2014 Dinámicas de talla y gestión de las materias primas silíceas a finales del Pleistoceno en el País Vasco. Tesis doctoral. Universidad del País Vasco/Euskal Herriko Unibertsitatea. Disponible en: https://mww.academia.edu/11484766/ Din\%C3\%A1micas_de_talla_y_gesti\%C3\%B3n_de_las_ materias_primas_sil\%C3\%ADceas_a_finales_del_Pleistoceno_en_el_Pa\%C3\%ADs_Vasco
GONZÁLEZ SÁINZ, C.

1989 El Magdaleniense Superior-Final de la región cantábrica. Universidad de Cantabria. Santander.

LAPLACE, G

1973 La typologie analytique et structurale: Base rationelle d'étude des industries lithiques et osseuses. Banques de Données Archéologiques 932, 91-143

1987 Un exemple de nouvelle écriture de la grille typologique. Dialektiké. Cahiers de Typologie Analytique, 30-38.

MERINO, J.M.

1984 Industria lítica del yacimiento Ekain, en ALTUNA, J., MERINO, J. M. El yacimiento prehistórico de la cueva de Ekain (Deba, Gipuzkoa). 65-175. Eusko lkaskuntza. Donostia.

1994 Tipología lítica. Munibe. Suplemento 9. Donostia.

MUJIKA, J.A.

1983 La industria de hueso en la Prehistoria de Guipúzcoa. Munibe 35, 451-631.

1993 La industria ósea del Paleolítico Superior y Epipaleolítico del Pirineo Occidental. Universidad de Deusto, Bilbao.

2011 Sondeo en Aizkoltxo. Arkeoikuska 10, 377-377.

MUJIKA, J.A., PEÑALVER, $X$

2012 La ocupación de la cuenca del Deba (Gipuzkoa) durante el Magdaleniense Inferior, en ARIAS, P., CORCHÓN, M. S., MENDÉNDEZ, M. \& RODRÍGUEZ, J. A. (Eds.). El Paleolitico Superior Cantábrico. Actas de la Primera Mesa Redonda. San Román de Candamo (Asturias), 26-28 abril de 2007. 97-113. Universidad de Cantabria. Santander.

NOIRET, P.

1990 Le décor des bâtons percés. Société préhistorique Ariège-Pyrénées. Lieja. (Préhistoire Liégeoise ; 25).

PEÑALVER, $X$.

2013 Praileaitz | leizea. Cueva de Praileaitz. Arkeoikuska 2012, 275-277.

2015 Praileaitz I leizea. Cueva de Praileaitz. Arkeoikuska 2014 320-322.

PEÑALVER, X., MUJIIKA, J. A.

2003 Suelo de ocupación magdaleniense en la cueva de Praile Aitz I (Deba, Gipuzkoa). Veleia 20, 157-182.

2005 La cuestión de las azagayas de base hendida magdalenienses en la Cornisa Cantábrica. Veleia 22, 9-20.

SÁENZ DE BURUAGA, A.

1991 El Paleolítico superior en la cueva de Gatzarria (Zuberoa País Vasco). Veleia Series Mayor 6, UPV/EHU, VitoriaGasteiz.

SAINT-PÉRIER, R. DE

1930 La Grotte d'Isturitz. I. Le Magdalénien de la Salle de Saint Martin. Paris. (Archives de l'Institut de Paleontologie Humaine, Mémoire 7).

1936 La Grotte d'Isturitz. II. Le Magdalénien de la Grande Salle. Paris. (Archives de l'Institut de Paleontologie Humaine. Mémoire 17). 